\title{
SYSTEM SPECIFICATION
}

\author{
FOR THE
}

\section{PLUTONIUM \\ STABILIZATION AND PACKAGING SYSTEM}

CONTRACT NO: DE-AC03-96SF20948

CDRL SEQUENCE NO. A002

Prepared for:

Department of Energy - Oakland

Prepared by:

BNFL Inc.

in association with

Stone and Webster Engineering Corporation

Raytheon Engineers \& Constructors, Inc.

Pajarito Scientific Corporation

Toeroek Associates, Inc.

BNFL Engineering, Ltd.

Denver, CO

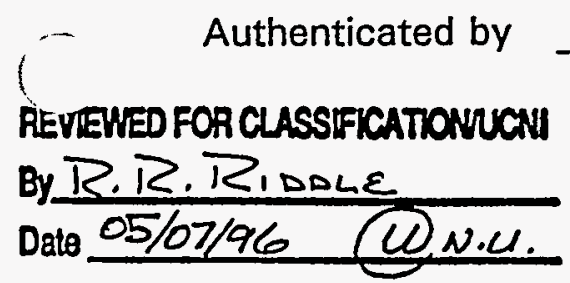

\section{Department of Energy - Oakland}

Date

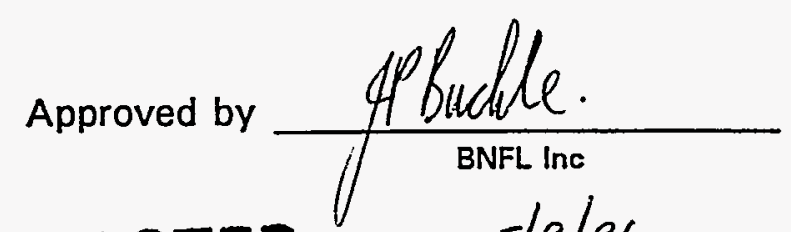

MASTER 


\section{DISCLAMMER}

This report was prepared as an account of work sponsored by an agency of the United States Government. Neither the United States Government nor any agency thereof, nor any of their employees, makes any warranty, express or implied, or assumes any legal liability or responsibility for the accuracy, completeness, or usefulness of any information, apparatus, product, or process disclosed, or represents that its use would not infringe privately owned rights. Reference herein to any specific commercial product, process, or service by trade name, trademark, manufacturer, or otherwise does not necessarily constitute or imply its endorsement, recom. mendation, or favoring by the United States Government or any agency thereof. The views and opinions of authors expressed herein do not necessarily state or reflect those of the United States Government or any agency thereof. 


\section{Table of Contents}

Section Titles

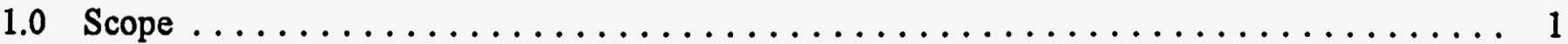

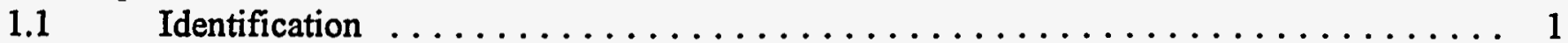

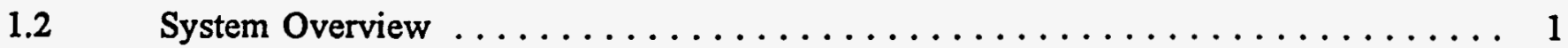

1.3 Document Overview $\ldots \ldots \ldots \ldots \ldots \ldots \ldots \ldots \ldots \ldots \ldots \ldots \ldots$

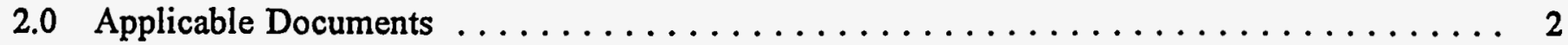

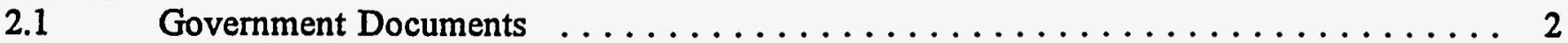

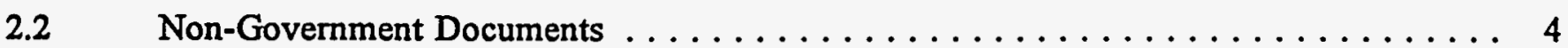

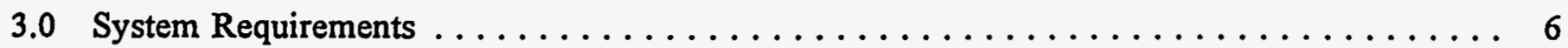

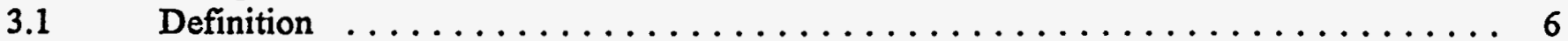

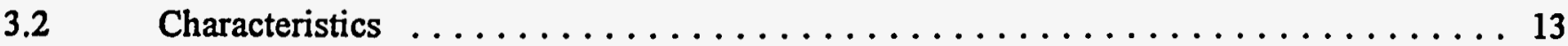

3.2.1 Performance Characteristics . . . . . . . . . . . . . . . . . . . 13

Receipt Area (15); Material Preparation Area (17); Transport Area (19); Furnace Area (20); LOI Test Area (21); Tipping/Dispense/Can Fill Area (23); Can Weigh and Cap Insertion Area (24); Intermediate Can Handling Area (25); Outer Can Weld and Monitoring Area (26); Lag Storage Trolley (27); Furnace Trays (28); Storage Packages (30); Receipt Hood/Fume Cabinet/Glovebox Atmosphere (33); Electrical (35); Support Structures and Platforms (36); Fire Protection (37); Pu SPS Control System (39); Process Radiometric Instrumentation (43)

3.2.2 System Capability Relationships $\ldots \ldots \ldots \ldots \ldots \ldots \ldots \ldots \ldots \ldots \ldots \ldots$

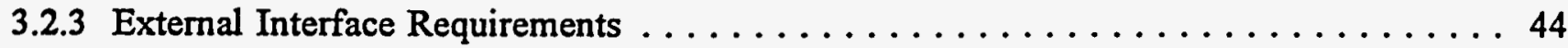

3.2.4 Physical Characteristics .............................. 44

Protective Coatings and Cleaning (45)

3.2 .5 System Quality Factors . . . . . . . . . . . . . . . . . . . . . 45

3.2.6 Environmental Conditions ......................... 47

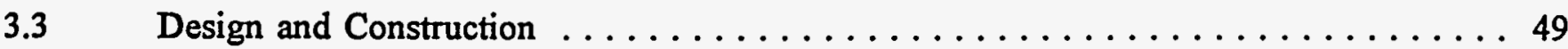

3.3.1 Materials ................................... 49

Toxic Products and Formulations (49); Use of Standard and Commercial Parts (50)

3.3.2 Electromagnetic Radiation ......................... 50

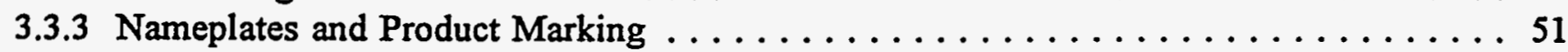

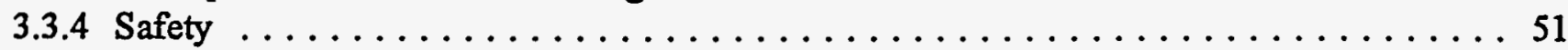

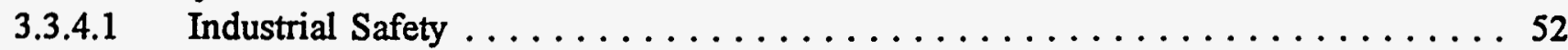

3.3.4.2 Radiation Protection ............................ 54 


\section{Table of Contents}

3.3.4.3 Gloveboxes ............................... 55

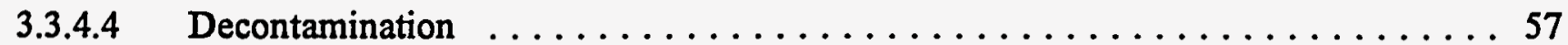

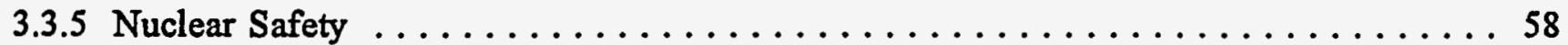

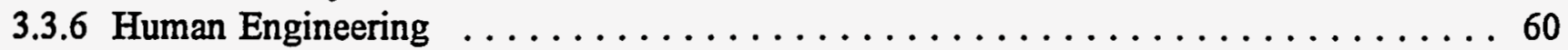

3.3 .7 System Security . . . . . . . . . . . . . . . . . . . . 62

3.3.8 Government Furnished Property Usage $\ldots \ldots \ldots \ldots \ldots \ldots \ldots \ldots \ldots \ldots \ldots 6 . \ldots \ldots$

3.3.8.1 Government Furnished Equipment . . . . . . . . . . . . . . . 63

3.3.8.2 Government Furnished Information $\ldots \ldots \ldots \ldots \ldots \ldots \ldots \ldots \ldots \ldots \ldots$

3.3.8.3 Government Furnished Software $\ldots \ldots \ldots \ldots \ldots \ldots \ldots \ldots \ldots \ldots$

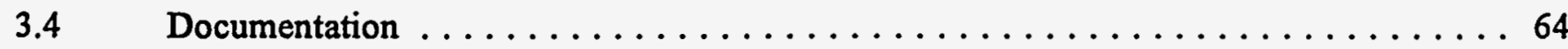

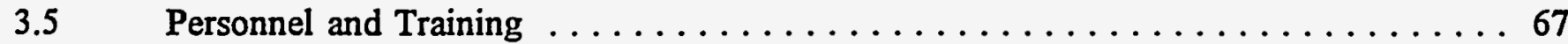

3.5.1 Personnel ................................... 67

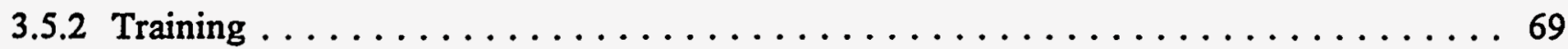

3.5.2.1 Training Approach and Responsibilities $\ldots \ldots \ldots \ldots \ldots \ldots \ldots \ldots 6 . \ldots \ldots 6$

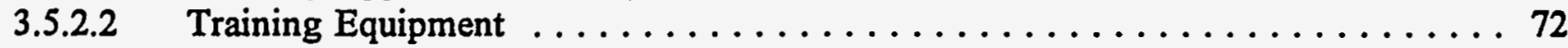

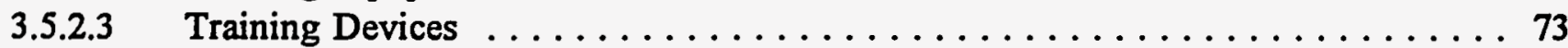

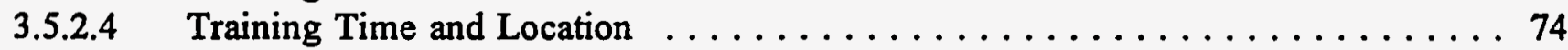

3.5.2.5 Source Material and Training Aids . . . . . . . . . . . . . 75

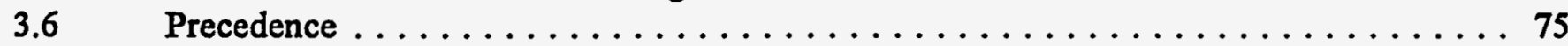

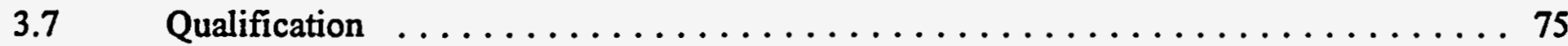

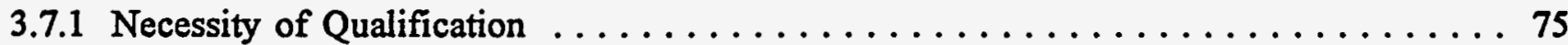

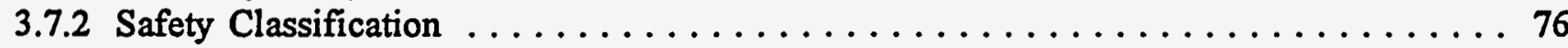

3.7.3 Qualification Demonstration . . . . . . . . . . . . . . . . . 76

$3.8 \quad$ Standard Samples . . . . . . . . . . . . . . . . . . . . 76

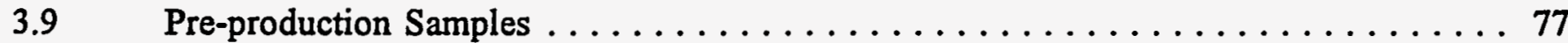

3.9.1 Furnace Tray Design Verification ....................... 77

3.9.2 Storage Package Redesign Verification $\ldots \ldots \ldots \ldots \ldots \ldots \ldots \ldots \ldots$

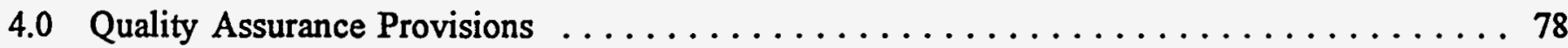

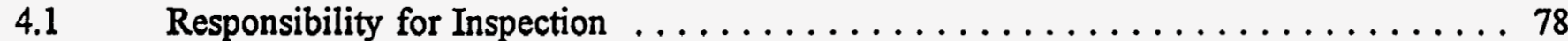

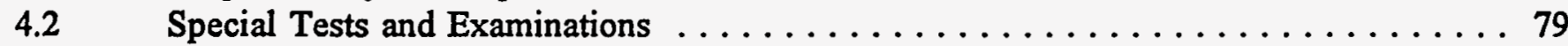

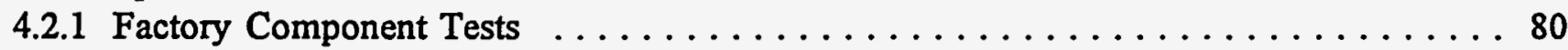

4.2.2 Pre-Operational Tests of Individual Components $\ldots \ldots \ldots \ldots \ldots \ldots \ldots \ldots . \ldots$

4.2.3 System Operational Tests . . . . . . . . . . . . . . . . . . 81

4.2.4 Performance Demonstration Tests . . . . . . . . . . . . . . . . . 81

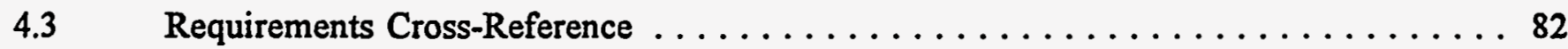

5.0 Preparation for Delivery $\ldots \ldots \ldots \ldots \ldots \ldots \ldots \ldots \ldots \ldots \ldots \ldots \ldots \ldots \ldots \ldots \ldots$

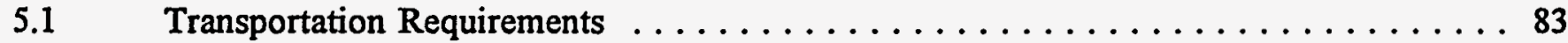




\section{Table of Contents}

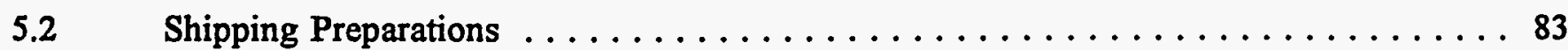

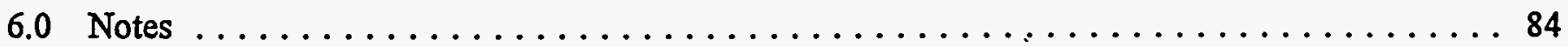

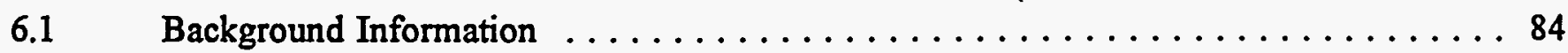

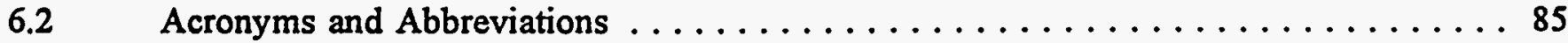

$6.3 \quad$ Glossary of Terminology $\ldots \ldots \ldots \ldots \ldots \ldots \ldots \ldots \ldots \ldots \ldots \ldots \ldots$ 


\section{Table of Contents}

Figures

Pu SPS Block Flow Diagram, Sheet 1 , Receipt and Material Preparation Areas . . . . . . . . 8

Pu SPS Block Flow Diagram, Sheet 2, Transport Area and Furnaces $\ldots \ldots \ldots \ldots \ldots \ldots \ldots 9$

Pu SPS Block Flow Diagram, Sheet 3, Tipping/Dispense/Fill Area ............... 10

Pu SPS Block Flow Diagram, Sheet 4, Can Weigh and Intermediate Can Handling . . . . . . 11

Pu SPS Block Flow Diagram, Sheet 5, Outer Can Weld and Monitoring Area $\ldots \ldots \ldots \ldots \ldots 12$

$\begin{array}{lll}\text { Appendices } & \text { Page }\end{array}$

A. Interface Requirements Document $[$ para 3.2 .3$] \ldots \ldots \ldots \ldots \ldots \ldots \ldots \ldots \ldots \ldots \ldots \ldots \ldots \ldots$

B. Methods of Demonstrating Compliance $[$ para 4.3$] \ldots \ldots \ldots \ldots \ldots \ldots \ldots \ldots \ldots \ldots$ B-1 
SPECIAL NOTE: There are contract changes regarding technical issues that are currently being negotiated and will affect this document. In most cases, anticipated contract changes are highlighted using double angles $<<$ example $>>$.

Bracketed italics [example] have been used to indicate contract requirements.

Italics have been used to indicate direct quotations from reference documents.

[The System Specification specifies the requirements for a system, and which upon Government approval and authentication, becomes the Functional Baseline for the system or segment.] 


\section{0 Șcope}

\subsection{Identification}

[This paragraph ... shall contain the approved identification number, title, and abbreviation, if applicable, of the system to which this System Specification applies.]

This document describes functional design requirements for the Plutonium Stabilization and Packaging System (Pu SPS), as required by DOE contract DE-AC03-96SF20948.

\subsection{System Overview}

[This paragraph ... shall briefly state the purpose of the system to which this System Specification applies.]

The overall objective of this system is to stabilize and package plutonium metals and oxides of $>50 \%$ wt, as well as other selected isotopes, in accordance with the requirements of the DOE standard for safe storage of these materials for 50 years (reference 2.1.5.1). This system will support completion of stabilization and packaging campaigns of the plutonium inventory at a number of affected sites before the year 2002. The storage package will be standard for all sites and will provide an minimum of two uncontaminated, organics free confinement barriers for the packaged material.

\subsection{Document Overview}

[This paragraph ... shall summarize the purpose and contents of this document.]

This document describes the Pu SPS system requirements from an overall design perspective. These system requirements establish the goals to be met in the system design document. They provide guidance for detailed system development, interface development, and testing procedures. The intended audience includes system engineers and the DOE. 


\subsection{Applicable Documents}

\subsection{Government Documents}

[This paragraph shall begin with one of the following two paragraphs, as applicable:

(1) The following documents of the exact issue shown form a part of this specification to the extent specified herein. In the event of conflict between the documents referenced herein and the contents of this specification, the contents of this specification shall be considered a superseding requirement.

(2) The following documents of the exact issue shown form a part of this specification to the extent specified herein. In the event of conflict between the documents referenced herein and the contents of this specification, the contents of this specification shall be considered a superseding requirement, except for specification (enter number of next higher-tiered specification) listed below.]

[Government documents shall be listed by document number and title in the following order:]

\section{SPECIFICATIONS:}

\subsubsection{Federal}

2.1.1.1 29 CFR 1910, Occupational Safety and Health Standards.

2.1.1.2 10 CFR 835, Occupational Radiation Protection.

2.1.1.3 41 CFR 101-19.6, Accommodations for the Physically Handicapped.

\subsubsection{Department of Energy}

2.1.2.1 DOE Order 6430.1A, General Design Criteria.

2.1.2.2 DOE Order 5840.24, Nuclear Criticality Safety.

2.1.2.3 DOE Order 5633.3B, Control and Accountability of Nuclear Materials.

2.1.2.4 DOE Order 5480.10, Contractor Industrial Hygiene Program.

2.1.3 [Other Government Agency]

2.1.3.1 U.S. Army and U.S. Air Force TM 5-801-10/AFM 122-25, General Design Criteria to Facilitate Decommissioning of Nuclear Facilities. 


\section{STANDARDS:}

\subsubsection{Federal}

None used.

\subsubsection{Department of Energy}

2.1.5.1 DOE-STD-3013-94, Criteria for Safe Storage of Plutonium Metals and Oxides.

2.1.5.2 DOE-STD-1021-94, Natural Phenomena Hazards Performance Categorization Criteria for Structures Systems and Components.

2.1.5.3 DOE-STD-1020-94, Natural Phenomena Hazards Design and Evaluation Criteria for Department of Energy Facilities.

2.1.5.4 DOE-STD-1029-92, Writer's Guide for Technical Procedures.

2.1.6 [Other Government Agency]

2.1.6.1 U.S. NRC Regulatory Guide 1.60, Design Response Spectra for Seismic Design of Nuclear Power Plants.

2.1.6.2 DOD MII-STD-1472D, Human Engineering Design Criteria for Military Systems, Equipment, and Facilities, 1989.

\section{DRAWINGS:}

2.1.7 [Where detailed drawings referred to in a specification are listed on an assembly drawing, it is only necessary to list the assembly drawing.]

None used.

\section{OTHER PUBLICATIONS:}

2.1.8 [Manuals, Regulations, Handbooks, Bulletins, etc.]

2.1.8.1 SRS Engineering Requirement 01060, SRS Structural Design Criteria.

2.1.8.2 RFETS Plant Standard SMU-302, Ventilation Design.

2.1.8.3 RFETS Plant Standard SG-403, Intake Filter Mounting Frame.

2.1.8.4 RFETS Plant Standard SG-404, 8" Exhaust Filter Frame and Plenum.

2.1.8.5 RFETS Plant Standard SG-407, 12" Exhaust Filter Frame and Plenum.

2.1.8.6 RFETS Plant Standard SE-805, Standard for Glovebox Overheat Detector Assembly.

2.1.8.7 WSRS-TM-95-1, Standard 16050, SRS Electrical Design Criteria.

2.1.8.8 DOE/EH-0256T, DOE Radiological Control Manual.

2.1.8.9 WSRS-TM-95-1, Standard 15980, Mechanical Installation of Safety Class and Safety Significant Instrumentation. 
2.1.8.10 RFETS Plant Standard SG-101, Clamp Strip Windows, 1/4" Thick Non-shielded.

2.1.8.11 RFETS Plant Standard SG-301, Glove Ring.

2.1.8.12 RFETS Plant Standard SG-304, Bagout Ring.

2.1.8.13 WSRS-TM-95-1, Standard 05951, Corrosion Evaluation: Stainless Steels and other Corrosion Resisting Alloy.

2.1.8.14 WSRS-TM-95-1, Standard 05952, Practices to Minimize Chloride Induced Stress Corrosion Cracking of Type 300 Series Austenitic Stainless Steels.

2.1.8.15 RFETS Plant Standard SG-503, Cover Plate and Type 3 Crit Drain Installation.

2.1.8.16 RFETS Plant Standard SMU-301, Dump Valve.

2.1.8.17 DOE Training Accreditation Program, Manuals 1 through 3.

2.1.8.18 LA-10860-MS

2.1.8.19 U.S. NRC document NUREG 0700, Guideline for Control Room Design Reviews, 1981.

2.1.8.20 U.S. NRC document NUREG CR-1331, A Methodology for Allocating Nuclear Power Plant Control Functions to Humans or Automatic Control, 1983.

2.1.8.21 SAIC Internal Report SAIC/RFFO-96-003, Loss on Ignition (LOI) Measurements on Plutonium Oxide, draft dated May 6, 1996.

Copies of specifications, standards, drawings, and publications required by suppliers in connection with specified procurement functions should be obtained from the contracting agency or as directed by the contracting officer.

\subsection{Non-Government Documents}

The following documents of the exact issue shown form a part of this specification to the extent specified herein. In the event of conflict between the documents referenced herein and the contents of this specification, the contents of this specification shall be considered a superseding requirement.

[The source for all documents not available through normal Government stocking activity shall be listed.]

[Non-Government documents shall be listed by document number and title in the following order:]

\subsubsection{SPECIFICATIONS:}

2.2.1.1 ASTM A480, Standard Specification for General Requirements for Flat Rolled Stainless and Heat Resisting Steel Plate, Sheet, and Strip. 
2.2.2 STANDARDS:

2.2.2.1 AG-1, Code on Nuclear Air and Gas Treatment Systems, 1991; with Addendum SA of 1993.

2.2.2.2 ACI-349, Code Requirements for Nuclear Safety Related Concrete Structures.

2.2.2.3 ASME/ANSI B31.3, Chemical Plant and Petroleum Refinery Piping.

2.2.2.4 AISC, Manual of Steel Construction, Allowable Stress Design, 9th Edition.

2.2.2.5 ASME NQA-1, QA Requirements for Nuclear Facilities, 1994.

2.2.2.6 ASME Boiler and Pressure Vessel Code, Section VIII, 1992.

2.2.2.7 ANSI N14.5, Standard for Radioactive Material, Leakage Tests on Packages for Shipment, 1987.

2.2.2.8 NFPA 101, Life Safety Code, Section 7.

2.2.2.9 American Glovebox Society, Guidelines for Gloveboxes.

2.2.2.10 ANSI/ANS-8.1, Guide for Nuclear Criticality Safety in the Storage of Fissile Materials, 1975.

2.2.2.11 Compressed Gas Association pamphlet P-1-1965, Safe Handling of Compressed Gases.

2.2.2.12 ANSI B19, Safety Code for Compressed Air Machinery, 1938.

2.2.2.13 ANSI Z136.1, Standard for Safe Use of Lasers, 1993.

\subsubsection{DRAWINGS:}

2.2.3.1 Pu SPS Block Flow Diagram, Sheet 1, Receipt and Material Preparation Areas

2.2.3.2 Pu SPS Block Flow Diagram, Sheet 2, Transport Area and Furnaces

2.2.3.3 Pu SPS Block Flow Diagram, Sheet 3, Tipping/Dispense/Fill Area

2.2.3.4 Pu SPS Block Flow Diagram, Sheet 4, Can Weigh and Intermediate Can Handling

2.2.3.5 Pu SPS Block Flow Diagram, Sheet 5, Outer Can Weld and Monitoring Area

\subsubsection{OTHER PUBLICATIONS:}

2.2.4.1 University of California document UCRL-15673, Human Factors Design Guidelines for Maintainability of Department of Energy Nuclear Facilities, 1985.

2.2.4.2 Illumination Engineering Society of North America, Lighting Handbook Application and Reference Volume, 1987.

Technical society and technical association specifications and standards are generally available for reference from libraries. They are also distributed among technical groups and using Federal Agencies. 


\subsection{System Requirements}

\subsection{Definition}

[This subparagraph ... shall provide a brief description of the system. This description shall address pertinent operational, and logistical considerations and concerns. A system diagram shall be provided.]

The materials to be stabilized and packaged for interim safe storage at RFETS consist of plutonium metals and oxides that contain greater than 50 weight-percent plutonium and are of weapons grade. Nominal isotopic compositions for these materials are given in Appendix A of reference 2.1.5.1 (per DE-AC03-96SF20948, Attachment $I$, Section 3.1.1). The range of material quantities received will range from a minimum of $200 \mathrm{gm}$ of material to the maximum quantity allowed by the DOT shipping package design and qualification criteria (per DE-AC03-96SF20948, Attachment II, Section 3.1.2). The BNFL Team has initiated development of an integrated system, the Pu SPS, to process this material. A system block flow diagram for the Pu SPS on the following pages identifies the sequence of operations for the overall description provided below.

Existing plutonium storage containers are transferred from storage in vaults to a Receipt Area for entry to the Pu SPS process, either from an existing conveyor or from a manual transfer trolley. The site storage packages from the transfer trolley are checked for contamination upon opening of the outer container, and are also transferred to the Material Preparation Area if the inner container has leaked. Otherwise, just the inner container (including packing material, if present) enters the Material Preparation Area through an airlock. Site storage packages from an existing conveyor are transferred directly into the Material Preparation Area, also through an airlock.

In the inerted glovebox atmosphere of the Material Preparation Area, any packing material is cut off and the inner containers are opened. The inner container contents are poured through a screen where plutonium oxides and fine metal pieces are dispensed into a tray. Large plutonium metal and alloy pieces are manually brushed for removal of any oxide powder layer. Convenience cans of brushed metal pieces are passed through the Transport Area to the Tipping/Dispense/Can Fill Area. Brushed oxides are added to the trays prior movement into a stabilization furnace via the Transport Area.

Exposure to sustained, elevated temperatures in a dry air atmosphere stabilizes the metal oxides. Loss on Ignition (LOI) testing is performed on an oxide sample to verify sufficient stabilization. Stabilized oxides are transferred to the packaging suite, where the tray contents are tipped into an empty convenience can and its screw top is replaced. Empty trays are returned to the Material Preparation Area for another batch of oxides.

The convenience cans of either metal or oxide are inserted into an intermediate can, followed by the insertion of a sealed hollow plug (or bung), which serves as the cap for the can. Helium from the glovebox atmosphere fills the space between the convenience can and the intermediate can. The 


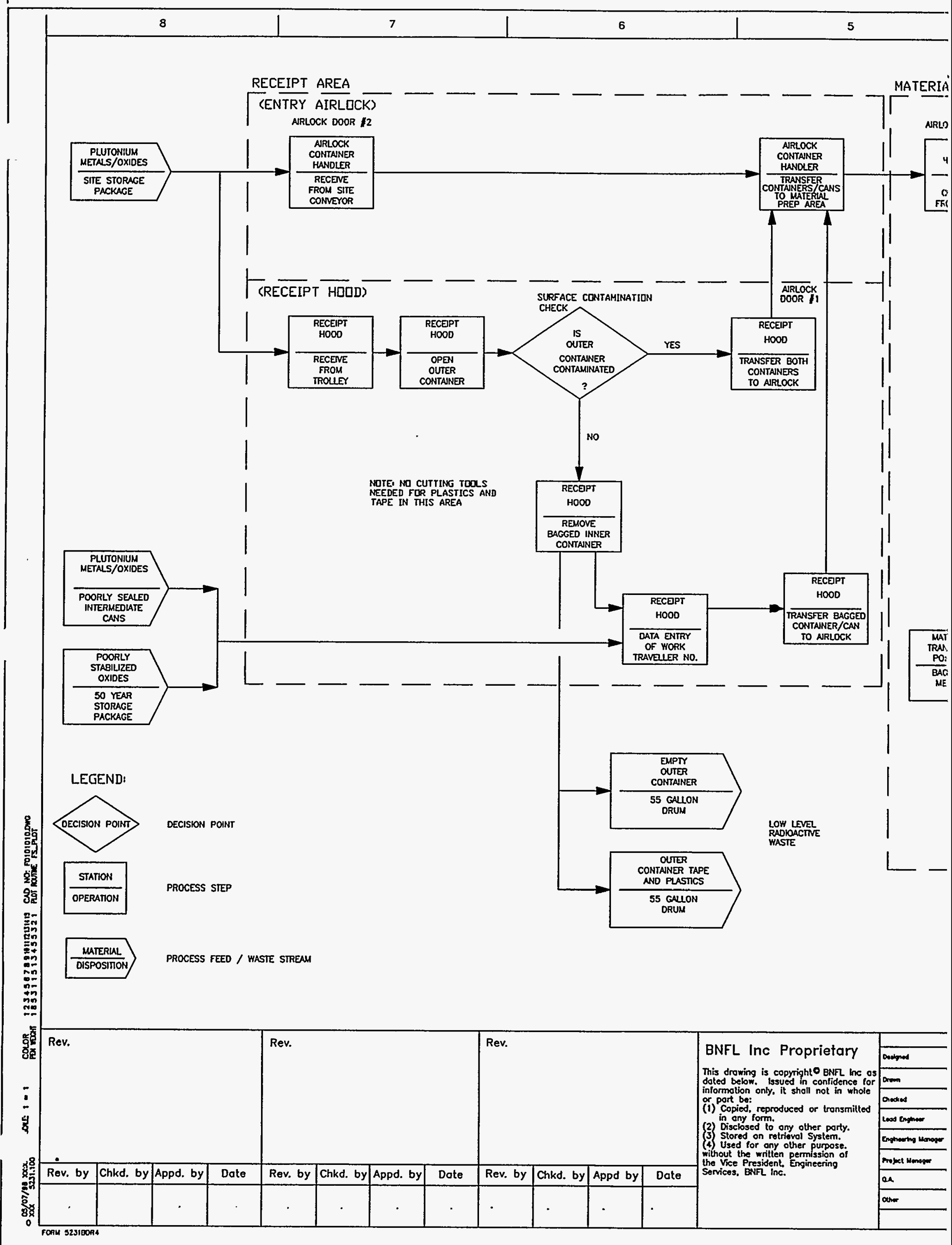



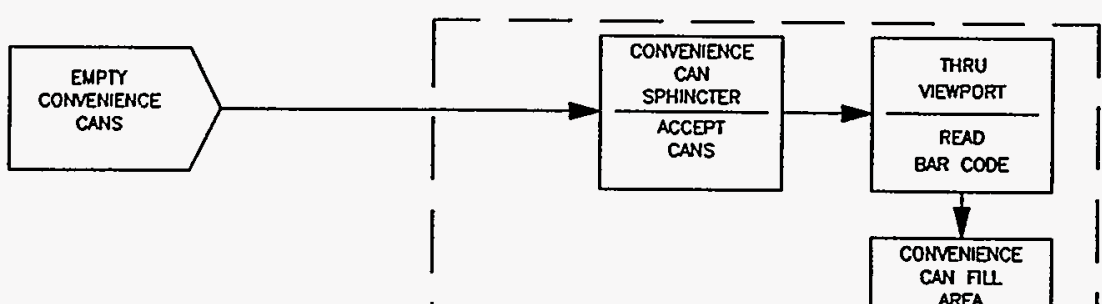

MATERIAL PREPARATION AREA

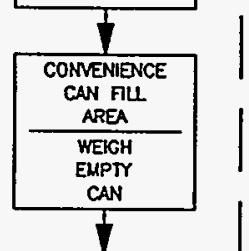

TRANSPIRT AREA
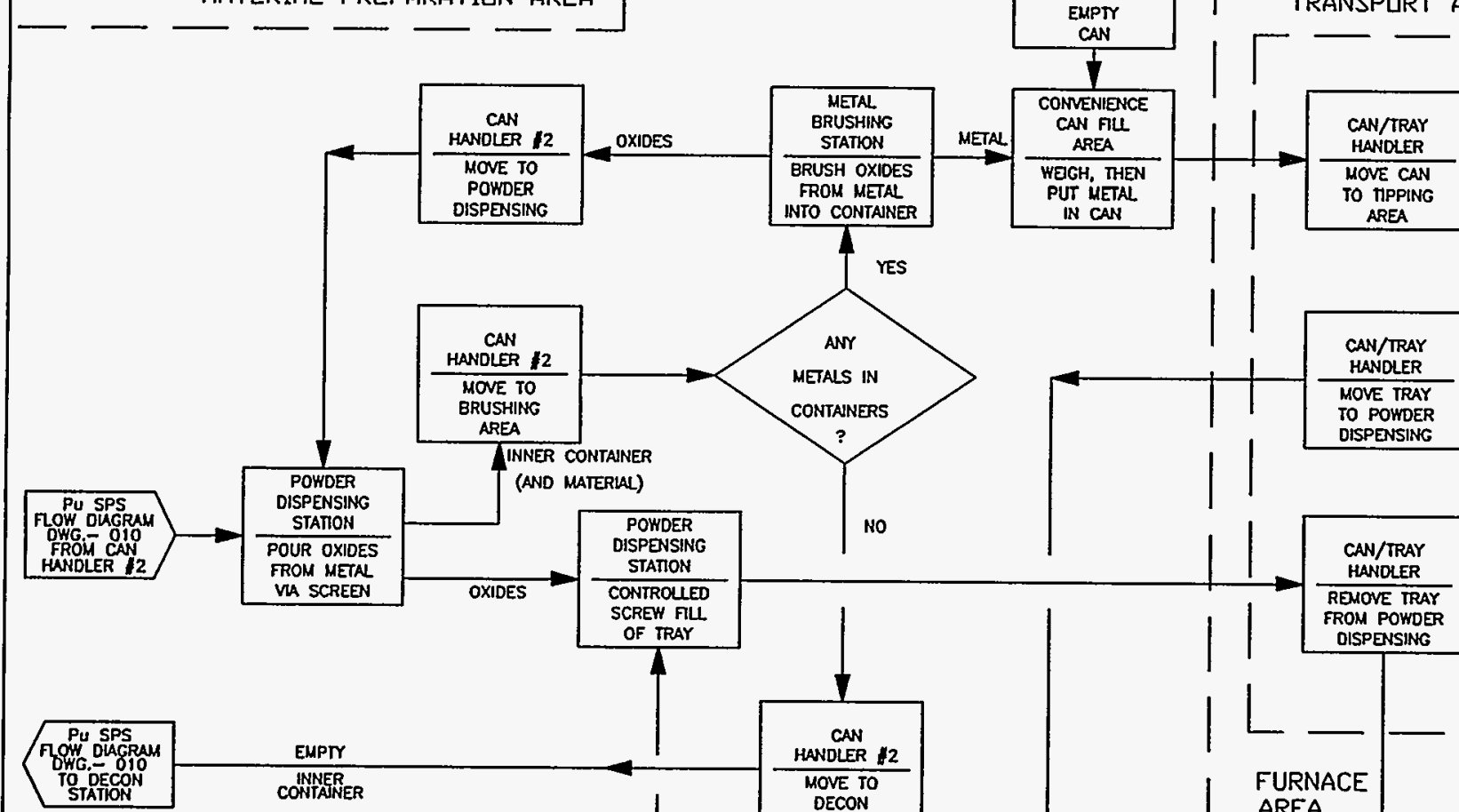

MA SCREEN
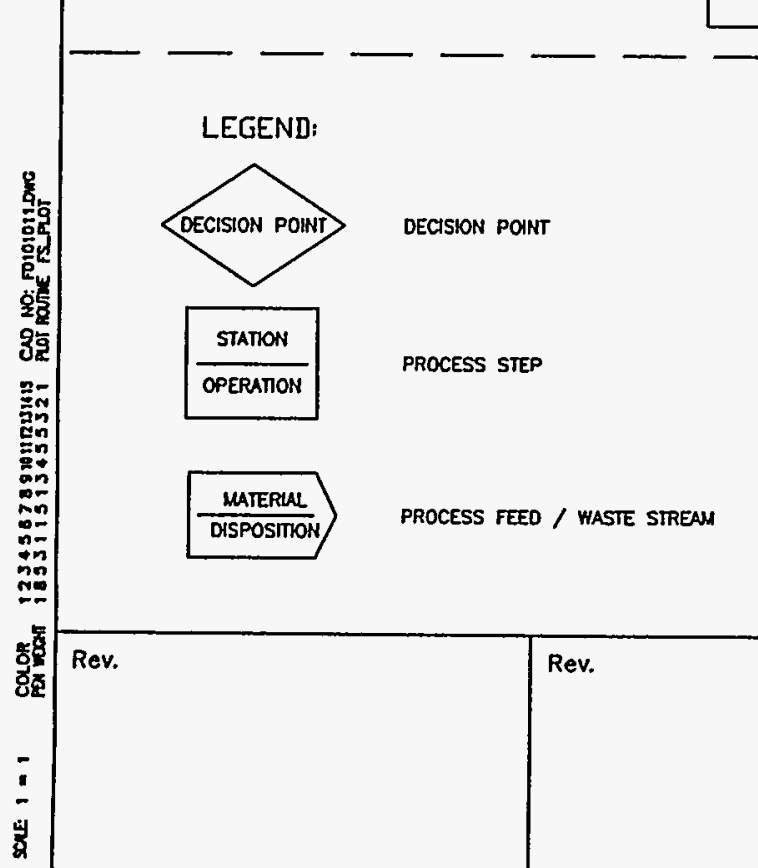

DECISION POINT
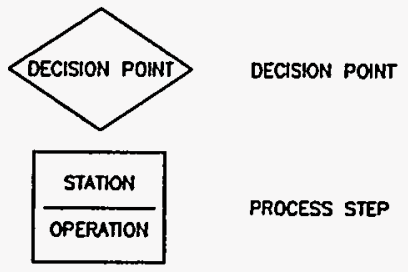

PROCESS STEP

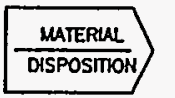

PROCESS FEEO / WASTE STREAM

TRAYS ARE NLMBERED WITH
HOLES AND EMPTY VEIGHTS

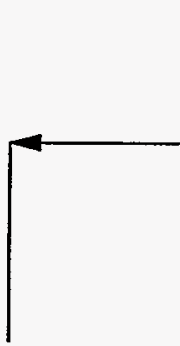

1

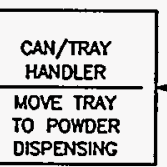

1
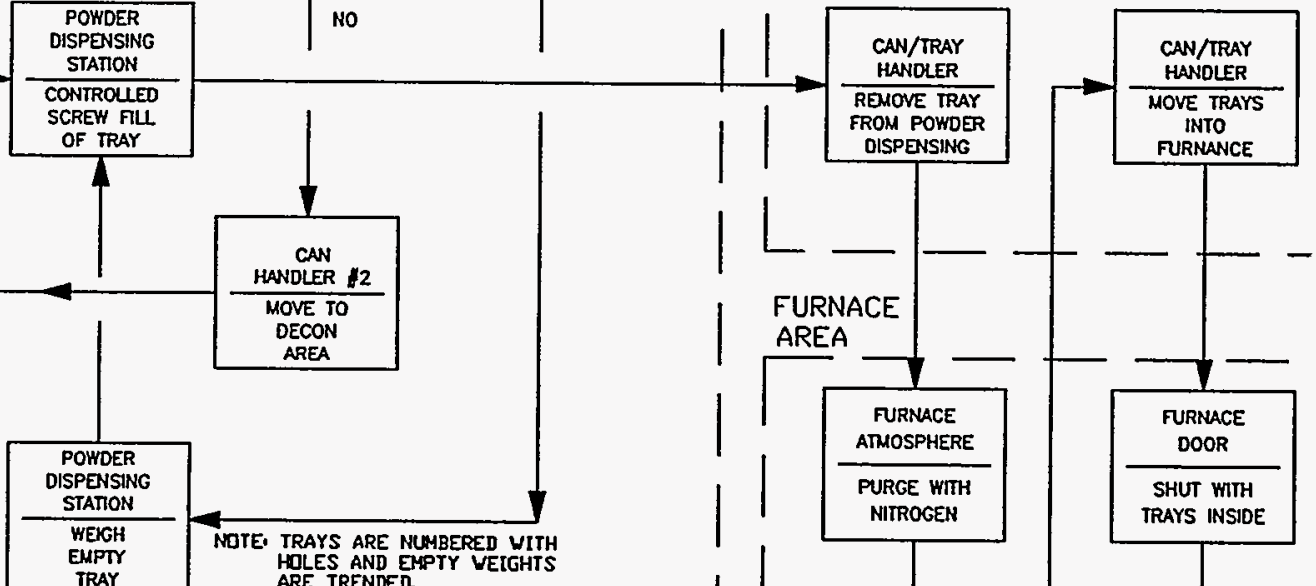

ARE TRENDED

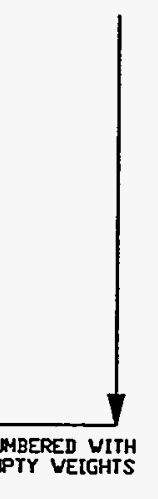

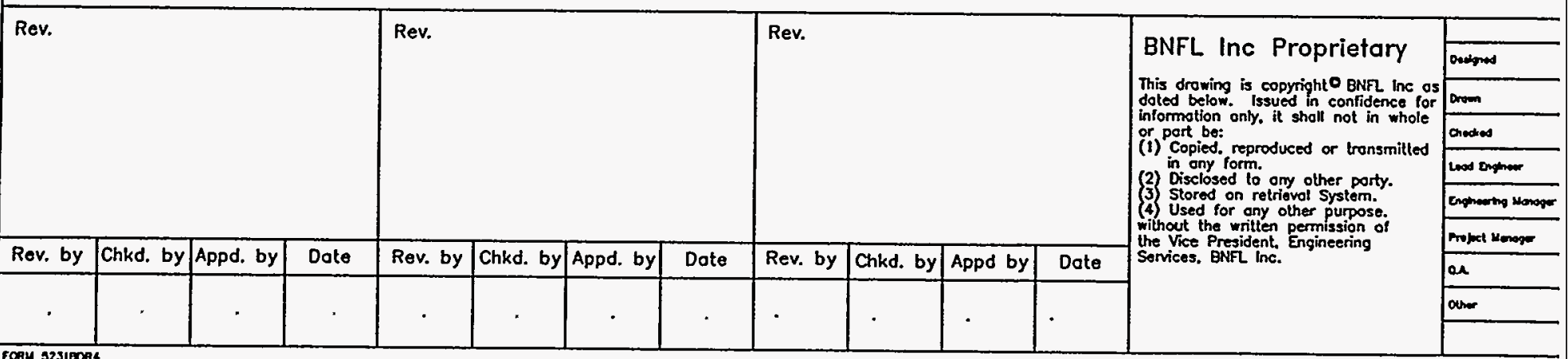




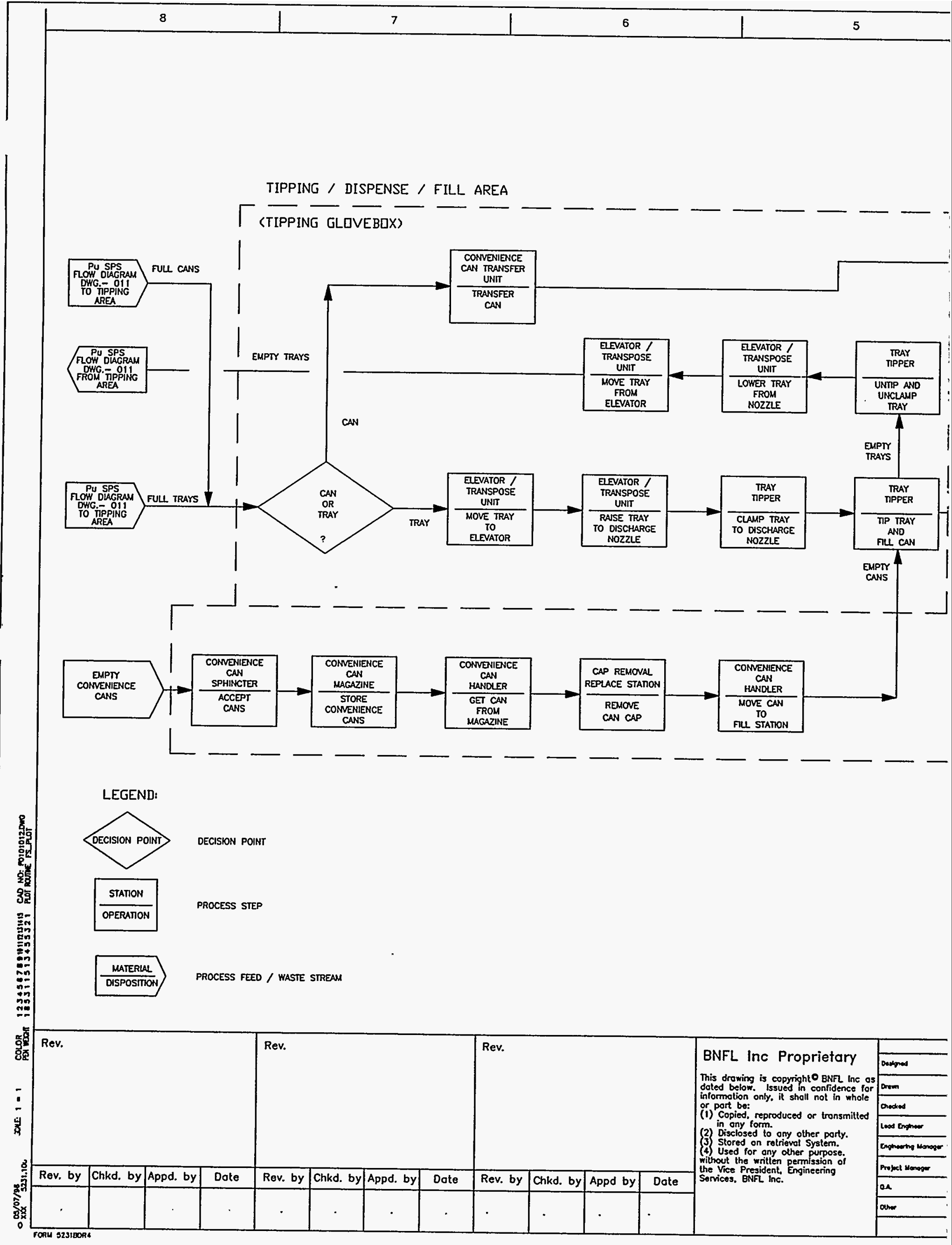




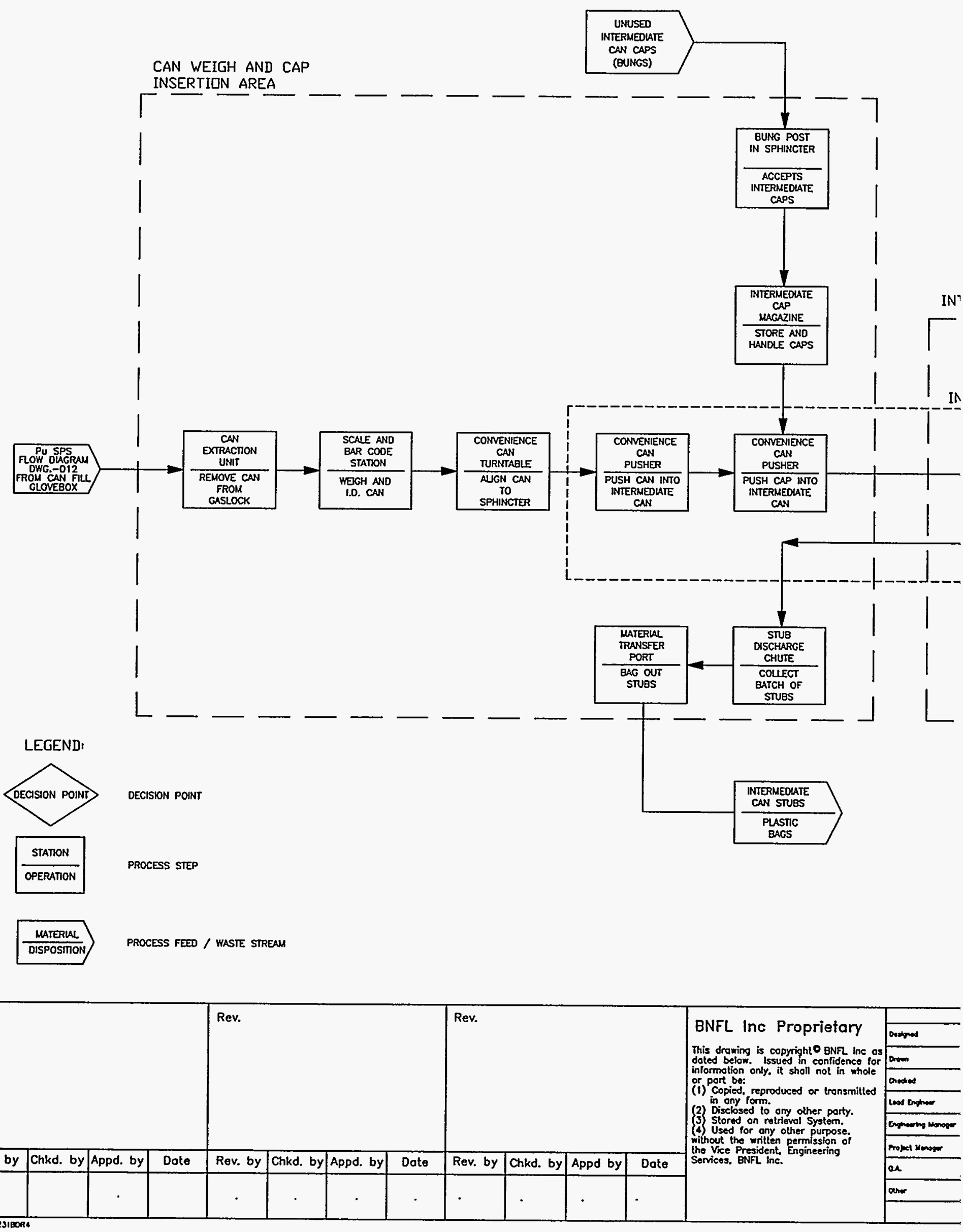




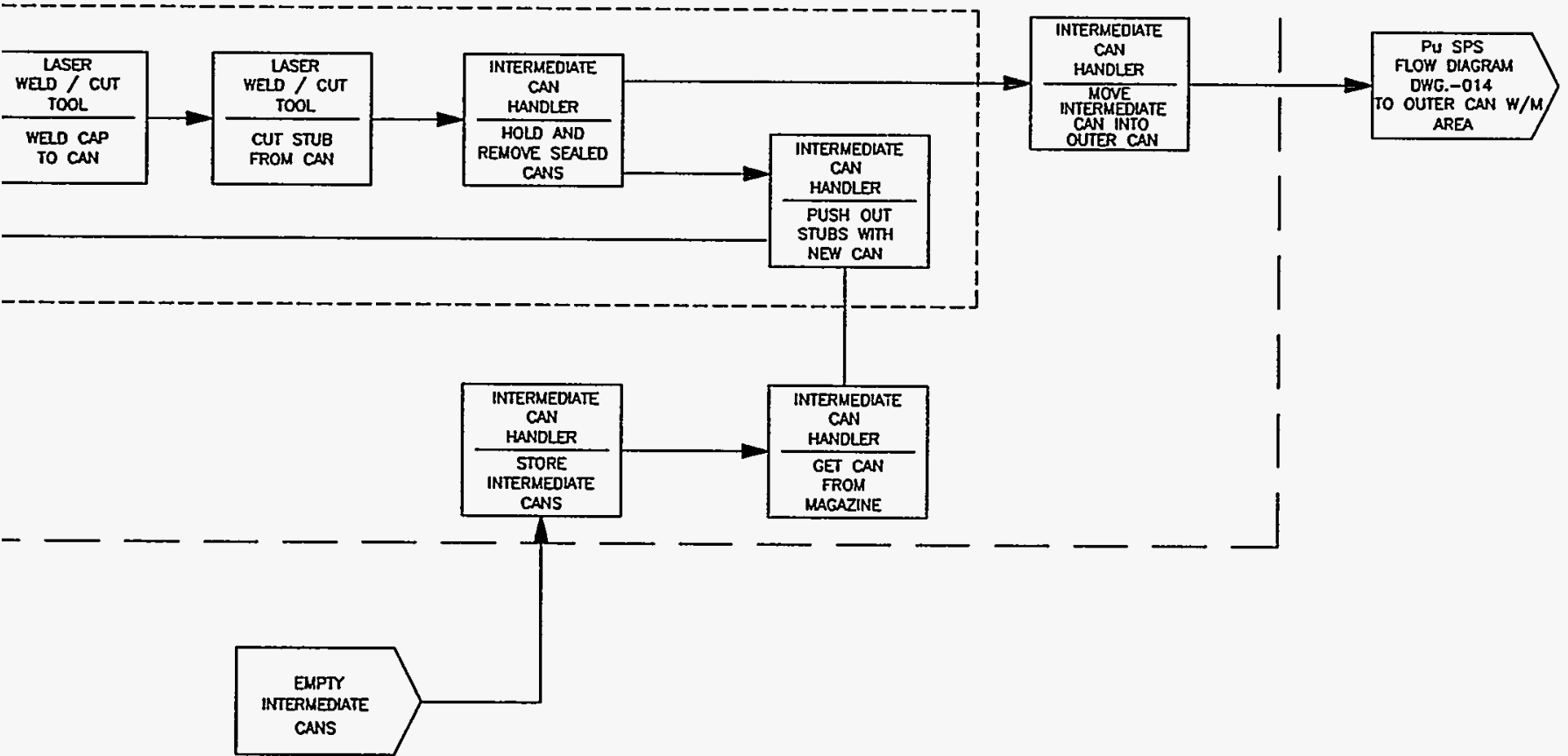

Prepared for:

U. S. DEPARTMENT OF ENERGY This Oakland Operations Office.

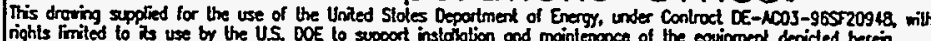

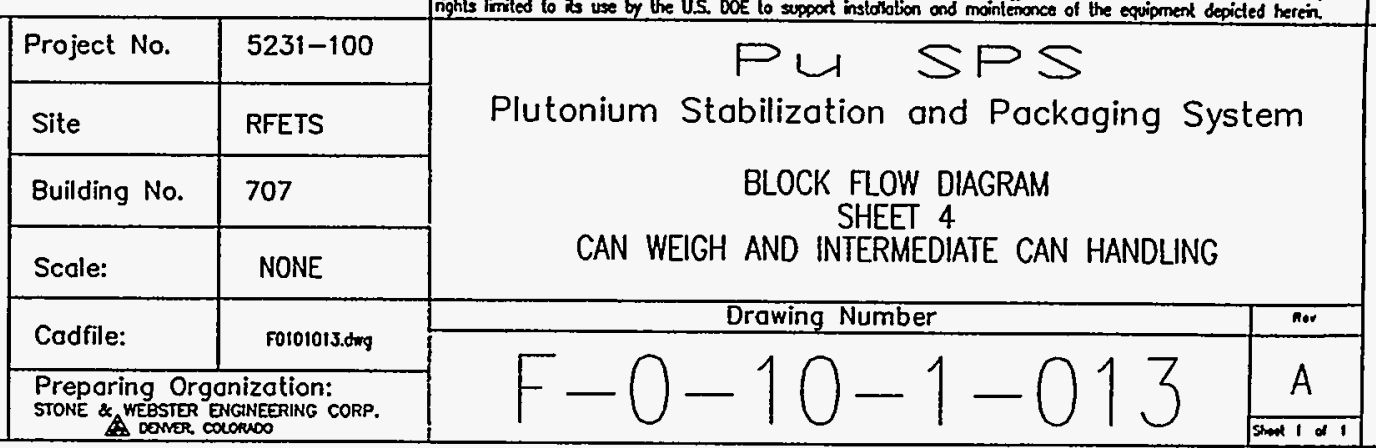


NOTE: SENT TO RECEIPT AREA

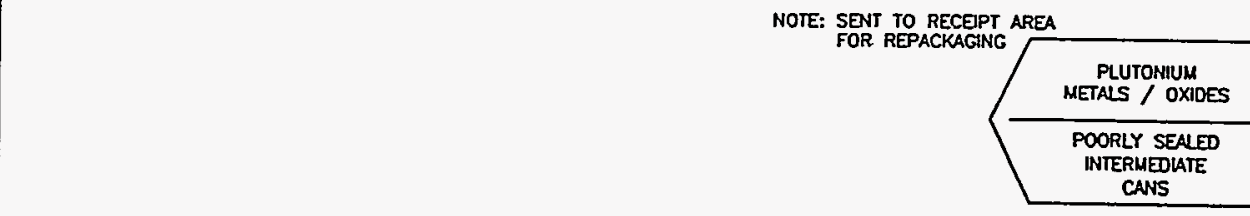

DUTER CAN WELD AND MONITURING AREA
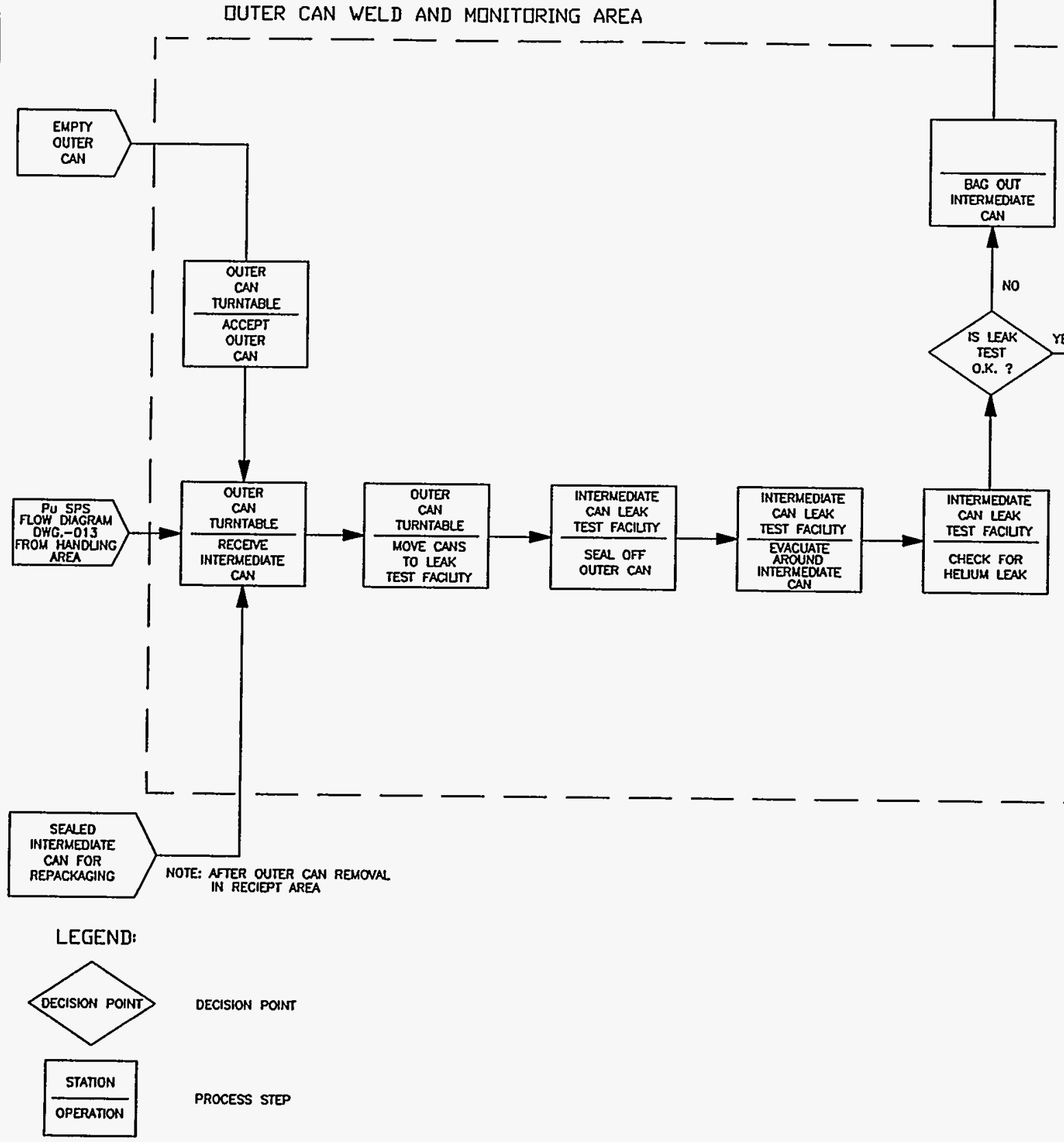

DECISION POINT

PROCESS STEP

MATERIAL DISPOSinON

PROCESS FEED / HASTE STREAN

Rev.

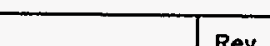

$$
\text { (n) }
$$




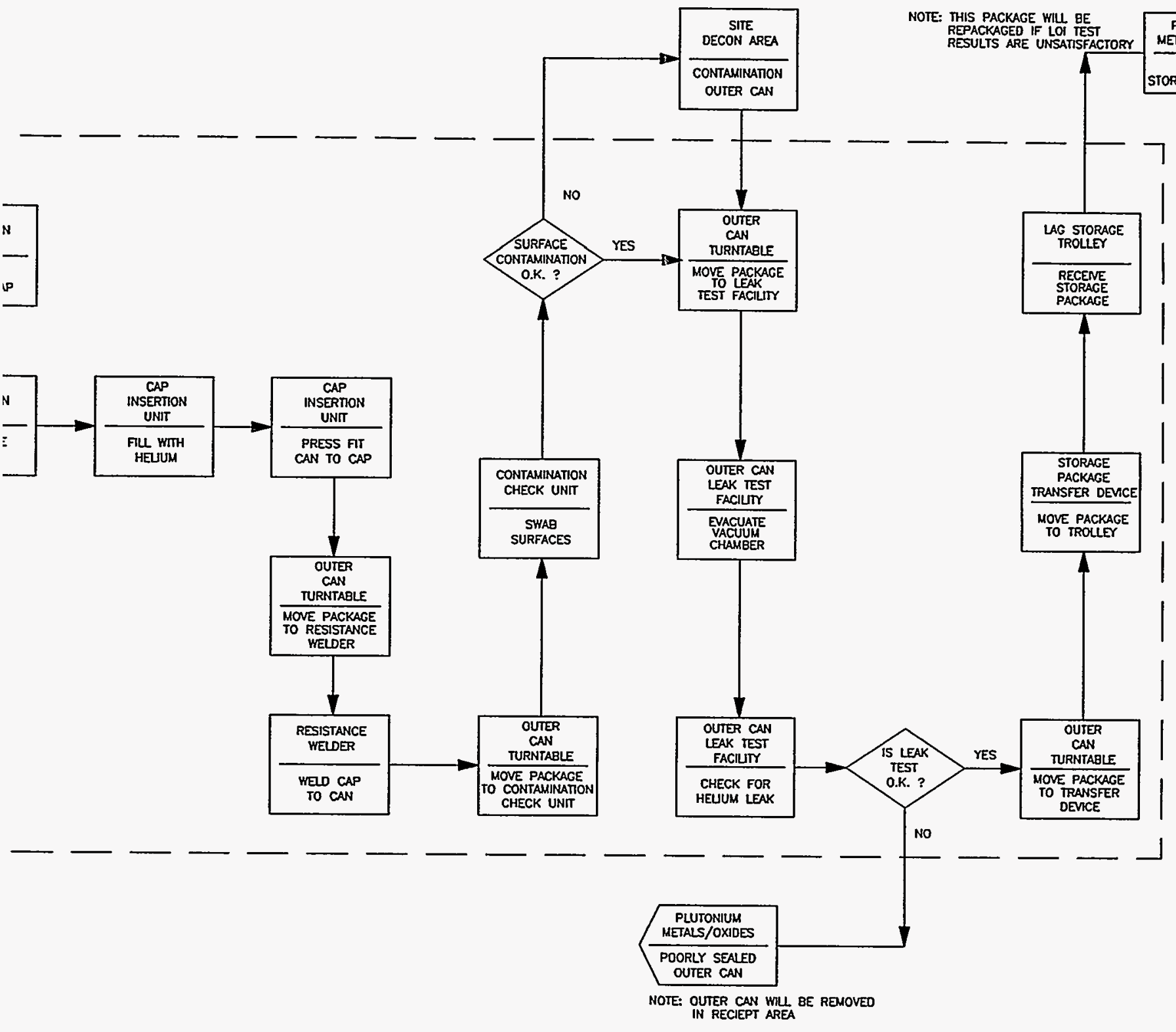

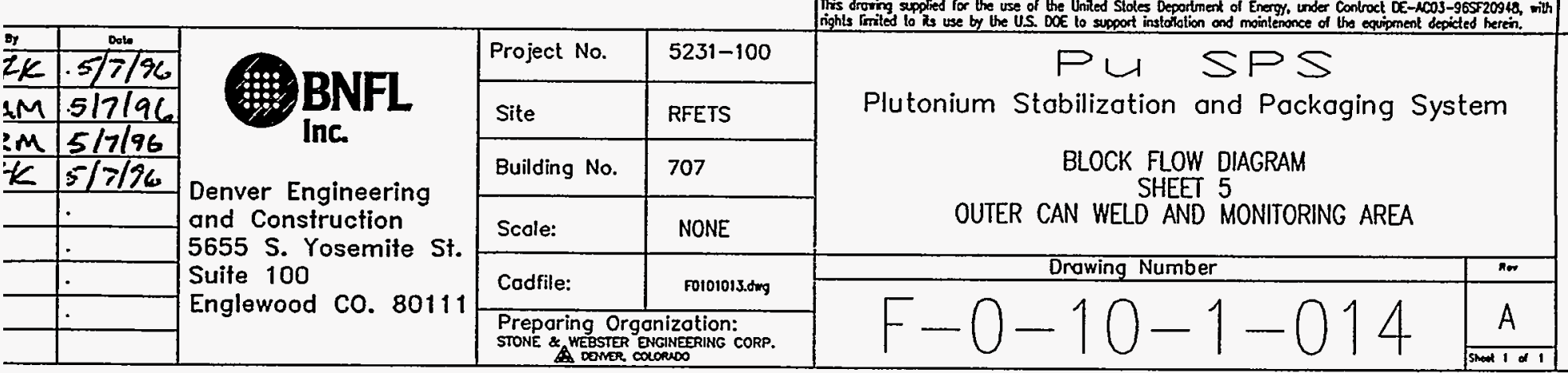

Prepared for:

u. S. DEPARTMENT OF ENERGY Oakland Operations Office

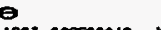




\subsection{Characteristics}

\subsubsection{Performance Characteristics}

[This paragraph ... shall be divided into subparagraphs to specify the system's capabilities. Each capability of the system shall be specified by uniquely identified requirements statements in order to provide for objective qualification.]

The subsections below identify the major areas that make up the Pu SPS and describe their requirements, including functional needs (inputs) and system/process results (outputs).

Certain functional requirements are applicable to the entire Pu SPS, as listed below.

SPS-1 Material processing shall be at least 2 containers per 8 hour shift.

(DE-AC03-96SF20948, Attachment II, Section 4.1.4)

SPS-2 SPS design shall minimize waste generation during operation and maintenance.

(DE-AC03-96SF20948, Attachment II, Section 4.1.4)

SPS-3 The SPS shall be capable of maintaining nuclear material control and accountability of the process materials and waste streams which are part of, or generated by, operations within the glovebox line in accordance with reference 2.1.2.3.

(DE-AC03-96SF20948, Attachment II, Section 4.2.7)

SPS-4 The system shall be capable of consistent, successive operation through the wall of a heavily contaminated $(\geq 250,000 \mathrm{dpm}$ surface count) glovebox.

(DE-AC03-96SF20948, Attachment II, Section 4.2.9) 《 An anticipated contract change may revise this requirement. $\gg$

SPS-5 The design of the SPS handling and processing equipment shall consider the pyrophoric and chemical reactivity of [plutonium] materials.

(DE-AC03-96SF20948, Attachment II, Section 3.1.3)

SPS-6 The design of the SPS shall take into consideration the hazards associated with adsorbed water [by plutonium oxide].

(DE-AC03-96SF20948, Attachment II, Section 3.1.4)

SPS-7 Note that some oxides and compounds will be very fine powders. Provisions for handling these fine powders shall be made to avoid dissemination of significant quantities in the confinement enclosures and the spread of contamination through the ventilation duct work.

(DE-AC03-96SF20948, Attachment II, Sections 3.1.4 \& 4.2.4) 
SPS-8 The SPS shall be designed to meet the requirements for PC-3 and System Group II (equipment must maintain structural and pressure boundary integrity but need not remain functional during and after the natural phenomena event) as defined in reference 2.1.5.2.

(DE-AC03-96SF20948, Attachment II, Section 4.1.2.2)

SPS-9 All SSCs will be designed to resist the applicable loading including dead weight, operating (thermal, vibration, etc.) and seismic hazard loading. The provisions of Reference 2.1.5.3 will be used for application of loads due to seismic hazards. Reference 2.2.2.1 seismic requirements will be considered for the design of "Safety Class" and "Safety Significant" HVAC systems.

(DE-AC03-96SF20948, Attachment II, Section 4.1.2.1)

Seismic load combination shall be per reference 2.1.8.1.

(DE-AC03-96SF20948, Attachment II, Section 4.1.2.3)

The following loads will be used in the analysis/evaluation of systems and equipment:

- Dead-weight Loads will include systems, equipment, and supporting structure weight;

- Operational Loads will include thermal, vibration, and Natural Phenomena Hazards Loads.

- Seismic Loads will be calculated based on:

- horizontal zero period acceleration (ZPA) of $0.25 \mathrm{~g}$ at the floor;

- vertical ZPA of $0.18 \mathrm{~g}$ at the floor;

- horizontal and vertical response spectra as provided in reference 2.1.6.1.

(DE-AC03-96SF20948, Attachment II, Section 4.1.2.3)

$<$ An anticipated contract change will revise these seismic loads. $>$

The dynamic approach shall be used for seismic analysis of the SPS. The calculated forces shall then be applied to the system or equipment statically in order to estimate the demand.

(DE-AC03-96SF20948, Attachment II, Section 4.1.2.4)

The capacities of piping systems shall be per reference 2.2.2.3 piping code. Capacities of all other systems, equipment, and their supports shall be per reference 2.2.2.4.

(DE-AC03-96SF20948, Attachment II, Section 4.1.2.4)

SPS-10 "Safety Class" and "Safety Significant" equipment and components shall be installed in accordance with reference 2.1.8.9. (DE-AC03-96SF20948, Attachment II, Appendix B)

SPS-11 Pu SPS design throughput shall be based on equal numbers of incoming containers of plutonium oxide and metal, presuming 2 incoming containers of plutonium metal per $\mathrm{Pu}$ SPS storage package, and 4 incoming containers of plutonium oxide per Pu SPS storage package, resulting in $4 \mathrm{Pu}$ SPS storage packages of plutonium metal and $2 \mathrm{Pu}$ SPS storage packages of oxide per 8 hour shift. 
SPS-12 Pu SPS design shall require that SNM/ONM will remain within the system during discontinuous operator work periods, with surveillances performed by site personnel as appropriate.

[Each capability subparagraph ... shall specify a capability of the system by name, and shall describe its purpose. This subparagraph shall identify the functions associated with the capability and specify the inputs and outputs of the functions. This subparagraph shall also identify the applicable parameters associated with the capability and shall specify them in measurable terms. Unique identifiers shall be assigned to functional and parametric requirements that are to be separately qualified.]

\subsubsection{Receipt Area}

\subsection{Purpose}

This area receives incoming plutonium storage containers from site storage and transfers them into the Material Preparation Area.

\subsection{Functional Requirements}

The functional requirements of this subsystem, including measurable parameters, are:

RA-1 The SPS shall provide the capability for the receipt of existing containers.

(DE-AC03-96SF20948, Attachment II, Section 4.2.2) Most materials will be received at the SPS in a DOT $2 R$ type primary containment vessel (PCV) or primary/secondary containment system containing boundary and material containers and/or slip-lid product cans that in turn contain the materials.

(DE-AC03-96SF20948, Attachment II, Section 3.1.1)

RA-2 The SPS shall be designed to interface with the J Module conveyor system in at least one of the connection locations of the gloveboxes removed to provide space for the SPS.

(DE-AC03-96SF20948, Attachment II, Section 4.1.3)

RA-3 The glovebox located at the material entry end of the glovebox system where containment vessels will be opened to remove material shall have an airlock of sufficient size to accept the largest shipping container containment vessels.

(DE-AC03-96SF20948, Attachment II, Appendix B) 
RA-4 For material control and accountability security reasons, the Pu SPS shall process (as data) only the work control "traveller" identification number for campaigned, incoming site plutonium storage packages, to supplement the limited nuclear information provided by the Container Assay System. Other information on the traveller shall not be processed by the $\mathrm{Pu}$ SPS.

RA-5 The Receipt Area shall provide the capability of receiving existing containers by a manual transfer trolley.

RA-6 The Receipt Area shall provide support services to allow detection of surface contamination within a just opened outer container. (The detection instrumentation for surface contamination is Government Furnished Equipment.)

\subsection{System Functional Needs (Inputs)}

a) Bar code scanning or manual operator input of work control "traveller" identification number for campaigned, incoming site plutonium storage containers.

b) Incoming containers of plutonium metals and oxides, within:

- an inner container, double bagged and within an outer container,

- an inner container, potentially contaminated from the existing conveyor,

- a convenience can, within a poorly sealed intermediate can that is bagged,

- a convenience can, within both an intermediate can and an outer can.

(The latter two instances are expected to be quite rare.)

c) Packaging materials for radioactive waste disposal, from site warehouse storage.

\subsection{System/Process Results (Outputs)}

a) Work control traveller numbers (as data) for the incoming campaign of plutonium storage containers.

b) Inner containers (obtained via a manual transfer trolley), along with unopened packing material (if any), are transferred into the Material Preparation Area.

c) Contaminated outer containers and outer packaging materials are transferred into the Material Preparation Area.

d) Inner containers (obtained from the existing conveyor and potentially contaminated) are transferred directly into the Material Preparation Area. 


\subsubsection{Material Preparation Area}

\subsection{Purpose}

This area prepares plutonium metals for storage, prepares plutonium oxides for stabilization, and prepares process waste streams for disposal/storage.

\subsection{Functional Requirements}

The functional requirements of this subsystem, including measurable parameters, are:

MPA-1 Capabilities shall be included for decontamination and unloading of existing packages, waste stream handling, and accountability of process materials and waste streams.

(DE-AC03-96SF20948, Attachment II, Section 4.2.2)

MPA-2 The SPS shall provide the capability to remove loose oxide from metal in an inert atmosphere (nitrogen or argon) with less than 5 percent oxygen (nitrogen) or 4 percent oxygen (argon) prior to repackaging. (DE-AC03-96SF20948, Attachment II, Section 4.2.3)

MPA-3 The oxide removed from the metals and alloys will be combined with oxides awaiting stabilization.

(DE-AC03-96SF20948, Attachment II, Section 4.2.3)

MPA-4 Plutonium oxide and metal removed during brushing shall be blended to homogenize material prior to stabilization.

(DE-AC03-96SF20948, Attachment II, Section 4.2.4)

MPA-5 Any plastic material or other undesirable extraneous material in the received material containers or slip-lid product cans will be removed during this repackaging operation.

(DE-AC03-96SF20948, Attachment II, Section 3.1.1)

MPA-6 The system shall have the capability for opening sealed containers for restabilization and repackaging, as necessary, or if the container closure does not meet the design requirements.

(DE-AC03-96SF20948, Attachment II, Section 4.2.8)

MPA-7 The container compactor must be able to compact the inner, incoming plutonium container (manufactured by Vollrath Group, model 88010 ).

MPA-8 The compacted height of the cans shall not exceed $2 \frac{1}{2}$ ".

MPA-9 The container compactor shall be interlocked to prevent its operation when a container is being manually handled.

MPA-10 The container compactor shall have a compaction cycle of less than five minutes. 
MPA-11 Contained, automated dispensing of plutonium oxide from existing containers into furnace trays in a manner suitable for stabilization.

MPA-12 Automated monitoring to prevent overfilling of a furnace tray with plutonium oxide, limiting both weight and level of oxide in the tray.

The Material Preparation Area also must meet certain requirements related to Process Radiometric Instrumentation (PRI-1) on page 43.

\subsection{System Functional Needs (Inputs)}

a) Inner containers (possibly within other packaging materials) of plutonium metal and oxide from the Receipt Area.

b) Bar code scanning or manual operator input of work control "traveller" identification number for campaigned, incoming site plutonium storage containers (if not done in the Receipt Area).

c) Empty convenience cans and lids from site warehouse storage.

d) Empty furnace trays from the Transfer Area.

e) Packaging materials for radioactive waste disposal, from site warehouse storage.

\subsection{System/Process Results (Outputs)}

a) Furnace trays of unstabilized plutonium oxide, available for transport.

b) Convenience cans filled with brushed plutonium metal, available for transport.

c) Work control traveller numbers (as data) for the incoming campaign of plutonium storage containers (if not done in the Receipt Area).

d) Metal packaging and crushed inner containers, bagged for removal and transport to disposal/storage.

e) Plastic packaging materials, bagged for removal and transport to disposal/storage. 


\subsubsection{Transport Area}

\subsection{Purpose}

This area transports convenience cans of plutonium metal and furnace trays (both empty and plutonium oxide filled) between the Material Preparation Area, the Furnace Area, the LOI Test Area, and the Tipping Area.

\subsection{Functional Requirements}

The functional requirements of this subsystem, including measurable parameters, are:

TA-1 Automated transport of cans of metal, with caps fitted in place, from the Material Preparation Area to the Tipping/Dispense/Fill Area, minimizing the potential for spillage.

TA-2 Automated transport of open trays of plutonium oxide from the Material Preparation Area, to/from the Furnace Area, to/from the LOI Test Area, and to the Tipping/Dispense/Fill Area. During this transfer, the powder in the tray must remain in a level uniform layer, and the potential for spillage minimized.

TA-3 Automated pickup and placement of cans and trays must be within an estimated $\pm 1 / 4^{\prime \prime}$.

\subsection{System Functional Needs (Inputs)}

a) Furnace trays of unstabilized plutonium oxide from the Material Preparation Area.

b) Furnace trays of stabilized plutonium oxide from the Furnace Area.

c) Furnace trays of LOI tested plutonium oxide from the LOI Test Area.

d) Empty furnace trays from the Tipping Area.

e) Convenience cans filled with brushed plutonium metal from the Material Preparation Area.

\subsection{System/Process Results (Outputs)}

a) Furnace trays of unstabilized plutonium oxide are placed into the Furnace Area.

b) Furnace trays of stabilized plutonium oxide are placed into the LOI Area.

c) Furnace trays of LOI sampled plutonium oxide are placed into the Tipping Area. 
d) Empty furnace trays are placed into the Material Preparation Area.

e) Convenience cans filled with brushed plutonium metal are placed into the Tipping Area.

\subsubsection{Furnace Area}

\subsection{Purpose}

This area is used for thermal stabilization of plutonium oxide.

The purpose of stabilization is to convert all plutonium oxide and any metal removed during brushing to purer oxide form and to remove all volatiles and moisture.

(DE-AC03-96SF20948, Attachment II, Section 4.2.5)

Plutonium metal is very reactive and corrodes rapidly in air to produce oxides mixed with small amounts of hydrides and metal fines that may be pyrophoric. In addition, plutonium oxide is hygroscopic and readily adsorbs water onto its surface; radiolytic decomposition of adsorbed water can, over time, pressurize a storage package. Heating the plutonium oxide mixture to elevated temperatures in dry air converts the mixture to a stable plutonium dioxide, drives off adsorbed water, and has an additional benefit of agglomerating the particles of plutonium dioxide. Larger particle sizes reduce both overall dispersion characteristics and the potential for water re-adsorption through reduced surface areas.

\subsection{Functional Requirements}

The functional requirements of this subsystem, including measurable parameters, are:

FURN-1 Thermal stabilization of the plutonium oxide shall be accomplished by maintaining the oxide at $1000 \pm 50^{\circ} \mathrm{C}$ in an oxidizing atmosphere for a minimum of one hour.

(DE-AC03-96SF20948, Attachment II, Section 4.2.5)

FURN-2 Throughput considerations shall be taken into account when determining the rate of temperature increase and the duration of soak times and cool down times.

(DE-AC03-96SF20948, Attachment II, Section 4.2.5)

FURN-3 The furnaces shall operate in an oxidizing atmosphere with a gas having less than 1000 ppm moisture. The flow of this gas shall be regulated to between 0.9 and $1.1 \mathrm{~cm}$. Filtration shall be required to assure no contamination of the material being stabilized. (DE-AC03-96SF20948, Attachment II, Section 4.2.5) 
FURN-4 The furnaces shall be operated inside a glovebox.

(DE-AC03-96SF20948, Attachment II, Section 4.2.5)

FURN-5 The maximum temperature of the outer shell of the furnace shall not exceed $50^{\circ} \mathrm{C}$.

(DE-AC03-96SF20948, Attachment II, Section 4.2.5 and Appendix B)

FURN-6 The controller for the furnace shall be located outside the glovebox and shall include a display of the furnace temperature. The furnace temperature shall also be continuously recorded by chart and by a data logger. The furnace shall be equipped with automatic high-temperature shutoff switches.

(DE-AC03-96SF20948, Attachment II, Section 4.2.5 and Appendix B)

FURN-7 Furnaces shall have the capability of stabilizing two trays of plutonium oxide at one time.

\subsection{System Functional Needs (Inputs)}

a) Plutonium oxide in furnace trays, blended, and spread to a thickness suitable for stabilization.

b) Furnace trays made of a high nickel alloy, suitable for operation into the furnaces at $1000^{\circ} \mathrm{C}$ with an oxidizing atmosphere. The inside tray size is approximately $10^{\prime \prime} \times 10^{\prime \prime} \times 2 "$, with an outside size of approximately $11^{\prime \prime} \times 11 "$.

c) An oxidizing atmosphere of air dried to less than $1000 \mathrm{ppm}$ moisture and filtered prior to heating by passage through a filter.

\subsection{System/Process Results (Outputs)}

a) Stabilized plutonium oxide in furnace trays, ready for LOI testing.

b) Air exiting the furnace is filtered by passing it through a sintered metal filter.

c) Air exiting the furnace will be swept from the furnace glovebox by nitrogen from the inert ventilation system, starting from the rear of the glovebox, across the furnace, and into the Transport Glovebox.

\subsubsection{LOI Test Area}

\subsection{Purpose}

This area verifies that plutonium oxide processed through the stabilization furnaces has achieved an acceptable Loss on Ignition (LOI) test value. 


\subsection{Functional Requirements}

The functional requirements of this subsystem, including measurable parameters, are:

LOI-1 The SPS shall include an in line capability for determining the LOI of a representative batch sample by heating the sample in an oxidizing atmosphere to a temperature of 1000 $0 /+50{ }^{\circ} \mathrm{C}$ for at least one hour ...

(DE-AC03-96SF20948, Attachment II, Section 4.2.5)

LOI-2 The plutonium oxide shall be thermally stabilized to less than 0.5 percent loss on ignition (LOI) and retain this characteristic through final packaging per the requirements of reference 2.1.5.1.

(DE-AC03-96SF20948, Attachment II, Section 4.2.5)

LOI-3 The sample should be removed from the [LOI] furnace when the temperature reaches 200 ${ }^{\circ} \mathrm{C}$ and placed in a desiccator to finish cooling to $25^{\circ} \mathrm{C}$.

(reference 2.1.8.21, section $\mathrm{V}(3)$ )

LOI-4 When the sample reaches room temperature, it should be removed from the desiccator and immediately weighed.

(reference 2.1.8.21, section $\mathrm{m}$, last paragraph)

The LOI Test Area also must meet certain functional requirements related to the Furnace Area (FURN-2, FURN-3, FURN-4, FURN-5, and FURN-6) on page 20.

\subsection{System Functional Needs (Inputs)}

a) Furnace trays of $\operatorname{cool} 25^{\circ} \mathrm{C}$, stabilized plutonium oxide.

b) Crucibles suitable for operation into the LOI furnace at $1000^{\circ} \mathrm{C}$ with an oxidizing atmosphere and capable of holding 20 to $30 \mathrm{gm}$ of plutonium oxide.

c) An oxidizing atmosphere of air dried to less than $1000 \mathrm{ppm}$ moisture and filtered prior to heating.

d) Ultra-dry air ( $<100 \mathrm{ppm}$ moisture) for the sample desiccator, at 1 to $3 \mathrm{scfm}$.

\subsection{System/Process Results (Outputs)}

a) LOI sampled plutonium oxide in furnace trays, available for transport.

b) The weight loss of each sample, obtained after reheating in the LOI furnace atmosphere.

c) LOI test results, entered into the PSCS. 
d) Tested samples, returned to the next (batch) furnace tray sampled.

e) Air exiting the LOI furnace is filtered by passing it through a sintered metal filter. The cleaned air is discharged into the LOI Glovebox.

\subsubsection{Tipping/Dispense/Can Fill Area}

\subsection{Purpose}

This area transfers oxides in furnace trays into convenience cans, and moves filled convenience cans (of both oxide and metal) to the Intermediate Cap Insertion Area.

\subsection{Functional Requirements}

The functional requirements of this subsystem, including measurable parameters, are:

TFA-1 Automated movement of furnace trays into a dispersion limiting discharge nozzle.

TFA-2 Automated removal and replacement of convenience can caps.

TFA-3 Controlled tipping of plutonium oxide into convenience cans.

TFA-4 Weight confirmation of a filled convenience can/an empty furnace tray.

TFA-5 Automated movement of convenience cans within the Tipping/Dispense/Fill Area.

TFA-6 Automated movement of convenience cans into the Gaslock.

\subsection{System Functional Needs (Inputs)}

a) Furnace trays of stabilized plutonium oxide from the Transport Area, placed into a defined location and in a specific orientation.

b) Convenience cans filled with brushed plutonium metal from the Transport Area, placed in a defined location.

c) Empty convenience cans from site warehouse storage.

\subsection{System/Process Results (Outputs)}

a) Convenience cans, filled and ready for storage. 
b) Empty furnace trays, available for transport, placed into a defined location and in a specific orientation.

\subsubsection{Can Weigh and Cap Insertion Area}

\subsection{Purpose}

This area loads an intermediate can with a convenience can, followed by a special cap (also called a bung).

\subsection{Functional Requirements}

The functional requirements of this subsystem, including measurable parameters, are:

CWCI-1 Automated movement of convenience cans out of the Gaslock.

CWCI-2 Automated movement of convenience cans within the Can Weigh and Cap Insertion Area.

CWCI-3 Automated weighing and identification of filled convenience cans.

CWCI-4 Automated insertion of a convenience can and the special cap into an intermediate can.

The Can Weigh and Cap Insertion Area also must meet certain requirements related to the Storage Packages (SP-7) on page 30.

\subsection{System Functional Needs (Inputs)}

a) Filled convenience cans from the Tipping/Dispense/Fill Area.

b) Intermediate caps (also called bungs) from site warehouse storage.

c) Packaging materials for radioactive waste disposal of the intermediate can "stubs."

\subsection{System/Process Results (Outputs)}

a) Weight and identification (bar code) of a filled convenience can.

b) Intermediate/convenience can assemblies, ready for sealing.

c) Intermediate can "stubs", bagged for removal and transport to disposal/storage. 


\subsubsection{Intermediate Can Handling Area}

\subsection{Purpose}

This area welds and cuts intermediate/convenience can assemblies, then transfers the sealed assembly to the Outer Can Weld and Monitoring Area.

\subsection{Functional Requirements}

The functional requirements of this subsystem, including measurable parameters, are:

ICHA-1 Automated welding and cutting of intermediate can assemblies.

ICHA-2 Automated movement of sealed intermediate cans from the rotating sphincter seal and into the outer can.

ICHA-3 Automated movement of empty intermediate cans into the rotating sphincter seal.

The Intermediate Can Handling Area also must meet certain requirements related to the Storage Packages (SP-7, SP-8) on page 30.

\subsection{System Functional Needs (Inputs)}

a) An intermediate can in the rotating sphincter, containing a filled convenience can and a plugged with a special cap (also called a bung).

b) Intermediate cans from site warehouse storage.

\subsection{System/Process Results (Outputs)}

a) Sealed intermediate/convenience can assemblies.

b) An empty intermediate can in the rotating sphincter, isolating the Can Weigh and Cap Insertion Area from the Intermediate Can Handling Area. 


\subsubsection{Outer Can Weld and Monitoring Area}

\subsection{Purpose}

This area checks the intermediate can assembly for leaks, seals the outer can, and checks the outer can for removable surface contamination and leaks.

\subsection{Functional Requirements}

The functional requirements of this subsystem, including measurable parameters, are:

OWM-1 ...provide helium leak detectors for testing the seal on both the material container and the boundary container. The leak detector system(s) shall be designed to:

1) have a sensitivity twice as great as the minimum leak. References 2.1.5.1 and 2.2.2.7 require the minimum leak to be less than or equal to $1 \times 10^{-7}$ standard cubic centimeters of gas per second across a pressure gradient of 1.0 atmospheres. This is equivalent to $4 \times 10^{-12}$ moles of air or helium per second.

2) minimize the potential for radioactive contamination should a container leak.

3) prevent pump oil from being drawn into the glovebox.

4) discharge vacuum pumps to a filtered exhaust system.

The location of the leak detectors shall take into consideration the potential for a false leak indication should the atmosphere outside the container become contaminated with helium.

(DE-AC03-96SF20948, Attachment II, Section 4.2.7)

OWM-2 Automated leak testing of the intermediate can weld.

OWM-3 Automated welding of the outer can assembly.

OWM-4 Automated testing of the outer can for removable surface contamination.

OWM-5 Automated leak testing of the outer can weld.

OWM-6 Automated receipt of sealed intermediate cans into empty outer cans.

OWM-7 Automated movement of the outer can assembly within the Outer Can Weld and Monitoring Area. 
OWM-8 Automated movement of the completed storage package into the Lag Storage Trolley.

The Outer Can Weld and Monitoring Area also must meet certain requirements related to the Storage Packages (SP-14, SP-16) on page 31.

\subsection{System Functional Needs (Inputs)}

a) Intermediate/convenience can assemblies from the Intermediate Can Handling Area.

b) Outer cans from site warehouse storage.

c) Outer can caps from site warehouse storage.

d) Packaging materials for transfer of potentially radioactive poorly sealed intermediate cans, or for transfer of outer can assemblies with detectable surface contamination.

\subsection{System/Process Results (Outputs)}

a) Storage packages, free of surface contamination, leaktight, and available for transport.

b) Poorly sealed intermediate/convenience can assemblies, bagged and available for rework (replacement of intermediate can).

c) Storage packages with detectable surface contamination, bagged and available for rework (cleaning and decontamination).

d) Poorly sealed storage packages, available for rework (replacement of outer can).

(The latter three instances are expected to be quite rare.)

\subsubsection{Lag Storage Trolley}

\subsection{Purpose}

This HWCI is used to transport processed storage packages from the Pu SPS to a remote storage area. 


\subsection{Functional Requirements}

The functional requirements of this HWCI, including measurable parameters, are:

LST-1 Each Lag Storage Trolley will be sized to handle two storage packages, stacked end to end.

LST-2 Interlocks will be provided to prevent the Lag Storage Trolley from disengaging from the $\mathrm{Pu}$ SPS when being filled or awaiting filling with completed storage packages.

LST-3 One spare Lag Storage Trolley will be provided to permit immediate replacement of a filled trolley with an empty one.

LST-4 Lag Storage Trolleys will be shielded to keep occupational exposure to ionizing radiation ALARA.

LST-5 Due to maneuverability needs for the Lag Storage Trolley, shielding of the storage packages may be divided between shielding that is physically attached to the trolley and shielding that is permanently fixed in the vicinity of the Pu SPS while the trolley is in its loading position.

\subsection{System Functional Needs (Inputs)}

a) Storage packages from the Outer Can Weld and Monitoring Area.

\subsection{System/Process Results (Outputs)}

a) Storage packages ready for transport to site vault storage.

\subsubsection{Furnace Trays}

\subsection{Purpose}

This HWCI transports plutonium oxide within the Pu SPS, from when it is removed from the inner container until it is placed into a convenience can, including stabilization within the Furnace Area. 


\subsection{Functional Requirements}

The functional requirements of this HWCI, including measurable parameters, are:

FT-1 Any single container, crucible, or ladle containing or transporting Special Nuclear Material (SNM) or Other Nuclear Material (ONM) in the glovebox systems shall be limited to the following quantities of material:
$239 \mathrm{Pu}$ metal and alloy
$4.5 \mathrm{~kg}$
$239 \mathrm{Pu}$ oxide
$5.1 \mathrm{~kg}$
$238 \mathrm{Pu}$ oxide (emergency conditions only)
$237 \mathrm{~Np}$ oxide
$0.2 \mathrm{~kg}$
$1.0 \mathrm{~kg}$

(DE-AC03-96SF20948, Attachment II, Appendix B)

FT-2 The plutonium oxide must be spread in a layer no more than an estimated 1.5 inches deep for the stabilization heating process.

FT-3 The tray must be sized to contain the quantity of oxide powder required in FT-1, at the maximum depth required in FT-2, at an estimated density of $2.3 \mathrm{gm} / \mathrm{cc}$ while leaving about 0.5 inches of freeboard between the top of the powder layer and the lip of the tray.

FT-4 The trays must be designed to withstand repeated heating and cooling between ambient temperature and $1,000^{\circ} \mathrm{C}$ without excessive oxidation, distortion, or degradation of the tray identifier technique.

\subsection{System Functional Needs (Inputs)}

a) Unstabilized plutonium oxide from the Material Preparation Area.

b) Spent samples of plutonium oxide from the LOI Test Area.

c) Transport mechanisms for tray movement between the Material Preparation Area, the Transport Area, the Furnace Area, the LOI Test Area, and the Tipping/Dispense/Fill Area.

\subsection{System/Process Results (Outputs)}

a) Plutonium oxide samples for LOI testing.

b) Stabilized plutonium oxide for convenience can filling in the Tipping/Dispense/Fill Area. 


\subsubsection{Storage Packages}

\subsection{Purpose}

This HWCI provides safe, interim 50 year storage of plutonium metal and its oxide.

\subsection{Functional Requirements}

The functional requirements of this HWCI, including measurable parameters, are:

SP-1 The storage package shall provide an minimum of two confinement barriers and shall be compatible with the SPS. The inner confinement barrier shall hold the processed material and shall be hereafter referred to as the material container. The outer confinement barrier shall be referred to as the boundary container. The combination of the material container nested in the boundary container shall be referred to as the storage package.

(DE-AC03-96SF20948, Attachment II, Section 4.2.5)

SP-2 The containers shall be free of organic materials such as plastic bags, organic coatings, and elastomeric gaskets per reference 2.1.5.1.

(DE-AC03-96SF20948, Attachment II, Section 4.2.5)

SP-3 The outer surface of each container shall be free of removable contamination after loading and sealing as defined by reference 2.1.8.8.

(DE-AC03-96SF20948, Attachment II, Section 4.2.5)

SP-4 The storage package shall be designed to continuously withstand a thermal load of 30 watts and a steady-state plutonium metal temperature of $100{ }^{\circ} \mathrm{C}$ without degradation of the container seals.

(DE-AC03-96SF20948, Attachment II, Section 4.2.5)

SP-5 Marking for the container shall be in accordance with Appendix $C$...

(DE-AC03-96SF20948, Attachment II, Section 4.2.5)

SP-6 The material container shall be capable of storing $4.5 \mathrm{~kg}$ of Pu metal and $5.1 \mathrm{~kg}$ of Pu oxide.

(DE-AC03-96SF20948, Attachment II, Section 4.2.6.1.1)

SP-7 The material container shall, after being filled with the material, be filled with helium in order to keep the plutonium in a stable condition and preclude the need to restabilize during the 50 year storage period.

(DE-AC03-96SF20948, Attachment II, Section 4.2.6.1.1) 
SP-8 The material container shall be sealed and remain leaktight as defined in reference 2.2.2.7, during the storage period.

(DE-AC03-96SF20948, Attachment II, Section 4.2.6.1.1)

SP-9 The material container and any closure device(s) shall be fabricated of ASTM $304 \mathrm{~L}$ stainless steel with a design life of 50 years.

(DE-AC03-96SF20948, Attachment II, Section 4.2.6.1.2) < An anticipated contract change would allow other materials. $\gg$

SP-10 The material container shall remain leaktight, as defined in reference 2.2.2.7, after the following one-time abnormal occurrences:

- $122 \mathrm{~cm}(4 \mathrm{ft})$ drop onto a flat, essentially unyielding, horizontal surface.

- $61 \mathrm{~cm}(2 \mathrm{ft})$ crush in which loaded containers collide.

- Compression weight of five full material containers stacked either horizontally or vertically.

(DE-AC03-96SF20948, Attachment II, Section 4.2.6.1.2)

SP-11 The material container design shall be proof tested to 1.5 times the maximum internal pressure.

(DE-AC03-96SF20948, Attachment II, Section 4.2.6.1.3)

... refer to Appendix $A$ of reference 2.1.5.1 for guidance in calculating the pressure rise and heat generated in the sealed containers, with the exception that the formula used is as follows:

$$
P=P i(T / T i)+[(L O I)(m)(T)] /[v-(0.0873 m)]+\left[\left(1.3 \times 10^{-1}(\mathrm{~m})(t)(T)\right] /[v-(0.0873 \mathrm{~m})]\right.
$$

where $T i$ is the initial temperature in $K$.

(DE-AC03-96SF20948, Attachment II, Section 3.1.4)

SP-12 The material container shall be cylindrical an sized to easily fit within the boundary container with an allowance for thermal expansion at $100^{\circ} \mathrm{C}$.

(DE-AC03-96SF20948, Attachment II, Section 4.2.6.1.4)

SP-13 The material container shall be capable of free standing on end.

(DE-AC03-96SF20948, Attachment II, Section 4.2.6.1.4)

SP-14 The boundary container, after receiving the material container, shall be filled with helium for leak testing, and shall remain leaktight as defined in reference 2.2.2.7, for the duration of the 50 year storage period.

(DE-AC03-96SF20948, Attachment II, Section 4.2.6.2.1) 
SP-15 The boundary container and any closure device(s) shall be fabricated of ASTM 304 stainless steel.

(DE-AC03-96SF20948, Attachment II, Section 4.2.6.2.) < An anticipated contract change would allow other materials. $>$

SP-16 The boundary container and any closure device(s) shall be designed and fabricated to the requirements of reference 2.2.2.6, except a code stamp is not required on the boundary container and plastic deformation is allowable.

(DE-AC03-96SF20948, Attachment II, Section 4.2.6.2.2)

SP-17 The boundary container shall be designed to withstand the maximum internal pressure as calculated using the method given in Appendix $A$ of reference 2.1.5.1 ...

(DE-AC03-96SF20948, Attachment II, Section 4.2.6.2.3) ... for the pressure rise and heat generated in the sealed containers, with the exception that the formula used is as follows:

$P=P i(T / T i)+[(L O I)(m)(T)] /[v-(0.0873 \mathrm{~m})]+\left[\left(1.3 \times 10^{-1}(\mathrm{~m})(t)(T)\right] /[v-(0.0873 \mathrm{~m})]\right.$

where $T i$ is the initial temperature in $K$.

(DE-AC03-96SF20948, Attachment II, Section 3.1.4)

Plastic deformation of the boundary container at the maximum internal pressure is allowable.

(DE-AC03-96SF20948, Attachment II, Section 4.2.6.2.3)

SP-18 The boundary container shall be designed to withstand an external pressure of $147 \mathrm{kPa}$ (21 psig) at $100{ }^{\circ} \mathrm{C}$.

(DE-AC03-96SF20948, Attachment II, Section 4.2.6.2.3)

SP-19 The boundary container shall be a cylinder and be capable of free standing on end even if plastic deformation should occur due to internal pressure buildup.

(DE-AC03-96SF20948, Attachment II, Section 4.2.6.2.4)

SP-20 The boundary container shall have a maximum outside diameter of $12.5 \mathrm{~cm}\left(4.9^{\prime \prime}\right)$ and have a maximum external height of $25.4 \mathrm{~cm}\left(10^{\prime \prime}\right)$.

(DE-AC03-96SF20948, Attachment II, Section 4.2.6.2.4)

SP-21 The storage package shall be designed to be remotely handled by a robotic manipulator or other remote handling fixture. Remote handling should be compatible with common types of commercially available robotic manipulators or other remote handling devices. Remote handling capability will permit access to and from the SPS and commonly used material control and accountability equipment (e.g., calorimeter). Remote handling is intended to permit future handling of the storage package by automated guided vehicles.

(DE-AC03-96SF20948, Attachment II, Section 4.2.6.3) 
SP-22 Each of the containers in the package shall be designed for automated closure in the SPS. ... Welding filler materials, if used, will be compatible with the materials of construction of the containers. Closure of the boundary container will not adversely affect the material container.

(DE-AC03-96SF20948, Attachment II, Section 4.2.6.3.1)

SP-23 The storage package, fully loaded, shall remain leaktight, as defined in reference 2.2.2.7, after the following one-time abnormal occurrences:

- 9 meter (30 ft) drop onto a flat, essentially unyielding, horizontal surface.

- 3 meter (10 ft) crush impact in which containers collide either along horizontal or vertical axis, or combination thereof.

- Compression weight of seven full storage packages stacked either horizontally or vertically.

(DE-AC03-96SF20948, Attachment II, Section 4.2.6.3.2)

\subsection{System Functional Needs (Inputs)}

a) Brushed plutonium metals or stabilized plutonium oxides.

b) Helium gas to surround the convenience can and the intermediate can (within the outer can).

\subsection{System/Process Results (Outputs)}

Not applicable. This HWCI stores material processed by the Pu SPS.

\subsubsection{Receipt Hood/Fume Cabinet/Glovebox Atmosphere}

\subsection{Purpose}

This subsystem controls gases in the receipt hood, fume cabinet, and gloveboxes of the Pu SPS.

\subsection{Functional Requirements}

The functional requirements of this subsystem, including measurable parameters, are:

HGA-1 Reference 2.2.2.1 seismic requirements will be considered for the design of "Safety Class" and Safety Significant" HVAC systems.

(DE-AC03-96SF20948, Attachment II, Section 4.1.2.1)

HGA-2 The design for the interface between the SPS and the ventilation system shall prevent backflow into the ventilation system and comply with the requirements of reference 2.1.8.2.

(DE-AC03-96SF20948, Attachment II, Section 4.1.3) 
HGA-3 The intake filters shall comply with the requirements of reference 2.1.8.3

(DE-AC03-96SF20948, Attachment II, Section 4.1.3)

HGA-4 The exhaust filters shall comply with the requirements of reference 2.1.8.4 and 2.1.8.5.

(DE-AC03-96SF20948, Attachment II, Section 4.1.3)

HGA-5 The design of any hoods used in the SPS shall be designed to minimize the CFM required to meet/ maintain a minimum face velocity of $150 \mathrm{ft} / \mathrm{min}$. These would be designs such a having three sides with a movable sash on the fourth side.

(DE-AC03-96SF20948, Attachment II, Appendix B)

HGA-6 Oxygen analysis and warning equipment shall be provided to ensure oxygen content in [inerted] gloveboxes does not exceed 5 percent (4 percent if argon is used).

(DE-AC03-96SF20948, Attachment II, Appendix B)

HGA-7 If an alarm (excess oxygen) condition is reached in the glovebox, the oxygen monitoring system shall:

- Shutdown operations and electrical power to the glovebox, provided that this does not create an additional hazard.

- Activate a local, audible alarm (as a minimum) and, if conditions warrant, cause a local visual alarm to be activated.

(DE-AC03-96SF20948, Attachment II, Appendix B)

HGA-8 Differential pressures in the SPS shall be such that the flow of air through leakage in the confinement systems will always be from areas of lower contamination to areas of higher contamination, for example, from the general facility, to the SPS room, to the interior of the gloveboxes or hoods. Backflow of air from a more contaminated area to a lesser contaminated area shall be prohibited.

(DE-AC03-96SF20948, Attachment II, Appendix B)

HGA-9 The exhaust exits from the gloveboxes shall have radial flow HEPA filtration. The ventilation supply shall include backflow dampers and HEPA filters in the supply and exhaust systems shall be located as close to the gloveboxes as practicable to minimize ductwork contamination.

(DE-AC03-96SF20948, Attachment II, Appendix B)

HGA-10 To prevent glovebox overpressurization, dump valves shall be provided on gloveboxes that have a potential pressure source. The dump valves shall be per reference 2.1.8.16.

(DE-AC03-96SF20948, Attachment II, Appendix B)[note: the site provides these valves] 


\subsection{System Functional Needs (Inputs)}

Functional needs (inputs) are addressed as external interfaces in the Interface Requirements Document, Appendix A.

\subsection{System/Process Results (Outputs)}

Process results (outputs) are addressed as external interfaces in the Interface Requirements Document, Appendix A.

\subsubsection{Electrical}

\subsection{Purpose}

This subsystem provides power distribution and lighting for the Pu SPS.

\subsection{Functional Requirements}

The functional requirements of this subsystem, including measurable parameters, are:

E-1 The design, fabrication, and installation of electrical equipment shall comply with reference 2.1.8.7.

(DE-AC03-96SF20948, Attachment II, Section 4.1.5)

E-2 Associated electronics, controls, and power supplies shall be contained in free standing cabinets mounted in a rack.

(DE-AC03-96SF20948, Attachment II, Section 4.1.5)

E-3 All electrical connectors within gloveboxes shall be dust tight.

(DE-AC03-96SF20948, Attachment II, Section 4.1.5)

E-4 Electrical connectors shall be plug-type disconnects at glovebox walls.

(DE-AC03-96SF20948, Attachment II, Section 4.1.5)

E-5 ...provide an uninterruptible power supply to the system if required by the safety analysis.

(DE-AC03-96SF20948, Attachment II, Section 4.4)

E-6 Lighting fixtures for gloveboxes shall have illuminaries with baffles, or other devices, to diffuse light and to assure that the bulb is not visible to the operator's eye. The lighting interior and exterior to the glovebox shall provide a method for adjustment to minimize glare. The ease of viewing at working surfaces and points of operation shall be considered during the design of lighting for gloveboxes. A desirable lighting level at these locations is 50-60 foot-candles.

(DE-AC03-96SF20948, Attachment II, Appendix B) 
E-7 Fluorescent lighting with $110 \mathrm{~V}$ receptacles is preferred but other types may be used when necessary. Lights may be grouped with a common switch for a number of lights serving a hood or glovebox.

(DE-AC03-96SF20948, Attachment II, Appendix B)

E-8 Lighting fixtures shall be installed exterior to the gloveboxes to the extent practical to aid in maintenance of the fixtures.

(DE-AC03-96SF20948, Attachment II, Appendix B)

\subsection{System Functional Needs (Inputs)}

Functional needs (inputs) are addressed as external interfaces in the Interface Requirements Document, Appendix A.

\subsection{System/Process Results (Outputs)}

a) Electrical power for $\mathrm{Pu}$ SPS process equipment.

b) Uninterruptible power as required by the safety analysis.

c) Lighting within the Pu SPS gloveboxes.

\subsubsection{Support Structures and Platforms}

\subsection{Purpose}

These HWCIs are used to physically support hoods, gloveboxes, and other Pu SPS equipment.

\subsection{Functional Requirements}

The functional requirements of these HWCIs, including measurable parameters, are:

SSP-1 All structures, systems and component (SSC) supports associated with the design shall be designed ... per the criteria found in ref. 2.1.8.1 for the appropriate Performance Category of the SSC.

$$
\text { (DE-AC03-96SF20948, Attachment II, Section 4.1.2.1 and Appendix B) }
$$

SSP-2 All structures, systems and component (SSC) supports associated with the design shall be ... constructed per the criteria found in ref. 2.1.8.1 for the appropriate Performance Category of the SSC.

(DE-AC03-96SF20948, Attachment II, Section 4.1.2.1 and Appendix B) 
SSP-3 Existing systems and equipment which are to be used for the SPS either modified or unmodified, will be reviewed to ensure their capability to withstand applicable loading. Existing systems and equipment which are not going to be used for the SPS, and are left as is in the area of the project location, will be reviewed for seismic interaction affecting safety related SPS equipment. (DE-AC03-96SF20948, Attachment II, Section 4.1.2.1)

SSP-4 Concrete anchorage will be designed using the guidelines of Reference 2.2.2.2 including commentary. (DE-AC03-96SF20948, Attachment II, Section 4.1.2.1)

SSP-5 Equipment supports will be designed to avoid resonance resulting from the harmony between the natural frequency of the structure and the operating frequency of supported reciprocation or rotating equipment per Reference 2.1.2.1, section 0111-2.8.1.

(DE-AC03-96SF20948, Attachment II, Section 4.1.2.1)

SSP-6 All internal structural members and supports and exterior stands shall be 304 stainless steel.

(DE-AC03-96SF20948, Attachment II, Appendix B)

SSP-7 Seismic decoupling shall be provided between the last stabilization process glovebox and the first packing process glovebox, which should accommodate axial movement (compression) and lateral movement during design basis seismic events.

\subsection{System Functional Needs (Inputs)}

Functional needs (inputs) are addressed as external interfaces in the Interface Requirements Document, Appendix A.

\subsection{System/Process Results (Outputs)}

a) Adequate supports and structures for $\mathrm{Pu}$ SPS equipment.

\subsubsection{Fire Protection}

\subsection{Purpose}

This subsystem provides local detection and suppression of fires in the Pu SPS. 


\subsection{Functional Requirements}

The functional requirements of this subsystem, including measurable parameters, are:

FPS-1 Coordinate with the site to provide the required fire detection and alarm equipment for the SPS and comply with the requirements of reference 2.1.8.6.

(DE-AC03-96SF20948, Attachment II, Section 4.1.3)

Gloveboxes containing plutonium must have a fire detection and alarm system.

(DE-AC03-96SF20948, Attachment II, Appendix B)

FPS-2 Magnesium oxide extinguishers or buckets of magnesium oxide shall be provided where pyrophoric plutonium metal exists. Dry chemical extinguishers are recommended where the fire potential is from other (non-metal) combustibles. $\mathrm{CO}_{2}$ extinguishers may be considered if Class $A$ combustibles are not a hazard in the glovebox.

Water shall not be used for fire suppression in gloveboxes.

(DE-AC03-96SF20948, Attachment II, Appendix B)

FPS-3 Quick-disconnect couplings shall be provided for portable fire extinguishers. These couplings should be installed so that the extinguisher discharge is directed away from the exhaust filtration. (Tests have shown that a single disconnect coupling supplied by a $5 \mathrm{lb}$. $(2.25 \mathrm{~kg})$ dry chemical extinguisher can cover approximately 18 square feet $\left(1.62 \mathrm{~m}^{2}\right)$.

If access is a problem, extension tubes or pipes that extend to accessible areas shall be used to provide coverage for areas where it is difficult to reach the quick-disconnect couplings.

Fire extinguishers with bayonet-type connectors may be used when it is not feasible to install quick-disconnect couplings. However, the designer should document the basis for not installing the quick-disconnect couplings in the design report.

(DE-AC03-96SF20948, Attachment II, Appendix B)

\subsection{System Functional Needs (Inputs)}

Functional needs (inputs) are addressed as external interfaces in the Interface Requirements Document, Appendix A. 


\subsection{System/Process Results (Outputs)}

a) Glovebox fire protection measures.

Additional process results (outputs) are addressed as external interfaces in the Interface Requirements Document, Appendix A.

\subsubsection{Pu SPS Control System}

The Pu SPS Control System, comprised of the PSCS, PPCS, and the DMS, allows the stabilization and packaging of plutonium metals and oxides to occur in a safe, reliable, and cost effective manner.

\subsection{Plutonium Stabilization Control System (PSCS)}

\subsection{Purpose}

This subsystem controls and monitors the stabilization process within the Pu SPS.

\subsection{Functional Requirements}

The functional requirements of this subsystem, including measurable parameters, are:

PSC-1 Monitor and control stabilization process equipment safety interlocks. Pending completion of a hazards analysis, these interlocks may include the following devices:

- material entry and exit airlocks,

- stabilization furnace operation,

- LOI furnace operation.

PSC-2 Monitor and control environmental conditions within the stabilization process for radiological contamination and inert atmosphere integrity.

PSC-3 Obtain selected manual inputs of stabilization process information.

PSC-4 Control automatic operations within the stabilization process.

PSC-5 Provide information from the stabilization process to the DMS for site material control and accountability requirements and storage package certification requirements. 


\subsection{System Functional Needs (Inputs)}

a) Process equipment sensor information.

b) Operator actions to manually enter data and initiate process operations.

c) Process information from the packaging process.

d) Site storage package identification information and Work Control Traveller number.

e) Convenience can identification information.

f) LOI test results (as required).

\subsection{System/Process Results (Outputs)}

a) Process equipment control signals.

b) Process information for the packaging process.

c) Process information in support of storage package certification.

d) Information to the DMS for site material control and accountability requirements and storage package requirements.

e) Alarm notification to operating personnel of abnormal operating conditions.

\subsection{Plutonium Packaging Control System (PPCS)}

\subsection{Purpose}

This subsystem controls and monitors the packaging process within the Pu SPS.

\subsection{Functional Requirements}

The functional requirements of this subsystem, including measurable parameters, are:

PPC-1 Balances shall be used to record the weight of material going into the material containers, the weight of the loaded material containers, the weight of the boundary container, and the final weight of the loaded storage package. Each balance requires a minimum range of 0 to 1.5 times the maximum package weight in grams. Balances shall meet the 
requirements of reference 2.1.2.3 for accuracy and repeatability. Balances shall have the capability to interface with remote recording equipment.

(DE-AC03-96SF20948, Attachment II, Section 4.2.7)

PPC-2 Monitor and control stabilization process equipment safety interlocks. Pending completion of a hazards analysis, these interlocks may include the following devices:

- material entry and exit airlocks,

- container placement,

- container orientation.

PPC-3 Monitor and control environmental conditions within the packaging process for radiological contamination and inert atmosphere integrity.

PPC-4 Obtain selected manual inputs of packaging process information.

PPC-5 Control automatic operations within the packaging process.

PPC-6 Provide information from the packaging process to the DMS for site material control and accountability requirements and storage package certification requirements.

PPC-7 Provide leak and contamination test information.

\subsection{System Functional Needs (Inputs)}

a) Process equipment sensor information.

b) Process information from the stabilization process.

c) Intermediate can identification information.

d) Outer can identification information.

f) Operator actions to manually enter and initiate process operations.

\subsection{System/Process Results (Outputs)}

a) Process equipment control signals.

b) Process information for the stabilization process. 
c) Process information in support of storage package certification.

d) Information to the DMS for site material control and accountability requirements and storage package certification requirements.

e) Alarm notification to operating personnel of abnormal operating conditions.

\subsection{Data Management System (DMS)}

\subsection{Purpose}

This subsystem is used for transitory process data collection and reporting of information for site material control and accountability requirements and storage package certification requirements.

\subsection{Functional Requirements}

The functional requirements of this subsystem, including measurable parameters, are:

DMS-1 Provide material control and accountability information in accordance with reference 2.1.2.3 to the RFETS computer system for SNM/ONM.

DMS-2 Periodic purging of process historical information for material control and accountability security reasons.

DMS-3 Provide data to support storage package certification requirements in reference 2.1.5.1.

DMS-4 Provide system operational information, for trending equipment performance and use.

\subsection{System Functional Needs (Inputs)}

a) Process information from the packaging process.

b) Process information from the stabilization process.

\subsection{System/Process Results (Outputs)}

a) Process information in support of material control and accountability requirements.

b) Process information in support of storage package certification requirements. 
c) System operation reports.

Additional process results (outputs) are addressed as external interfaces in the Interface Requirements Document, Appendix A.

\subsubsection{Process Radiometric Instrumentation}

\subsection{Purpose}

Process radiometric instrumentation obtains radiation measurements in support of criticality requirements, information for site material control and accountability requirements, and radiation measurements in support of monitoring the radiation content of waste materials leaving the Pu SPS.

\subsection{Functional Requirements}

The functional requirements of this subsystem, including measurable parameters, are:

PRI-1 ...provide equipment for assaying material entering the SPS ... and in accordance with reference 2.1.2.3.

(DE-AC03-96SF20948, Attachment II, Section 4.2.7)

PRI-2 ...provide sodium iodine detectors in the gloveboxes to monitor for the accumulation of ${ }^{239} \mathrm{Pu}$ "hold up" materials.

(DE-AC03-96SF20948, Attachment II, Section 4.2.7)

PRI-3 Assay information electronically transferred to PSCS will be limited as required by material control and accountability security requirements.

\subsection{System Functional Needs (Inputs)}

a) Operator manual entry of container type information (feed container, empty container, calibration container, or background container)

b) Operator manual entry of plutonium material type information (metal or oxide).

c) Operator manual (or bar code) entry for identification of the work control traveller, the container, and the operator.

\subsection{System/Process Results (Outputs)}

a) Visual display of incoming material assay information (plutonium content, grams, and measurement uncertainty). 
b) Instrument status (normal or malfunction).

c) Limited material nuclear assay information to the PSCS.

Additional process results (outputs) are addressed as external interfaces in the Interface Requirements Document, Appendix A.

\subsubsection{System Capability Relationships}

[This subparagraph ... shall summarize the relationships between system capabilities.]

The BNFL Team will design all of the Pu SPS areas as an integrated system.

\subsubsection{External Interface Requirements}

[This subparagraph ... shall be divided into the following subparagraphs to describe requirements for interfaces with other systems. Detailed quantitative interface requirements may be defined in separate interface specifications and referenced herein. All referenced interface specifications are considered part of this specification.]

[This subparagraph ... shall identify an external system with which this system interfaces. This subparagraph shall describe the interfaces to the external system. This subparagraph shall identify the purpose of each interface and shall describe the relationship between each interface and the states and modes of the system. When possible, each interface shall be specified in detailed, quantitative terms (e.g., dimensions, tolerances, loads, speeds, communications protocol).]

Detailed interface requirements are defined in the Interface Requirements Document (Appendix A).

\subsubsection{Physical Characteristics}

[This subparagraph ... shall specify the requirements for the physical characteristics (e.g., weight limits, dimensional limits) of the system.]

The following physical characteristics have been identified as having an impact on the Pu SPS design:

PHYS-1 All material brought into Building 707 for installation in Module $J$ will be brought through the loading dock in Room 185. (per a telephone conversation between R. Berry \& W. Fillingim and G. Treiste on 3-26-96). 
PHYS-2 The dimensional limits for the largest single component (including packaging) that can be physically moved into RFETS, Building 707 (due to corridor limitations) are approximately 6 ' -6 " high by $5^{\prime}-6$ " wide by 8 ' long.

PHYS-2 The Pu SPS for RFETS, Building 707 must be designed to fit into the space available after existing gloveboxes $\mathrm{J}-10, \mathrm{~J}-20, \mathrm{~J}-30, \mathrm{~J}-40$, and $\mathrm{J}-50$ are removed.

An additional physical functional requirement is related to the Receipt Area connection with the existing conveyor (RA-2) on page 15.

\subsubsection{Protective Coatings and Cleaning}

[This subparagraph ... shall specify, if applicable, protective coating requirements to assure protection from corrosion, abrasion, or other deleterious action.]

COAT-1 After fabrication and inspections have been completed, all system components shall be thoroughly cleaned, descaled, and degreased. All surfaces shall be cleaned to remove such debris and contaminants as weld flux, oil, grease, shop dust, masking tape, cutting fluids, grinding residue and temporary markings. Cleaning may be accomplished by mechanical means, with non-halogenated solvents, or by using water, steam or non-halogenated detergent cleaning agents or any combination thereof. Caustic or acid cleaning shall not be used. Final wash and rinse shall be accomplished with potable water meeting the requirements of the Public Health Service Drinking Water Standards. Drying after final rinsing shall be accomplished using forced dry air. Compressed air used for drying shall be free of water and oil.

(DE-AC03-96SF20948, Attachment II, Section 4.7.3)

COAT-2 No stainless steel surfaces, interior or exterior, shall be painted unless specifically called for in the specification. All unfinished carbon steel components of the equipment ... shall be thoroughly cleaned by sandblasting or pickling to remove all chemical contamination, mill scale, rust scale and rust and shall be painted with one coat of epoxy paint. The paint shall be "Tennaco" modified epoxy protective coating. No paint shall be applied within $1 / 2$ inch of the field weld areas.

(DE-AC03-96SF20948, Attachment II, Section 4.7.3)

\subsubsection{System Quality Factors}

[This paragraph ... shall specify the applicable requirements pertaining to system quality factors of reliability and maintainability. The requirements shall apply to maintenance in the planned 
maintenance and support environment and shall be stated in quantitative terms. Examples are:

a. Mean and maximum down time, reaction time, turnaround time, mean and maximum times to repair, mean time between maintenance actions, mean time between failure.

b. Maximum effort required to locate and fix an error.

c. Maintenance man-hours per specific maintenance action, operational ready rate, maintenance hours per operating hour, frequency of preventative maintenance.

d. Number of people and skill levels, variety of support equipment.

e. Maintenance costs per operating hour, man-hours per overhaul.]

In order to support DNFSB recommendations for repackaging of plutonium metals and oxides, the Pu SPS shall be capable of consistent and robust operations through the initial campaign ending approximately seven years after startup. During the initial campaign the SPS will operate five days per week, two shifts (16 hours) per day without interruption for lengthy planned maintenance. The system design should support performance of required maintenance activities during a single eight hour shift for the initial seven year campaign. The system design should also support restoration to service in the minimum possible time after the failure of any component.

RAM-1 The SPS shall have a design life of 50 years. Material handling and processing equipment shall be designed for consistent and robust operations through the initial campaign ending approximately seven (7) years after startup. Periodic low volume operations shall be required for 7 to 50 years. Robust operation is defined as a ratio of operating time to maintenance (corrective and preventive) down time of greater than 100.

(DE-AC03-96SF20948, Attachment II, Section 4.2.9) (Robust operation corresponds to a minimum overall system availability of 0.990 , at the design system throughput capacity of two containers per eight hour shift.)

RAM-2 Consistent operation is defined as consecutive packaging operations using the same parameters with the same results and no system failures requiring major repair activities. These shall be demonstrated during prototype operation.

(DE-AC03-96SF20948, Attachment II, Section 4.2.9)

RAM-3 The system shall be easily maintainable as defined by the demonstrated replacement of critical wear parts within two hours.

(DE-AC03-96SF20948, Attachment II, Section 4.2.9)

(Critical wear parts are defined as any parts, critical to the operation of the Pu SPS, that are expected to require replacement or repair during the initial seven year campaign.) 
RAM-4 Any maintenance operation should generate no more waste than an equivalent normal shift operation.

(DE-AC03-96SF20948, Attachment II, Section 4.2.9)

RAM-5 Space shall be provided adjacent to all equipment and confinement systems to allow easy access for maintenance.

(DE-AC03-96SF20948, Attachment II, Section 4.2.9)

RAM-6 To the extent practical, equipment and components inside gloveboxes shall be maintainable from the exterior of the glovebox.

(DE-AC03-96SF20948, Attachment II, Section 4.2.9)

RAM-7 The radiation shielding for gloveboxes should be designed to facilitate installation, removal, and decommissioning of Pu SPS equipment. (reference 2.1.1.2, section 1002)

RAM-8 An appropriate number of spares shall be provided for parts subject to wear or other deterioration that can credibly be predicted to require replacement at (preliminary) frequency of one year or less, and that are not readily available for procurement.

\subsubsection{Environmental Conditions}

[This paragraph ... shall specify the environmental conditions that the system must withstand during transportation, storage, and operation such as:

a. Natural environment (e.g., temperature, geographic location, seismic levels)

b. Induced environment (e.g., motion, shock, noise, electromagnetic radiation, ionizing radiation)]

ENVR-1 Elevation - All equipment and associated components shall be designed to function at ground level elevations ranging from 0 to 8000 feet above sea level.

(DE-AC03-96SF20948, Attachment II, Section 4.1.5)

ENVR-2 Room Environment - Equipment will be located in a temperature controlled indoor air space:

- Temperature, $68^{\circ} \mathrm{F}$

- Humidity, $70 \%$ maximum

ENVR-3 Glovebox Environment - Equipment located inside gloveboxes will be subjected to an inert nitrogen or helium gas environment:

- Oxygen content, 0 to 5 percent.

- Temperature, 55 to $80^{\circ} \mathrm{F}$

- Humidity, $25 \%$ maximum 
Seismic issues are addressed earlier in this document, specifically in the discussion of overall system requirements (SPS-9) on page 14. 


\subsection{Design and Construction}

[This paragraph ... shall be divided into subparagraphs that specify minimum system design and construction standards which have general applicability to system equipment and are applicable to major classes of equipment (e.g., support equipment) or are applicable to particular design standards. To the maximum extent possible, these requirements shall be specified by incorporation of the established military standards and specifications. In addition, this paragraph shall specify criteria for the selection and imposition of Federal, Department of Energy, and contractor specifications and standards.]

As identified throughout this document, the specifications and standards for many components, including major ones, have been specified in the DOE contract (DE-AC03-96SF20948). Appropriate specifications and standards for other components that will ensure compliance with the functional requirements identified throughout this document will be identified prior to procurement of those components.

\subsubsection{Materials}

[This subparagraph ... shall specify those system-peculiar requirements governing use of materials, parts, and processes in the design of system equipment. In addition, requirements for the use of standard and commercial parts shall be specified.]

MATL-1 Gasket materials shall be chosen as needed for low permeation, compatibility with low humidity, argon, and oil resistance if necessary.

(DE-AC03-96SF20948, Attachment II, Appendix B)

MATL-2 Inside special hardware shall be Type 300 series stainless steel, however, galling characteristics of special hardware with respect to 300 series stainless steels shall be evaluated. Commercial stainless steel hardware may be used outside the glovebox for handles and hinges. All austenitic stainless steels shall be tested and used in accordance with the requirements of references 2.1.8.13 and 2.1.8.14.

(DE-AC03-96SF20948, Attachment II, Appendix B)

\subsubsection{Toxic Products and Formulations}

[This subparagraph ... shall specify requirements for the control of toxic products or formulations to be used in the system or to be generated by the system.] 
Toxic and hazardous substances are defined and regulated by reference 2.1.1.1, subpart $Z$. Since the presence of toxic or hazardous substances would complicate operation and decontamination of the $\mathrm{Pu}$ SPS, the use and/or production of substances regulated under Subpart $\mathrm{Z}$ should be carefully evaluated and any usage minimized.

TOX-1 Asbestos or asbestos-bearing materials shall not be used.

(DOE 6430.1A, Section 1525-1)

TOX-2 Mercury or mercury-bearing materials shall not be used.

TOX-3 Polychlorinated biphenyls (PCB) or PCB-bearing materials shall not be used.

TOX-4 Metallic lead, which may be used for radiation shielding purposes, shall be encapsulated in stainless steel cladding.

TOX-5 All materials installed or used in the Pu SPS shall be used in accordance with OSHA Material Safety Data Sheets (MSDS) requirements in reference 2.1.1.1, subpart Z.

\subsubsection{Use of Standard and Commercial Parts}

Parts which are subject to wear, corrosion, or other deterioration should be of standard, readily available commercial design to the extent practical. This practice will simplify maintenance of failed and deteriorated components.

PART-1 Mechanical fasteners may be of either US or metric standard dimensions, materials, and strengths.

PART-2 Electrical connectors, starters, disconnects, overcurrent protection devices, and boxes shall be NEMA or IEC, as appropriate.

\subsubsection{Electromagnetic Radiation}

[This subparagraph ... shall contain requirements pertaining to limits on the electromagnetic radiation which the system is permitted to generate.]

Electromagnetic interference may impact the accuracy of non-destructive assay equipment that involve active or passive radiation measurement or calorimetry. The facility design should provide a suitable environment for this equipment.

EMR-1 If required, non-destructive assay equipment shall be protected from electromagnetic radiation sources.

(reference 2.1.2.1, section 1300-10.3.3) 


\subsubsection{Nameplates and Product Marking}

[This subparagraph ... shall contain requirements for nameplates, part marking, serial and lot number marking, software media marking, and other identifying markings required for the system. Reference may be made to existing standards on the content and application of markings.]

The Pu SPS process will be installed at more than one site, each with its own numbering system. For consistency and coordination within the BNFL Team's design efforts a "vendor" or BNFL Team numbering system will be used within the project, and a "customer" or site-specific number will be cross-referenced to the BNFL Team number for each site. Equipment installed at each site will be labeled per site requirements.

NAME-1 All equipment, controls, instruments, and panels included in the SPS shall have unique identification numbers. The equipment numbers shall be obtained from the site specific equipment numbering system and shown on the drawing.

(DE-AC03-96SF20948, Attachment II, Section 4.7.2)

NAME-2 The Contractor shall provide a Master Equipment List containing the equipment ID numbers, description, part number, and specifications (eg, range, set point, alarm point).

(DE-AC03-96SF20948, Attachment II, Section 4.7.2)

Additional product marking requirements are identified in the discussion of storage packages (SP-5) on page 30.

\subsubsection{Safety}

[This subparagraph ... shall specify those safety requirements which are basic to the design of the system, with respect to equipment characteristics, methods of operation, and environmental influences. This paragraph shall also specify those safety requirements, which prevent personnel injury and equipment degradation without degrading operational capability (e.g., restricting the use of dangerous materials where possible, handling and storing, toxic material detection and warning devices, grounding of electrical system, cleanliness and decontamination.]

Personnel protection shall be provided to protect operations personnel from injury or exposure to hazardous environments. Protective equipment includes, but is not limited to handrails on platforms, guards on rotating equipment, insulation on accessible surfaces above $140^{\circ} \mathrm{F}$, shielding from radioactive materials, and appropriate labeling. Radiation monitors, airborne contamination monitors, criticality monitors, emergency showers, and eye wash stations shall be provided by the respective site buildings. Administrative controls shall also be implemented to ensure that personal protective equipment appropriate for the hazardous environment are used, including contamination control 
clothing, eye protection, safety shoes, and appropriate respiratory protection, in accordance with the RFETS Health and Safety Manual.

\subsubsection{Industrial Safety}

The following general safety and health issues, other than radiological safety considerations, have been identified which may have an impact on the final design of the Pu SPS. These issues have been identified based on an initial review of the technical proposal and are based on standards promulgated by the Occupational Safety and Health Administration, recognized professional societies and good safety practices.

SAFE-1 The SPS design shall protect workers sufficiently from hazards to ensure that workers can perform actions required during normal operations, anticipated operational occurrences, and postulated accidents. ... SPS design shall consider the safety of the operator in accordance with reference 2.2.2.8. (DE-AC03-96SF20948, Attachment II, Section 4.5.1)

SAFE-2 The design shall ensure prompt, safe shutdown in emergencies, and allow ready access to areas where manual corrective actions are required.

(DE-AC03-96SF20948, Attachment II, Section 4.5.1)

SAFE-3 The SPS design shall ensure that "Safety Class" components will continue to perform their functions during all normal operations and anticipated operational occurrences and during and after any postulated emergency or accident condition. Safety Class components or items shall continue to operate until appropriate corrective actions can be taken to bring the facility or system to a safe condition and the function of the Safety Class item is no longer required. "Safety Class" items are systems, components, and structures, including portions of process systems, whose failure could adversely affect the environment or the safety and health of the public. See reference 2.1.2.1.

(DE-AC03-96SF20948, Attachment II, Section 4.5.1)

SAFE-4 The design of the gloveboxes and the equipment, or location of equipment, in the gloveboxes shall prevent pinch points and shall prohibit sharp corners and protrusions that can puncture glovebox gloves. ... All comers shall be smooth and rounded - minimum radius of about $5 / 8$ inches. (DE-AC03-96SF20948, Attachment II, Appendix B)

SAFE-5 Egress Requirements - Operators will have a ready means of egress from their work station in the event of the need to evacuate the area quickly. The SPS design shall conform with the general requirements for egress described in reference 2.1.1.1, Subpart $E$, Means of Egress, and including sections 36 and 37, General Requirements for Egress. 
SAFE-6 Machine Guarding - Machinery and moving parts which are accessible to operators will be sufficiently guarded to prevent injury from inadvertent contact. Machine guards shall meet the requirements of reference 2.1.1.1, Subpart O, Machinery and Machine Guarding, and including section 212, General Requirements for All Machines.

SAFE-7 Electrical Safety - All electrical components shall meet all local and site code requirements as well as those in reference 2.1.1.1, Subpart S, Electrical Standards, and including sections 302 to 308, Design Standards for Electrical Systems.

SAFE-8 Lock Out/Tag Out Requirements - Potential sources of hazardous energy (i.e. electrical, hydraulic, high pressure lines, etc.) will have the capability to be locked out in accordance with reference 2.1.1.1, section 147, Control of Hazardous Energy Sources. The hardware to perform such lock outs will be consistent with the RFETS Safety and Health Practices Manual.

SAFE-9 Work Platforms and Work Surfaces - Work platforms and surfaces shall meet the requirements of reference 2.1.1.1, Subpart $\mathrm{O}$, Walking and Working Surfaces, and including section 23(c), Protection of Open Sided Floors, Platforms and Runways, and section 24, Fixed Industrial Stairs.

SAFE-10 Compressed Gases - The storage facilities and systems for compressed gases shall meet the requirements of reference 2.1.1.1, Subpart M, Compressed Gases and Compressed Air Equipment, and all incorporated references, including reference 2.2.2.11 and 2.2.2.12.

In addition, as good engineering practice, fittings for the inert gases will be developed to ensure that compressed air or oxygen cylinders cannot be inadvertently connected to the systems which are used to inert glove boxes and enclosures. The use of compressed air to power pneumatic machinery in areas of the process where there is the potential for ignition of plutonium or other materials shall be minimized to the extent practical.

SAFE-11 Laser Light - The installation of lasers in the system shall meet the requirements of reference 2.2.2.13. 


\subsubsection{Radiation Protection}

Radiological shielding materials will provide a working environment that adequately protects the worker from the hazards of ionizing radiation. The expected shielding materials are steel-clad Jabroc ${ }^{\mathrm{mM}}$ from neutron radiation and steel for gamma radiation. Based on preliminary analyses, the approximate total shielding thicknesses are between $4 "$ and 6". The expected shielding materials for viewing windows are acrylic for neutron radiation and leaded glass for gamma radiation. The expected shielding for worker extremities will be provided through the use of lead-lined gloves and local shielding.

RADP-1 As Low As Reasonably Achievable (ALARA) considerations shall be incorporated into the design for the maintainable and replaceable components.

(DE-AC03-96SF20948, Attachment II, Sections 3.1.1 \& 4.2.9)

RADP-2 The measured or calculated exposures should include the logged time/dose for all processing steps in the SPS, including those performed both inside and outside the gloveboxes. The following classes of materials shall be considered for the calculation of radiation exposures:

1) ${ }^{239} \mathrm{Pu}$ metal or alloy $(4.5 \mathrm{~kg})$ or oxide $(5.1 \mathrm{~kg})$ with no significant ${ }^{211}$ Am content;

2) ${ }^{239} \mathrm{Pu}$ metal or alloy $(4.5 \mathrm{~kg})$ or oxide $(5.1 \mathrm{~kg})$ with $10 \mathrm{gm}{ }^{241} \mathrm{Am}$;

3) ${ }^{239} \mathrm{Pu}$ metal or alloy $(4.5 \mathrm{~kg})$ or oxide $(5.1 \mathrm{~kg})$ with $15 \mathrm{gm}{ }^{241} \mathrm{Am}$

(DE-AC03-96SF20948, Attachment II, Sections 3.1.1)

RADP-3 Assume no self-shielding for the material itself. The only shielding which can be credited is that provided by the container(s) and the equipment.

(DE-AC03-96SF20948, Attachment II, Sections 3.1.1) < An anticipated contract change will allow self-shielding. $>$

RADP-4 Radiation exposure to occupational workers shall comply with the requirements of reference 2.1.8.8. (DE-AC03-96SF20948, Attachment II, Appendix B)

RADP-5 Shielding shall be included in the design of the gloveboxes. Operator exposures shall be maintained ALARA with a goal of 500 mrem per year to the whole body.

(DE-AC03-96SF20948, Attachment II, Appendix B) 《 An anticipated contract change will clarify the 500 mrem/year is from the Pu SPS only. $>$ 
RADP-6 Shielding materials and components for gloveboxes will meet the general guidelines provided in reference 2.2.2.9. Lead shall be used to shield gamma radiation and water shall be used to shield neutron radiation. Windows shall use a combination of glass containing high concentrations of lead and acrylic to shield gamma and neutron radiation, respectively.

(DE-AC03-96SF20948, Attachment II, Appendix B) 《 An anticipated contract change would allow other materials. 》>

RADP-7 The design limit for occupational exposure to the extremities shall be ALARA and not exceed 10 rem per yr. (reference 2.1.1.2, sections 202 and 1002)

RADP-8 Measures shall be taken to maintain radiation exposure as low as reasonably achievable (ALARA) through facility and equipment design. ALARA considerations shall be incorporated into the design for maintainable and replaceable components. The primary methods used shall be physical design features (e.g., confinement, ventilation, remote handling, local shielding, and overall area shielding). Administrative controls and procedural requirements shall be employed only as supplemental methods to control radiation exposure. (reference 2.1.1.2, section 1001)

RADP-9 Control of contamination should be achieved by confinement of radioactive material. (reference 2.1.8.8, article 128)

RADP-10 Components should be selected to minimize the buildup of radioactivity. (reference 2.1.8.8, article 128)

RADP-11 Shielding placement and thicknesses shall be based on information from a time-and-motion study of Pu SPS operations, thus optimizing its use.

Additional radiation protection requirements are identified in the discussion of the Lag Storage Trolley (LST-4, LST-5) on page 28 and System Quality Factors (RAM-7) on page 47.

\subsubsection{Gloveboxes}

BOX-1 The gloveboxes ... shall adhere to reference 2.2.2.9 and shall satisfy the applicable requirements of reference 2.1.2.1 sections $1161-1$ and 1161-2.

(DE-AC03-96SF20948, Attachment II, Appendix B)

BOX-2 Gloveboxes and hood shells shall be at least 7 gauge Type 304 stainless steel. All internal structural members and supports and exterior stands shall be 304 stainless steel.

(DE-AC03-96SF20948, Attachment II, Appendix B) 
BOX-3 Light windows located on top of the gloveboxes shall be $1 / 4$ inch wire glass per reference 2.1.8.10. All other light and viewing windows shall be safety plate glass.

(DE-AC03-96SF20948, Attachment II, Appendix B) « An anticipated contract change would allow other materials. $>$

BOX-4 Glove rings/ports shall be constructed to provide a means to install airtight flexible gloves for access and manipulation inside the enclosure. All glove ports/rings shall be per references 2.1.8.11 and 2.1.8.12. Gloves shall be provided ... for 90 percent of the glove ports. Plugs shall be provided for the remaining glove ports.

(DE-AC03-96SF20948, Attachment II, Appendix B)

BOX-5 A goal, which should be followed when possible, is to provide storage shelves inside gloveboxes and hoods for tools and equipment parts. However, items welded directly to the gloveboxes should be kept to a minimum such that future modifications to the gloveboxes can be accommodated.

(DE-AC03-96SF20948, Attachment II, Appendix B)

BOX-6 Continuous butt welds are required for the glovebox skin and should be located away from corners or edges. Whenever possible, gloveboxes shall be welded to one another, to entry cabinets, and to airlocks. Gloveboxes without stands shall fit well with the floor but high grade caulking is acceptable to seal box or storage cabinet to floor covering.

(DE-AC03-96SF20948, Attachment II, Appendix B)

BOX-7 Gloveboxes shall be provided with airlocks to pass equipment from one glovebox to another. Each airlock shall be fabricated from stainless steel, finished the same as the glovebox and equipped with a transfer tray. ... Two general types of airlocks will be provided. One will be used between gloveboxes having different atmospheres (inerted vs. dry air). It will have provisions to allow the airlock to be purged and backfilled with the appropriate atmosphere to minimize dilution of the atmosphere in the inerted gloveboxes. The other type airlock will be between gloveboxes having the same atmosphere. These airlocks provide barriers for the spread of contamination. No provisions for backfilling these airlocks will be necessary. However, vents to equalize pressure between the airlock and the adjoining gloveboxes will be required to act as "vacuum breakers." The airlocks shall have piping connections to the vacuum system and dry air or inert atmosphere supply system, as appropriate, for airlock evacuation and backfilling.

(DE-AC03-96SF20948, Attachment II, Appendix B)

BOX-8 All gloveboxes of a single type or those located in a specific room should have finishes produced by the same technique (e.g., electropolishing or glass bead blasting) to prevent a mixture of so-called equals that actually appear different. ... All exterior surfaces that are visible and accessible should have a uniform appearance as near the interior box finish as possible. Where possible the fabricators finish should be able to be duplicated or matched 
in the field where assembly welds are matched to maintain a uniform appearance. Surfaces of structural members inside gloveboxes shall correspond to the shell finish. Machined surfaces shall have a 63 to 125 AA finish and rounded corners. Outside structural members shall have a mill finish, aesthetically similar to the exterior shell finish.

(DE-AC03-96SF20948, Attachment II, Appendix B)

BOX-9 All process and service piping as well as electrical and instrument lines shall enter or exit gloveboxes by means of pass-through connectors that do not compromise leak tightness (e.g., welding, low-permeability gaskets, or potting).

(DE-AC03-96SF20948, Attachment II, Appendix B)

BOX-10 All gas supply lines shall be filtered (HEPA equivalent) before they pass through the glovebox shells in order to prevent migration of contamination into the clean supply lines.

(DE-AC03-96SF20948, Attachment II, Appendix B)

BOX-11 Glovebox openings shall be blanked off and the gloveboxes shall be tested for overall box leak tightness to $1 \times 10^{-2} \mathrm{~atm}-\mathrm{cc} / \mathrm{sec}$ of helium or equivalent.

(DE-AC03-96SF20948, Attachment II, Appendix B)

BOX-12 If a glovebox requires a cooling system, heat exchangers will be sized to meet the needs of individual glovebox loads. Limit the number of different sizes to help control spare parts. A sensor can monitor the glovebox temperature and, via controller, regulate the coolant flow to the heat exchanger. Water is an acceptable coolant fluid. If water is used as a coolant, provisions shall be made to prevent leakage of water into the glovebox based on criticality concerns...

(DE-AC03-96SF20948, Attachment II, Appendix B)

BOX-13 Criticality drains (if required) shall be fabricated and installed per reference 2.1.8.15.

(DE-AC03-96SF20948, Attachment II, Appendix B)

BOX-14 Utilities (e.g., water, air, gas) serving gloveboxes shall be provided with remote shutoff or isolation valves.

(DE-AC03-96SF20948, Attachment II, Appendix B)

BOX-15 Airlock and gaslock doors shall be interlocked to not operate if personnel are in accessible and operational gloveports.

\subsubsection{Decontamination}

The following general design considerations have been identified which may affect the decommissioning of the Pu SPS. The general decommissioning design considerations are based on provisions promulgated by references 2.1.2.1 and 2.1.3.1, and general good health physics practices. 
DECON-1 Crevices and sharp corners shall be eliminated from the glovebox design, including equipment installed in the glovebox, to prevent the accumulation of contaminated materials that are inaccessible for cleanup. The design of the glovebox and the installation of the equipment in the glovebox shall not create areas that are inaccessible for cleaning. ... Seals that can collect materials that cannot be removed shall be avoided.

(DE-AC03-96SF20948, Attachment II, Appendix B)

DECON-2 Gloveboxes shall have metal surfaces polished to a \#4 finish per reference 2.2.1.1 to promote contamination control and to provide for enhanced cleanup.... The objective should be that all interior surfaces are smooth to facilitate cleaning and decontamination.

(DE-AC03-96SF20948, Attachment II, Appendix B)

DECON-3 Wherever practical, porous surfaces in the Pu SPS process area should be sealed or provided with a surface liner to prevent the entrapment of contamination to facilitate the cleanup of the process area. The selection of sealers and surface liners should follow the general recommendation of references 2.1.2.1 and 2.1.3.1.

DECON-4 Gloveboxes and large, heavy components should be provided with appropriate lifting lugs to facilitate dismantlement and decontamination activities. This follows the recommended design guidelines in references 2.1.2.1 and 2.1.3.1.

DECON-5 Where practical, equipment and gloveboxes subject to contamination should be designed for easy and effective decontamination and dismantlement. This enhances the effectiveness of the eventual decontamination, dismantlement, and relocation of process equipment. This follows the recommended design guidelines in references 2.1.2.1 and 2.1.3.1.

\subsubsection{Nuclear Safety}

[This subparagraph ... shall specify system requirements for nuclear control for prevention of inadvertent criticality and other safety concerns per DOE 5480 standards.]

CRIT-1 Provisions shall be included in the design of the glovebox system to assure that the materials, as applicable, are always in a desirable geometry and array to prevent criticality. Geometric control of the material and array using administrative controls shall be allowed only if no other practical control method can be used.

(DE-AC03-96SF20948, Attachment II, Appendix B)

CRIT-2 ...all glovebox criticality limits will be based on maintaining a system with moderation sufficient to represent operator's arms in the glovebox.

(DE-AC03-96SF20948, Attachment II, Appendix B) 
The criticality safety of the Pu SPS is dependent upon the proper implementation of the Double Contingency Principle stated in reference 2.2.2.10. The controls listed below represent the minimum set of controls necessary to ensure the entire Pu SPS process remains subcritical under all normal and all credible abnormal events. The standards used in developing these controls are found primarily in reference 2.2.2.10, as required by reference 2.1.2.2. For example, several single parameter subcritical limits have been applied directly from the standard, such as the one on plutonium oxide for half theoretical density oxide.

The Pu SPS contains two plutonium streams, metal and oxide, with identical mass restrictions. In this case, the metal brushing and repackaging process will provide the bounding scenarios for the development of controls during normal operation, and the oxide process drives the controls from a severe accident standpoint (i.e. DBE). The largest single piece of plutonium metal is presumed to have a mass of $3 \mathrm{~kg}$ or less. Plutonium oxide bulk density is presumed to be less than $3 \mathrm{gm} / \mathrm{cc}$, and incoming oxide is presumed to be dry. Because of the mass loaded into the new convenience can, sufficient controls must be implemented to render the close-packing of three fully loaded convenience cans incredible. Likewise, the scenario of multiple stacked furnace trays of oxide becoming water saturated must be rendered incredible as well. Then all single process upsets such as two containers side by side, flooding of the glovebox during DBE or major fire, stacking oxide trays, and overbatch of a single container will remain subcritical. The two essential controlled parameters are mass and moderation. Mass will be controlled administratively and moderation control will be achieved primarily through engineered features. The controls are listed below, with a brief justification for each.

CRIT-3 No sources of water or other hydrogenous liquids will be in a glovebox or area. (Ensures that no single breach of fluid containment, an anticipated event, will be available to flood the box or saturate the oxide trays.)

CRIT-4 Accurate (to about 10\%) measurement of container contents will be performed prior further processing of the material introduced to the Pu SPS in the original container. (This measurement is already planned for with the presence of the Container Assay System. It is necessary to drive down the likelihood of inserting the wrong container into the system due to a simple paperwork or human error. This control mitigates against mass overbatch scenarios and is an independent check on the process. A $10 \%$ uncertainty is sufficient to preclude against double batching and is typically assumed in criticality evaluations.)

CRIT-5 All containers of plutonium metal will have designated, fixed locations with at least 2" spacing. (The fixed spacing will mitigate against spacing violations in the glovebox and reduces neutron interaction to an acceptable level. Without fixed spacing and fixed locations for all metal operations, spacing violations are anticipated events that cannot be tolerated on a routine basis, given the masses involved. The spacing requirement is derived from 
The inner container is physically smaller than the convenience can, and limiting the number to one limits the size of the credible overbatch due to the presence of numerous containers.)

CRIT-13 Only $8 \mathrm{~kg}$ of plutonium metal may be in a localized work station area at one time. (This control restricts the credible overbatch and makes it unlikely that more than two fully loaded convenience cans will ever exist side-by-side in contact. This control is implemented by work control travellers and/or mass balance cards, as compared with Container Assay System information, to provide near real time monitoring.)

CRIT-14 Only $20 \mathrm{~kg}$ of plutonium oxide may be in a localized work station area at one time. (Administrative controls on the mass of oxide in the Pu SPS will be sufficient to preclude criticality, given the relatively large margin allowed by the single parameter subcritical limit for oxides of the density being considered here.)

Several criticality functional requirements are identified elsewhere, as described below:

BOX-13 (on criticality drains, which are required at RFETS) on page 57.

(Precludes accumulation of water and liquids deeper than $2^{\text {N }}$ even in severe events such as the DBE, major fires, inadvertent sprinkler activation, or plenum deluge, which are highly unlikely events. Two inches has been shown to maintain subcriticality for all plutonium solutions of concern in reference 2.1.8.18.)

FT-1 and SP-6 (on tray/can plutonium mass limits) on pages 29 and 30.

(The mass is a design parameter set by throughput and final interim storage requirements. It has been shown acceptable from both a single item standpoint and during process upsets where two full containers are placed side-by-side (unlikely) or up to four trays are stacked (unlikely), per reference 2.2.2.10.)

FT-2 (on oxide depth in trays) on page 29.

(Plutonium oxide criticality is not an issue in the furnace tray, even assuming its saturation with water, due to the limited volume and geometry constraints.)

\subsubsection{Human Engineering}

[This subparagraph ... shall specify human engineering requirements for the system or for specific configuration items. This paragraph shall reference applicable documents and specify any special or unique requirements (e.g., constraints on allocation of capabilities to personnel and communications, and personnel/equipment interactions). This paragraph shall include those specific areas, stations, or equipment which would require concentrated human engineering attention due to the sensitivity of the 
operation or criticality of the task; i.e., those areas where the effects of human error would be particularly serious.]

The safety and reliability of a process operation can be greatly improved by incorporating known facts about human characteristics (human factors) into the design of the system. This subparagraph summarizes the results of a review of operations associated with the Pu SPS for compliance with key principles of human factors engineering and design. The human factors design criteria presented here are applied very generally to establish the feasibility of particular operations. These criteria should be applied more rigorously during the detailed design and development phases of the project. These factors represent a compilation of basic principles documented in the references cited, which were screened for applicability to the Pu SPS.

HENG-1 Gloveboxes and hoods may be single wall construction with the main working surface 36 inches to 38 inches from the floor, where possible. The height and depth shall be determined to provide optimum orientation and access to the equipment in each enclosure. (DE-AC03-96SF20948, Attachment II, Appendix B)

HENG-2 Internal supports shall be placed to minimize interference with normal operation and maintenance. (DE-AC03-96SF20948, Attachment II, Appendix B)

HENG-3 Human Dimensions Considerations - The dimensions of the human body shall be considered when selecting equipment and designing systems for use on the project. Equipment shall be arranged in a manner to provide easy access for operations, maintenance, and repair. Tools, platforms and other operator aids shall be provided as required. Equipment shall accommodate the fifth to ninety-fifth percentile of the population as specified in reference 2.1.8.19.

HENG-4 Process Controls - The process control strategy developed should provide for centralized monitoring and a readily identifiable control hierarchy.

HENG-5 Process Controls - Operating procedures should provide clear, concise guidance for manual system operations under normal, abnormal, and emergency operating conditions.

HENG-6 Display Devices - The control system display must be designed to provide the operators with sufficient information to control the process, without compromising their ability to respond to upset conditions due to cognitive overload. Control panel layouts should permit easy access to controls and visual indications. Computer graphics screens should consider the use of color, contrast, and text size in formulating displays. Dynamic process data (process parameters, equipment status) should be readily interpreted, and abnormal conditions should be clearly identifiable to the operator. Reference 2.1 .8 .20 provides guidance in the development of computer interfaces. 
HENG-7 Warning Indicators - It is essential that operators be advised of abnormal or potentially hazardous situations in a clear, concise and timely manner. Local and remote indication shall be included as appropriate to notify operators of process alarms. Local area and general building alarms shall alert all personnel in project areas of environmental hazards in accordance with established RFETS Standards and Health and Safety procedures. General warning guidelines are presented in reference 2.1.6.2.

HENG-8 Labeling - Equipment and instrumentation shall be appropriately labelled to permit proper identification during normal, abnormal, emergency and surveillance operations. Guidance is provided in references 2.1.2.1, 2.1.6.2, and 2.1.8.19.

HENG-9 Handicap Access - Fire, criticality, and radiological hazards will require rapid evacuation of the project areas. Due to this constraint, access to the area by handicapped people may be restricted. Specific exemption from the Architectural Barriers Act, Public Law 90-480, shall be addressed in accordance with reference 2.1.1.3 during the design phase.

HENG-10 Environmental Conditions - The environmental conditions under which operation and control actions are performed affect the performance that may be expected of operators. To provide operators with conditions to support the proper execution of required tasks, ambient temperature, humidity, air flow, noise level, and illumination should be controlled within acceptable limits. Applicable limits for these parameters are specified in:

- Temperature - reference 2.2.4.1

- Humidity - reference 2.2.4.1

- Ventilation - reference 2.1.2.1, Section 1550-1.5

- Illumination - reference 2.2.4.2

- Emergency Lighting - reference 2.2.2.8

- Noise Level - reference 2.1.2.4

- Vibration Levels - reference 2.2.4.1

Additional human engineering issues are addressed in other sections of this document, specifically, maintainability (System Quality Factors, section 3.2.5) on page 46 and operator protection (Safety, section 3.3.4) on page 52 .

\subsubsection{System Security}

[This subparagraph ... shall specify security requirements that are basic to the design of the system with respect to the operational environment of the system. This subparagraph shall also specify those security requirements necessary to prevent compromise of sensitive information or materials.] 
SECR-1 Control system computer security is provided by password protection to the configuration software.

\subsubsection{Government Furnished Property Usage}

[This subparagraph ... shall specify any Government Furnished Equipment (GFE) to be incorporated into the system design. In addition, this paragraph shall specify any Government Furnished Information (GFI) and Government Furnished Software (GFS) to be incorporated Into the system. This list shall identify the Government furnished property by reference to its nomenclature, specification number, and/or part number. If the list is extensive, it may be included as an appendix to this specification and referenced in this paragraph.]

\subsubsection{Government Furnished Equipment}

The following government furnished property will be used in the Pu SPS, per RFETS drawing 514000203, Rev A:

- Glovebox Window Gaskets

- Glovebox Gloves and Internal Rings

- Glovebox Lighting

- Glovebox Intake Filters

- Glovebox Exhaust Filters

- Magnahelic Pressure Gauges

- Selective Alpha Air Monitors (SAAMs)

The following government furnished property also will be used in the Pu SPS:

- Radioactive Surface Contamination Detection Instrumentation

- Glovebox Dump Valves

- Liquid Nitrogen Transfer Devices (dewar flasks)

- Incoming Container Trolley(s)

- Waste Containers

- Surrogate Materials for Plutonium Metals and Oxides

\subsubsection{Government Furnished Information}

The following government furnished information also will be used in the Pu SPS:

- RFETS Work Control Traveller Identification 


\subsubsection{Government Furnished Software}

No government furnished software will be used in the Pu SPS.

\subsection{Documentation}

[This subparagraph ... shall specify the requirements for system documentation such as specifications, drawings, technical manuals, test plans and procedures, and installation instruction data.]

\section{DRD No. Description}

A001 System Design Document, including

- Block Flow Diagram

- Interface Requirements Document

- Interface Locations Drawing

A002 System Specification Document/System Requirements Document, including

- Process Flow Diagram

- General Arrangement Drawings

- Pu SPS Control Block Drawing

A003 SAR per DOE 5480.23

< An anticipated contract change would substitute USQD per DOE 5480.21. 》

A004 TSRs per DOE 5480.22

< An anticipated contract change would substitute OSRs. >>

A005 Pre-Operational Test Procedures

- for individual components

- for systems

- for startup and performance demonstration testing

A006 Pre-Operational Test Reports

A007 Quality Assurance Program

A008 Quality Assurance Records (to establish pedigree)

- drawings

- specifications

- calculations

A009 Seller's Inspection Records (including certification records)

- material certifications

- certificates of compliance

- non-destructive examinations

- welding records

- construction/fabrication inspections

- calibrations 
- performance testing

- samples

A010 Operating Procedures and Manuals

(formatted per reference 2.1.5.4)

- normal operations

- abnormal and emergency operations

- decontamination/repair/restoration

- leak testing of storage container

A011 Installation and Maintenance Manual

(formatted per reference 2.1.5.4)

- surveillance procedures

A012 Training Courseware (reproducible and electronic)

(in accordance with reference 2.1.8.17 or equivalent)

- for supervisors

- for operators

- for maintenance personnel

- for trainers

A013 Master Equipment List

- with equipment numbers, description, part number, and specifications

- will include an electrical load list

- will include an instrumentation list

A014 Spare Parts List

A015 As-Built Drawings and Specifications

- prints, reproducibles, and electronic format (PC based ACAD v11.0 or higher)

A016 OSHA Safety Basis and Surveillance Requirements (per reference 2.1.1.1)

A017 Software Codes and Documentation

- for application software developed by the BNFL Team

A018 Glovebox Testing Reports, that address:

- general design requirements

- configuration

- materials of construction

- structural design

- shielding

- assembly

- airlocks

- finish

- lighting

- leak tightness

- ventilation

A019 Design Review Report/Minutes

A020 Post Installation Checklist (up to final utility tie-in)

A021 Post Utility Tie-In Checklist 
A022 Acceptance Criteria (compliance document)

A023 Site Specific Safety and Health Requirements

- Construction Project Safety and Health Plan

- Preliminary Hazards Analysis (for construction)

- Construction Activity Hazards Analysis

Other Documentation Submittals

3.4.1 Cycle time for a complete transfer (stabilization and packaging) shall be determined and calculations made to estimate maximum throughput per 8 hour shift and shall be provided to DOE.

(DE-AC03-96SF20948, Attachment II, Section 4.1.4)

3.4.2 Failure modes and predicted/actual failure rates for each mode shall be determined... This includes identification of potential common-mode failure mechanisms. This information shall be provided to DOE.

(DE-AC03-96SF20948, Attachment II, Section 4.1.4)

3.4.3 Waste streams generated by the SPS operations shall be identified and characterized including solid and liquid transuranic, high level and low level waste. Hazardous waste streams shall also be identified. Daily generation rates should be determined by actual measurements or material balance modeling... This information shall be provided to DOE.

(DE-AC03-96SF20948, Attachment II, Section 4.1.4)

3.4.4 ...provide an evaluation of the accumulative long term effects of operations on all system components including plutonium holdup.

(DE-AC03-96SF20948, Attachment II, Section 4.2.9)

3.4.5 ...perform requirements analysis and definition tasks as follows:

- Perform system comparisons and analyses to include life cycle cost, health, safety, operability, compatibility with existing systems, reliability, and maintainability...

(DE-AC03-96SF20948, Attachment II, Section 4.3.1)

3.4.6 ...provide the site with all essential documentation necessary to qualify, operate and maintain the SPS in a safe manner. The documentation provided shall include...

(DE-AC03-96SF20948, Attachment II, Section 4.7.1.1)

A complete process description including a list of materials of construction to be used. This list will include, as a minimum any hazardous materials.

A list of all design and operation parameters including process diagrams and equipment layout diagrams. 
A list of actions (either automatically or by the operator) to be taken in the event of offnormal or accident conditions.

A list of systems that are necessary to meet OSHA and/or IS\&H requirements for anticipated accidents (e.g. fire suppression systems, ventilation systems).

$A$ list of energy sources used in the process.

An analysis of credible accidents and associated mitigating design features.

(DE-AC03-96SF20948, Attachment II, Section 4.5.2)

《 An anticipated contract change concerning SAR/USQD support may impact the above list. $\gg$

\subsection{Personnel and Training}

\subsubsection{Personnel}

[This subparagraph ... shall specify personnel requirements which must be integrated into system design. These requirements shall be stated in terms of numbers plus tolerance and shall be the basis for contractor design and development decisions. Requirements stated in this paragraph shall be the basis for determination of system personnel training, training equipment, and training facility requirements. Personnel requirements shall include:

a. Numbers and skills of support personnel for each operational deployment mode and the intended duty cycle, both normal and emergency.

b. Skills and numbers of personnel that shall be allocated to the operation, maintenance, and control of the system.]

Personnel requirements for the Pu SPS will be dictated by the tasks required to maintain efficient, safe and ALARA process and maintenance operations. Specific functional training (as described in section 3.5.2 on page 69) will be provided to personnel based on the modes of operations and skills required to accomplish these operations.

The operational crew of the Pu SPS is expected to require approximately six personnel: 1 foreman, 4 process operators/material handlers and 1 radiation control worker. The number of process operators may vary \pm 1 , depending on the final equipment layout and process operations.

Operational deployment modes for the Pu SPS are considered to be:

- material transfer (can opening) 
- waste management

- consumable management

- metal preparation

- oxide stabilization

- supervisory control

Supporting and integrating functions are:

- control systems

- glovebox operations

- safety/emergency shutdown operations

- maintenance

PERS-1 All personnel who operate or perform maintenance on the Pu SPS are expected to be experienced and maintain the basic skills required for radiation work and hands on glovebox operations prior to operations on the Pu SPS.

PERS-2 All process operators will be required to have the necessary skills to support the above operational deployment modes and functions. At a minimum, the skills required to operate the Pu SPS during these modes are as follows:

Material transfer:

container handling, conveyor transfers, container opening

Waste management: electrostatic decontamination, can compaction, bag in/out operations, material transfer port use

Consumable loading:

sphincter operation, letter door operation

Metal preparation:

plutonium metal handling, brushing, sorting, packaging

Oxide stabilization:

plutonium oxide dispensing, LOI testing

Glovebox operations:

glove entry/exit, airlock/gaslock operation, control systems 
PERS-3 Supervisory personnel will be required to possess the skills dictated by PERS-2 and an overall knowledge level of the Pu SPS, as well as management and training skills. The foreman/supervisor will support the training of process operators.

PERS-4 The Radiological Control Technician, along with normal functions of health physics controls, will be knowledgeable in the deployment modes of the Pu SPS and can assist operators.

\subsubsection{Training}

[This subparagraph ... shall include the following training requirements:

a. Contractor and Government responsibility for training. This subparagraph shall also specify the concept of how training shall be accomplished (e.g., school, contractor training).

b. Equipment that will be required for training purposes.

c. Training devices to be developed, characteristics of the training devices, and training and skills to be developed through the use of training devices.

d. Training time and locations available for a training program.

e. Source material and training aids to support the specified training.]

\subsubsection{Training Approach and Responsibilities}

BNFL Team member, Toeroek Associates, will provide training to the first-line supervisors designated by the facility to operate the Pu SPS equipment. This follows the approach currently used on successful DOE projects, such as the RFETS National Conversion Pilot Project, called "train-the-trainer." By training the first line supervisors to train others on their staff, the supervisors must buy-in to the project and take responsibility for proper accomplishment of the project. As a further step to assure the success of this approach, close coordination with the supervisors will occur during preparation of training materials. It is presumed throughout this program that the facility will provide personnel for training on the Pu SPS who are qualified by the facility to train others.

Training will include classroom training sessions; hands-on training, otherwise referred to as on-the-job (OJT) training; and demonstration of competence. The training will be biased toward OJT, whenever practical. 
Toeroek Associates will provide training materials and will train-the-trainers. The DOE is responsible for reviewing training deliverables within two weeks of submittal, in order to maintain the overall project schedule. The facility is responsible for:

- providing personnel to be trained who are qualified to train others,

- providing adequate space for training at the facility (RFETS Building 60 , or equivalent),

- providing escorts for BNFL Team personnel into RFETS Building 707,

- providing copies of all DOE guidance documents or other regulations that must be followed for training.

The key attributes of the Pu SPS training program are:

- The approach was developed based on references 2.1.2.1 and 2.1.8.17, so that the materials will be appropriate for any DOE site.

- The approach allows adaptations and customization to each DOE facility.

- The approach is to provide only the training needed. This is a graduated "need-to-know" approach to information, and yet it is also a team approach to implementation. As a team, the operators need to know all some level of detail about the aspects of the Pu SPS operation and maintenance. As an individual, the operator needs to know only the details of their assigned task.

- The program allows recognition of the trainee's existing knowledge, skills, and abilities, thereby eliminating unnecessary, repeat training.

- The preferred method of training is practical, hands-on training and evaluation.

The Pu SPS training program generally follows the DOE Training Accreditation Program (TAP) guidance in reference 2.1.8.17 and uses those steps in TAP appropriate for the Pu SPS program. The development of the training program consists of five steps: analysis, design, development, implementation and evaluation. The following is a brief outline of each step.

\section{Analysis}

The analysis step ensures that the training program is oriented specifically to the job tasks of the function being trained. This phase identifies training requirements for a specific job position. Training needs are determined by a needs analysis, a job analysis, and task analysis. These analyses identify requirements that serve as the basis for the design and development of a performance-based training 
program. The following will be done in this phase:

- Analysis of job tasks and training needs

- Development of a Task-to-Training Matrix

- Identification of selected tasks for training

- Evaluation of existing training materials

\section{Design}

The information collected during the analysis phase is used to develop the blueprint for the design phase. The program design will include methods for writing objectives, setting training standards, designing tests, and preparing training plans. The following will be done in this phase:

- Development of training objectives

- Development of test items

- Construction of tests

\section{Development}

The development component of the training program incorporates the results of both the design activities and describes the selection of appropriate training methods, the methodology for developing lesson plans, the preparation and use of training aids, and the verification of materials before the training program is fully implemented. The following will be done during this phase:

- Selection of training methods

- Development of lesson plans

- Development of training aids

- Conducting pilot training

\section{Implementation}

The Pu SPS training program will be implemented by taking the results of the development phase into the training setting and actually conducting the training. The specific tasks for this phase include:

- Verifying the base competence of the trainees 
- Conducting a pilot run (or dry-run) of the Pu SPS equipment with the trainees. This will constitute a provisional qualification, based on the successful operation of the system with surrogate material (no plutonium)

- Conducting evaluations

- Providing training support to the facility trainers

- Documenting training

\section{Evaluation}

This step includes periodic reviews of the training materials. It also incorporates ideas and methods for soliciting feedback from those trained on the effectiveness of the training provided. The evaluation phase is the quality assurance component of performance-based training.

There are three major components of the evaluation phase: monitoring indicators, analyzing information, and determining corrective actions. The following are minimum indicators to be used to determine the effectiveness of training:

- Evaluations of training curriculum and presentation

- Evaluations of pilot runs

- Evaluation of trainees and trainers

- Evaluations of the Pu SPS process and procedures

- Periodic follow-up evaluations at three- and six-month intervals after the system is deemed operational

\subsubsection{Training Equipment}

The equipment required for training includes:

- training manuals

- copies of all DOE and site guidance documents and regulations specific to training programs

- equipment operating and safety procedures

- overhead projector 
- classroom space to comfortably accommodate personnel

- the assembled Pu SPS for a dry-run of the system using surrogate material

\subsubsection{Training Devices}

Training manuals will be developed based on a needs analysis. The needs analysis will include the job skills to be acquired through training and the job task analysis. Existing training material for the packaging process, which is operating in England, will be evaluated for use at RFETS. It is expected that all, if not most, of this training material will be directly incorporated into the training materials generated for use at RFETS.

Once the needs analysis is complete, the type and number of training manuals to be developed will be defined, as well as the trainer qualification requirements. Other training devices to be used in addition to the manuals are overheads and handouts to enhance classroom training. A video is also available which shows the packaging process as it operates in England.

Training tryouts, that is, testing the effectiveness of the training materials on a test audience prior to use at the facility, will be conducted. The tryout ensures that the manuals are workable and effective.

An important part of the training process is the qualification of trainees. Once the training needs are defined, a qualification package will be developed that corresponds to the competence objectives. The qualification package will have assigned pass marks and a policy for those steps the trainee must take if he/she does not pass the course. Qualification will take the form of written tests to assess knowledge, and practical exercises with oral questioning as necessary to assess skill. In the case of practical exercises, the trainee will be observed while performing tasks and the trainee's competence will be verified against a checklist of key safety and operational features relating to each training course. The qualification procedure will be described in the Training Manual. The Manual will provide a procedure for exam mediation or requalification of the trainee. Trainees who do not meet the qualification standard (the competence objectives set in the Training Manual) will undergo remediation training and will be allowed to repeat the qualification step before being certified.

A course review will be included in the Training Manual so that the trainers can receive constructive feedback on the quality of the course.

Training will be given in courses according to the job function of the trainee. The detailed implementation procedure with the lesson plans contained in the Training Manuals will be followed by the trainers. It is assumed that personnel to be trained are certified by RFETS to train others.

Operating and safety procedures are currently being developed by the engineering group, so the final structure of the training manuals cannot be determined at this time. However, it is planned that the 
training manuals will include the following topics:

- Introduction

- Purpose of the Pu SPS

- Description of the System, including:

Overview of the equipment

Component parts

Illustrations and Exploded Views

Theory and Principles of Operation

Principles underlying the mechanics

- Key features of the safety analysis and technical safety requirements

- Operating Instructions

- Basic Equipment operation

- Maintenance and Repair Procedures

- Preventive Maintenance

- Troubleshooting - including symptoms, causes, and corrective actions

- Corrective Maintenance

- Emergency Operating Procedures

- Automated system response

- Operator actions

- Credible accidents and mitigation

- Measurement of Competence

- Course Evaluation

Records, including personnel certification documentation, will be kept as an integral part of the training process and the recordkeeping procedure will be detailed in the Training Manuals. Recordkeeping will be consistent with the system required by DOE.

\subsubsection{Training Time and Location}

The classroom training will be conducted after DOE has approved all the Training Manuals. The pilot run will be conducted after completion of the utility tie-ins and engineering testing of the Pu SPS.

Classroom training will be conducted in RFETS Building 60. OJT will be conducted in Module $\mathrm{H}$ of Building 707 at RFETS.

Toeroek Associates will continue training support during the first six months of operation of the Pu SPS, as permitted by DOE funding limits. Refinements of the system result in the need for training modifications, which can be provided to ensure that the operators are trained to the highest standards. 


\subsubsection{Source Material and Training Aids}

Source material includes all relevant guidance and standards issued by DOE relative to training. DOE-approved Training Manuals are also a source for the training sessions. Training aids, in addition to the Training Manuals, include overheads, hand-outs and video. For OJT sessions, the Pu SPS must be fully installed and operational. The pilot run of the Pu SPS will be conducted with surrogate material, similar in form to plutonium oxide, but not radioactive or toxic.

\subsection{Precedence}

[This paragraph ... shall either specify the order of precedence of the requirements or assign weights to indicate the relative importance of the requirements.]

The Pu SPS project, due to its inherent nature, does not have an order of precedence for its requirements and does not assign weights to its requirements.

\subsection{Qualification}

[This paragraph ... shall state the requirements for verification or validation, as applicable, of capabilities in a specific application. Each qualification test shall be identified in a separate subparagraph and the specific application shall be described. Requirements shall be included for the conditions of testing, the time (program phase) of testing, period of testing, number of items to be to be tested, and any other pertinent qualification requirements.]

\subsubsection{Necessity of Qualification}

Safety class items shall be designed to withstand the effects of, and be compatible with, the environmental conditions associated with operation, maintenance, shutdown, testing, and accidents. The environmental capability of equipment shall be demonstrated by appropriate testing, analysis, and operating experience, or other methods that can be supported by auditable documentation, or a combination of these methods.

(reference 2.1.2.1, section 1300-3.4.1)

Equipment qualification shall provide assurance that safety class items will be capable of performing required safety functions under $D B A$ conditions. The qualification shall demonstrate that the equipment can as least perform for the period of time that its safety functions are required. Subsequent equipment failure, after its safety function is no longer required, may be allowable. Temperature, pressure, and humidity environments shall be based on the most severe postulated accidents affecting the particular item. The postulated environment shall reflect an environment that considers both radiological composition (e.g., elements, isotopics, total radioactivity, and chemical 
composition (e.g., abrasives, acids, smoke, caustic vapors) of all material physical forms likely to affect the equipment.

Testing or a combination of testing and analysis shall be the preferred method of demonstrating the operability of fluid system components, mechanical equipment, instrumentation, and electrical equipment that are required to operate during and following a DBE. Seismic experience data may be used as an alternative to testing or dynamic analysis where such data have been documented and validated.

(reference 2.1.2.1, section 1300-3.4.3)

\subsubsection{Safety Classification}

The methodology to be used for determining the appropriate safety classifications of SSCs will be developed and included in the System Design Document. Initial safety classifications of SSCs will also be provided in the System Design Document, along with the operational environment imposed upon them. These safety classifications will be confirmed later in the design analysis process and will provide the basis for determining which SSCs require qualification by testing or other means.

\subsubsection{Qualification Demonstration}

In the event that the safety classifications dictate that certain SSCs must be qualified, those SSCs shall be procured as qualified items whenever possible.

In the event that qualification is required but no qualified items are available for procurement, qualification methods will be established to provide assurance that safety class SSCs will be capable of performing required safety functions under DBA conditions. These methods may include analysis, testing, or documented operating experience. Where testing is the preferred method of qualification, a test procedure will be developed, including testing conditions, schedules, durations, sample quantities, acceptance criteria and other pertinent qualification test elements.

\subsection{Standard Samples}

[This paragraph ... if applicable, shall describe requirements for the production of one or more standard samples. Standard samples shall be limited to the illustration of qualities and characteristics that cannot be described using detailed test procedures or design data or that cannot be definitively expressed.]

Standard samples are identical specimens of test material, models, or patterns to be used in verifying a process during operations. An example is a machined pattern to be used for comparison with machined production samples. Standard samples do not include pre-production samples, periodic production samples, pilot models, or pilot lots which are discussed in Section 3.9. No requirements have been identified to produce standard samples for the Pu SPS operations. 


\subsection{Pre-production Samples}

[This paragraph ... if applicable, shall describe requirements for producing a pre-production or periodic production sample, a pilot model, or a pilot lot.]

\subsubsection{Furnace Tray Design Verification}

Pre-production samples of furnace trays will be manufactured so that they may be tested in conjunction with the stabilization furnace qualification. The purpose of the tests is to verify that the trays can withstand heating and cooling between room temperature and $1,000{ }^{\circ} \mathrm{C}$ without excessive oxidation or distortion, and to verify the utility of the tray identifier system.

\subsubsection{Storage Package Redesign Verification}

Reduction of the diameter and height of the existing BNFL Storage Package, coupled with the use of a solid intermediate can lid vice a sintered filter, requires the performance of a full range of pressure and leak-tightness tests specified in reference 2.1.5.1 to meet certain functional requirements identified for Storage Packages (SP-8, SP-10, SP-11, SP-20, and SP-23) on page 31. 


\subsection{Quality Assurance Provisions}

The BNFL Quality Assurance Plan (QAP) contains the organizational description, functional responsibilities, levels of authority, and interfaces for the Pu SPS project quality program. The QAP identifies the methodology for applying quality controls to the Pu SPS, which is a graded approach.

QUAL-1 Design, fabrication, and procurement of equipment for the SPS shall meet the requirements of ... a Quality Assurance Program which meets the requirements of reference 2.2.2.5 or equal.

(DE-AC03-96SF20948, Attachment II, Sections 4.1.5 \& 4.6)

QUAL-2 ...perform all work in accordance with the contract documents and ... ensure all work is in compliance with all quality and design requirements contained in the contract documents.

(DE-AC03-96SF20948, Attachment II, Section 4.6)

QUAL-3 Those Pu SPS systems, subsystems, and portions of subsystems required to perform an identified safety function are classified as (project) Quality Level 1 and will be engineered and designed in accordance with applicable BNFL procedures for Quality Level 1 equipment. (Quality Assurance Plan, Procedure QA-1, Section 2)

QUAL-4 Those Pu SPS systems, subsystems, and portions of subsystems required to perform an identified safety function are classified as (project) Quality Level 1 and will be constructed in accordance with applicable BNFL procedures for Quality Level 1 equipment. (Quality Assurance Plan, Procedure QA-1, Section 2)

During the design, engineering, and testing process, a compilation will be made of all attributes needed to demonstrate that the Pu SPS storage packages will perform as a 50 year interim storage device for plutonium metals and oxides. These attributes may range from documented analysis to records of process data within a previously identified range of acceptance to actual package testing data. This collective group of information will be referred to as storage package certification documentation.

\subsection{Responsibility for Inspection}

[This paragraph ... shall assign responsibilities for performance of inspections of delivered products, materials, or services for determining compliance with all specified requirements.]

The Pu SPS project will implement a detailed and documented inspection program to ensure that delivered products, materials, and/or services are in accordance with the specified engineering and design criteria, including applicable codes and standards. Inspections will be performed by BNFL Team personnel who report to the Project QA Manager. This inspection staff will be comprised of individuals who have the appropriate background and experience for the assigned inspections. 
Additionally, these personnel will have no responsibility for the products, materials, or services for which they are inspecting. Inspections will be planned to ensure that all specified criteria have been included in the inspection. The inspections shall be performed and documented in accordance with $\mathrm{Pu}$ SPS project procedures, which will provide the required pedigree for the items inspected. Any nonconformances to the approved, specified criteria will be identified and documented. The nonconformance will be evaluated and appropriate corrective or preventive actions implemented.

Inspection activities may be witnessed by DOE personnel at any time. Hold/witness points will be included in inspection activities to ensure that the required notifications and inspections are conducted as required.

QUAL-5 Whenever testing of materials, equipment, or systems is required, the [BNFL Team] shall be fully responsible for preparing, setting up, and reporting on such tests and shall provide all necessary testing equipment and devices at its own expense. The DOE or its representative(s) may witness such tests and approve the adequacy of the method employed... Certified reports from recognized testing laboratories are normally considered acceptable evidence of tests performed.

(DE-AC03-96SF20948, Attachment II, Section 4.6.3)

\subsection{Special Tests and Examinations}

[This paragraph ... shall specify any special tests and examinations required for sampling, lot formation, qualification evaluation, and any other tests or examinations as necessary. Each test and examination shall be described in a separate subparagraph.]

The BNFL team will prepare Test/Startup Procedures, conduct testing, and provide documentation demonstrating the functional and operational readiness of the Pu SPS to stabilize and package plutonium metals and oxides. The functional tests will consist of those tests necessary to verify the requirements of this document. The operational tests will consist of those tests necessary and sufficient to demonstrate that the system can operate according to the operational scenarios described in the System Design Document. The overall testing approach will be:

- Pre-energization checking of electrical and mechanical equipment and systems.

- Functional testing of electrical equipment following energization.

- Check out of equipment or systems on an individual basis.

- Check out of equipment or systems with all interfacing equipment or systems.

- Software verification by simulation and/or integration with equipment.

- Control loop acceptance tests.

- Process controller check out with all interconnecting systems.

- Confirmation testing of all engineered protective systems. 
Testing categories will include:

- Furnace Tray Design Verification (addressed in section 3.9.1 on page 77)

- Storage Package Redesign Verification (addressed in section 3.9.2 on page 77)

- Factory Component Tests

- Pre-Operational Tests of Individual Components

- Pre-Operational Tests of Systems (System Operational Tests)

- Startup and Performance Demonstration Tests (using actual containers and surrogate materials).

The location and general conduct of these tests are described below. The stabilization system will be assembled and tested as a subsystem at the PAFCo facility in Pocatello, Idaho. The packaging system will be assembled and tested as a subsystem in the United Kingdom.

\subsubsection{Factory Component Tests}

Factory component tests will be conducted for selected items prior to release for shipment to the subsystem assembly points. Designation of items for factory tests will consider the component's uniqueness, fabrication schedule, vendor alternatives, and other factors that would suggest the necessity of factory testing. The following items have been identified to date as requiring factory testing are:

- Electrostatic Decontamination Equipment in the Material Preparation Area.

- Container Compactor in the Material Preparation Area.

- Stabilization test furnace, including the use of surrogate materials.

- Can/Tray Handler in the Transport Area.

- Powder Dispensing Station in Material Preparation Area.

- Laser generation and welding/cutting system.

- Resistance Welder.

\subsubsection{Pre-Operational Tests of Individual Components}

These tests will be conducted at the subsystem assembly points in the United Kingdom and at PAFCo in Idaho. These tests allow the component to be tested under operational conditions, including all related subsystems and components. The following pre-operational tests have been identified to date:

- Individual glovebox leak tightness.

- Container Assay System in the Material Preparation Area.

- Airlock/gaslock door operation.

- Operation of the Container Compactor inside the glovebox. 
- Bagless transfer operation, including:

Leak testing of the glovebox and the rotating sphincter seal,

Welding of intermediate can and stub cutoff with the laser beam,

Leak testing of the intermediate can weld.

- Welding of outer can with the Resistance Welder.

- Tray tipper operation.

\subsubsection{System Operational Tests}

These tests are intended to demonstrate that the system can operate according to the operational scenarios described in Section 3.5 of this document. These tests will be performed at either the subsystem assembly locations or after final assembly in Module $J$ at RFETS, depending upon the nature of the test. The following system operational tests have been identified to date:

- Multi-glovebox assembly leak tightness.

- Airlock/gaslock door interlocks.

- Handling of furnace trays by the Can/Tray Handler at the Powder Dispensing Station and the Stabilization Furnaces.

- Handling of trays and convenience cans into the Tipping Glovebox.

- Operation of the interface between the existing S-16 conveyor and the Pu SPS entry airlock.

- Confirmation of Pu SPS interfaces with RFETS utility systems.

\subsubsection{Performance Demonstration Tests (using actual containers and surrogate materials)}

These tests are intended to demonstrate the operational readiness of the entire Pu SPS, using typical site-furnished containers prepared with metal and oxide forms of surrogate materials. This testing will also aid in training for the RFETS operating crew.

The following performance demonstration tests have been identified to date:

- Throughput rates for feeds (including receipt, assay, container opening, tray filling, metal repackaging, stabilization heating, LOI testing, tray tipping, oxide placement in storage packages, sealing of packages, and testing of packages).

- Efficacy of waste handling operations (including can decontamination and compaction, waste assay, waste bagout, and stub bagout). 


\subsection{Requirements Cross-Reference}

[This paragraph ... shall list the quality assurance provisions that will be used to verify that the requirements of this specification are met, such as method (test, simulation, analysis, visual inspection, course certification), level (integrated system, subsystem, component, individual personnel, group of personnel) and event (Design Review, Factory Mockup Demonstration, Installation Site Demonstration, Training Course, etc.). This paragraph also shall correlate each uniquely identified system requirement in sections 3 and 5 to the defined quality assurance provisions. This paragraph may reference a requirements cross reference table which may be provided as an appendix to this specification.]

The following methods will be used to verify that the requirements of this specification are met:

Design Check - a review performed during preparation of design documents by discipline engineers. Analysis - a formal calculation or study performed by, engineers during the design process. Report - a formal, comprehensive analysis of the design, as verified by the actual installation. Internal Design Review - an integrated review of the overall design by a team of engineers. Test - a formal, documented verification of equipment performance.

Quality Control - a formal, documented inspection report of the actual or installed equipment. Post Installation Checklist - a formal, documented inspection report of the actual system installation. Training - a formal program to ensure operations personnel have the prescribed Pu SPS knowledge. DOE-Approved Quality Assurance Plan - establishes programmatic requirements for project quality.

The following levels of verification will be used for the requirements of this specification:

Subcomponent - \{no usage identified to date\}

Component - an item of equipment preforming a distinct function.

Subsystem - a group of equipment items with interrelated functions.

Process - all equipment in either the stabilization or packaging process.

Integrated System - all equipment in both the stabilization or packaging processes.

The following events indicated the general timeframe for verifying the requirements of this specification:

Pre-Procurement - before procurement documents have been issued to vendors or fabricators. Pre-Site Delivery - before procured equipment is released for shipment from the vendor or fabricator. Integrated System Startup - upon completion of startup \& performance testing of the entire Pu SPS.

Appendix B identifies each of the requirements identified in sections 3 and 5 of this document, and also identifies the specific method and approximate timeframe for demonstrating compliance to these requirements. 


\subsection{Preparation for Delivery}

[This section ... shall specify requirements for the preparation of the system and all its components for delivery, including packaging and handling. This section shall include requirements to document any non-standard practices in appropriate system end item specifications. This section may impose requirements to comply with standard practice by referencing appropriate military specifications and standards to be used as the basis for preparing Section 5 of each specification for system end items.]

\subsection{Transportation Requirements}

The stabilization subsystem will be assembled in the PAFCo facility in Pocatello, Idaho. The packaging subsystem will be assembled in the United Kingdom. Following successful completion of the subsystem tests at the assembly locations, the two subsystems will be broken down into subassemblies small enough to be taken into Module $J$ of Building 707. These subsystems then must be prepared for shipment to RFETS, subject to the constraints identified for Physical Characteristics (PHYS-1, PHYS-2) on page 44.

TRANS-1 No components or subassemblies of the Pu SPS will be delivered directly to RFETS. All will be initially delivered to the stabilization or packaging subsystem locations and then trans-shipped to RFETS along with the subsystems.

TRANS-2 Delivery from Idaho to RFETS will be via truck.

TRANS-3 Delivery from the United Kingdom to RFETS may be via air freight.

\subsection{Shipping Preparations}

SHIP-1 Items shall be prepared for delivery in accordance with the requirements of reference 2.2.2.5, Subpart 2.2, "Quality Assurance Requirements for Packaging, Shipping, Receiving, Storage, and Handling of Items for Nuclear Power Plants."

SHIP-2 All equipment will be crated in wood. Any loose items within the gloveboxes or subsystems will be secured. All equipment will be suitably protected from exposure to the natural environment.

SHIP-3 All penetrations and openings in gloveboxes shall be sealed to protect the opening and sealing surfaces.

SHIP-4 Sealing tape in direct contact with stainless steel shall have a chloride content of less that 50 ppm. 


\subsection{Notes}

[This section ... shall contain any general information that aids in understanding this document (e.g., background information, glossary). This section shall contain an alphabetical listing of all acronyms, abbreviations, and their meanings as used in this document.]

\subsection{Background Information}

Within the DOE complex there are several sites, which, due to the abrupt halt in weapons production and the associated use of plutonium, have plutonium inadequately stored or in a state that is unacceptable from a safety standpoint. The DNFSB has recommended that an integrated program be formulated to convert such materials to a form or condition suitable for a safe interim storage period of 50 years. Further, it has been recommended that all separated plutonium metals $(>50 \% \mathrm{wt})$ be repackaged and plutonium oxides be stabilized and repackaged to meet current storage standards of DOE-STD-3013-94 by May 2002.

To achieve this program, the DOE requires a prototype unit to be installed at RFETS in Module J of Building 707. After approval of the design, systems are intended to be installed in Room 3206 of Building 371 at RFETS, at the Hanford Site, and possibly at the SRS. This program requires a systems engineering approach, involving the integration of several DOE sites, to develop a robust system that is easily adaptable to the facility and material conditions prevailing at each site. 


\subsection{Acronyms and Abbreviations}

$\begin{array}{ll}\text { ALARA } & \text { As Low As Reasonably Achievable (exposure to ionizing radiation) } \\ \text { BNFL } & \text { British Nuclear Fuels Ltd. } \\ \text { CSCI } & \text { Computer Software Configuration Item } \\ \text { DBE } & \text { Design Basis Earthquake } \\ \text { DBW } & \text { Design Basis Wind } \\ \text { DHCS } & \text { Data Highway Communications Software } \\ \text { DNFSB } & \text { Defense Nuclear Facilities Safety Board } \\ \text { DMS } & \text { Data Management System } \\ \text { DOT } & \text { (U.S.) Department of Transportation } \\ \text { HEPA } & \text { High Efficiency Particulate Air (filter) } \\ \text { HWCI } & \text { Hardware Configuration Item } \\ \text { IRD } & \text { Interface Requirements Document } \\ \text { IWCP } & \text { Integrated Work Control Program (used at RFETS) } \\ \text { LCO } & \text { Limiting Condition of Operation } \\ \text { LOI } & \text { Loss on Ignition (for testing oxide stabilization) } \\ \text { MC\&A } & \text { Material Control and Accountability (ref: DOE Order 5633.3) } \\ \text { NDE } & \text { Non-Destructive Examination } \\ \text { NEC } & \text { National Electric Code } \\ \text { NFPA } & \text { National Fire Protection Association } \\ \text { NRC } & \text { (U.S.) Nuclear Regulatory Commission } \\ \text { OIU } & \text { Operator Interface Unit } \\ \text { OJT } & \text { On the Job Training } \\ \text { ONM } & \text { Other Nuclear Material (includes neptunium ???) } \\ \text { ORR } & \text { Operational Readiness Review (ref: DOE Order 5480.5) } \\ \text { OSHA } & \text { Occupational Safety and Health Administration (or Act) } \\ \text { OSR } & \text { Operational Safety Requirement } \\ \text { PC } & \text { Performance Category (ref: DOE-STD-1021-93) } \\ \text { PCV } & \text { Primary Containment Vessel } \\ \text { PLC } & \text { Programmable Logic Controller } \\ \text { PPCS } & \text { Plutonium Packaging Control System } \\ \text { PSCS } & \text { Plutonium Stabilization Control System } \\ \text { Pu SPS } & \text { Plutonium Stabilization and Packaging System } \\ \text { PVC } & \text { Poly Vinyl Chloride (plastic bag material) } \\ \text { QAP } & \text { Quality Assurance Plan } \\ \text { RAM } & \text { Reliability, Availability, and Maintainability (analysis) } \\ \text { RCRA } & \text { Resource Conservation and Recovery Act } \\ \text { RFETS } & \text { Rocky Flats Environmental Technologies Site } \\ \text { SAAM } & \text { Selective Alpha Air Monitor } \\ \text { SAN } & \text { Safeguards Accountability Network (a classified system at RFETS) } \\ \text { SDD } & \text { System Design Document } \\ & \\ & \\ \text { INT } & \end{array}$




\subsection{Acronyms and Abbreviations (continued)}

SNM Special Nuclear Material (plutonium or uranium-235)

SRS Savannah River Site

SS System Specification/System Requirements Document

SSCs Structures, Systems, and Components

TID Tamper Indicating Device

TSR Technical Safety Requirement (ref: DOE Order 5480.22)

UPS Uninterruptible Power Supply (for safety equipment electrical power)

USQD Unreviewed Safety Question Determination (ref: DOE Order 5480.21)

VAC Volts - Alternating Current

VDC Volts - Direct Current

VDU Visual Display Unit

VOC Volatile Organic Compound

WIPP Waste Isolation Pilot Project (Carlsbad, New Mexico) 


\subsection{Glossary of Terminology}

Radiation Controlled Area - An area requiring Health Physics access control. There are three subdivisions, based on radiation type and level (and thus ventilation zoning):

Zone 1 - Areas of process within confinement, such as gloveboxes.

Zone 2 - Manned areas immediately outside Zone 1 areas.

Personnel in Zone 2 areas are segregated from the potential of internal exposure to ionizing radiation by virtue of separate ventilation (but not from the potential of direct exposure to ionizing radiation).

Zone $\underline{3}$ - Manned areas outside of Zone 2 areas.

Personnel in Zone 3 areas are further segregated from the potential of internal exposure to ionizing radiation and are generally shielded from the potential of direct exposure to ionizing radiation by intervening walls and equipment.

\section{Confinement Systems:}

(DOE Order 6430.1A, 1304-6.1)

Primary Confinement - Primary confinement is provided by piping, tanks, gloveboxes, encapsulating material, and the like, and any off-gas system that controls effluent from within the primary confinement. It provides confinement of hazardous material to the vicinity of its processing.

Secondary Confinement - Secondary confinement is provided by walls, ceilings, floors, and associated ventilation exhaust systems of the cell or enclosure surrounding the process material or equipment. Except in the case of glovebox operations, the area inside this barrier is usually unoccupied; it provides protection for operating personnel.

Tertiary Confinement - Tertiary confinement is provided by the walls, floor, roof, and associated ventilation exhaust system of the facility. It provides a final barrier against release of hazardous material to the environment.

Storage Packages - The multi-component assembly for plutonium storage. For clarity they are described as:

Containers - The site-furnished plutonium storage packages that enter the Pu SPS process. Generally they consist of:

- inner container (with the plutonium material)

- sealed plastic bags (around the inner container)

- outer container (for transport of the bagged inner container). 


\section{Appendix A \\ INTERFACE REQUIREMENTS DOCUMENT}

\section{SCOPE}

10.1 This document identifies the interface requirements for the Plutonium Stabilization and Packaging System (Pu SPS) in Building 707 at RFETS.

10.2 Section 20 of this document will identify the external system interfaces for each individual Pu SPS subsystem. This section will identify the purpose of each interface and will describe the relationship between each interface and the states and modes of the Pu SPS subsystem. Detailed quantitative interface requirements including specific characteristic and capacity requirements will be defined and a drawing reference will be given for the physical location of each external interface point.

10.3 Section 30 of this document will summarize the interface requirements for each applicable Building 707 system. These summary requirements can be used by RFETS to determine if the existing systems can support the installation and operation of the Pu SPS, to determine if modifications or upgrades to existing systems are necessary, and to determine if new systems must be installed.

\section{Pu SPS SUBSYSTEM EXTERNAL SYSTEM INTERFACE REQUIREMENTS}

\subsection{RECEIPT AREA}

\subsubsection{Receipt Hood}

The purpose of the receipt hood is to receive incoming material containers after they are removed from the outer container and to confine any radioactive contamination within the hood during the handling of the material containers.

External System Interfaces:

\subsubsection{Downdraft System}

1) The downdraft system exhausts air from the receipt hood to maintain a minimum face velocity of $150 \mathrm{ft} / \mathrm{min}$ across the largest possible hood opening.

2) The downdraft system must exhaust air from the receipt hood during all modes of Pu SPS 
system operation.

3) The required exhaust flow from the receipt hood to the plenum PL-104 Exhaust System is (later) $\mathrm{cfm}$. The interface connection will be a (later)-inch $150 \mathrm{lb}$ RF flange. The balancing valve and local flow indicator in the exhaust ductwork will be furnished and installed by RFETS.

4) The interface location for the downdraft system exhaust connection is on the top of the Receipt Hood at Point 1 shown on Drawing F-0-10-1-020.

\subsubsection{2 $\quad 120$ Volt AC Power Supply System}

1) The 120 volt ac power supply system provides power to the receipt hood lighting and to the internal and external electrical receptacles.

2) The 120 volt ac power supply system must supply power to the receipt hood lighting and electrical receptacles during all normal modes of Pu SPS System operation.

3) The interface connection for the 120 volt ac power supply to the receipt hood lighting will be a 2-pole, 3-wire grounding plug that will plug into an overhead receptacle provided by RFETS. Power for the internal and external electrical receptacles is provided by the 120 volt ac distribution system described in Section 20.11.1.2. All wiring between the 120 volt ac distribution panel and the electrical receptacles will be furnished and installed by BNFL.

4) The interface location for the 120 volt ac power supply connection to the receipt hood lighting will be an overhead receptacle strip at Point 2 on Drawing F-0-10-1-020.

\subsubsection{Entry Airlock}

The purpose of the entry airlock is to control the atmosphere changes during the transfer of material containers from the receipt hood or from the S16 Chainveyor into the inert atmosphere of the Material Preparation Glovebox.

External System Interfaces:

20.1.2.1 S16 Chainveyor

1) The S16 Chainveyor provides a means of transfering material into the Pu SPS system from other areas in Building 707 in an inert primary confinement.

2) The S16 Chainveyor interface is a passive interface and is not affected by any mode of $\mathrm{Pu}$ SPS system operation. 
3) The Receipt Area Glovebox will be designed to bolt to the existing flanged connection on the S16 Chainveyor where glovebox J-20 was removed.

4) The interface location for the S16 Chainveyor connection is on the side of the chainveyor at Point 3 shown on Drawing F-0-10-1-020.

\subsubsection{Downdraft System}

1) The downdraft system exhausts air from the entry airlock to maintain the required negative pressure in the airlock with respect to the room during normal operations, and to provide the capability to purge the airlock during purge and backfill operations when the airlock atmosphere is changed from air to a nitrogen inerted atmosphere.

2) The downdraft system must exhaust air from the entry airlock during all modes of Pu SPS system operation except when the door between the airlock and the S16 Chainveyor or the door between the airlock and the Material Preparation Glovebox is open.

3) The required exhaust flow from the entry airlock to the plenum PL-104 Exhaust System is (later) $\mathrm{cfm}$. The interface connection will be a (later)-inch $150 \mathrm{lb}$ RF flange. The balancing valve, local flow indicator, and the air operated isolation valve in the exhaust ductwork will be furnished and installed by RFETS.

4) The interface location for the downdraft system exhaust connection is on the top of the entry airlock at Point 4 shown on Drawing F-0-10-1-020.

\subsubsection{Inert Ventilation System}

1) The inert ventilation system provides the capability to backfill the entry airlock with the nitrogen inerted atmosphere before the airlock is opened to the S16 Chainveyor or to the Material Preparation Glovebox to minimize any increase in oxygen concentration in the inerted chainveyor or glovebox atmosphere.

2) The inert ventilation system is used to backfill the entry airlock before the airlock will be opened to the S16 Chainveyor or to the Material Preparation Glovebox and the airlock atmosphere must be changed from air to the nitrogen inerted atmosphere. The inert ventilation system supply line to the entry airlock is normally isolated at all other times.

3) The required supply flow to the entry airlock from the plenum PL-102 Supply System during backfill operations is (later) $\mathrm{cfm}$. The supply interface connection will be a (later)inch $150 \mathrm{lb}$ RF flange. The balancing valve and the air operated isolation valve in the supply ductwork will be furnished and installed by RFETS.

4) The interface location for the inert ventilation system supply connection is on the top of 
the entry airlock at Point 5 on Drawing F-0-10-1-020.

\subsubsection{Plant Air System}

1) The plant air system supplies air to the three airlock door cylinder operators, to the downdraft system exhaust valve operator, and to the inert ventilation system supply valve operator.

2) The plant air system must supply air to the airlock door cylinder operators, to the downdraft system exhaust valve, and to the inert ventilation system supply valve during all normal modes of Pu SPS System operation.

3) The required plant air flow when operating the airlock doors is (later) $\mathrm{cfm}$ at a minimum pressure of (later) psig. A solenoid valve will be provided to control the plant air flow to each of the three airlock door cylinder operators and the air piping for the three operators will be piped to a single interface connection point. The interface connection will be one (later)-inch NPT connection. The plant air piping and solenoid valve for the downdraft system exhaust valve and the inert ventilation system supply valve will be designed, furnished, and installed by RFETS.

4) The interface location for the plant air system connection to the airlock door cylinders is on the top of the entry airlock at Point 6 shown on Drawing F-0-10-1-020.

\subsubsection{120 Volt AC Power Supply System}

1) The 120 volt ac power supply system provides power to the entry airlock lighting, to the control system that supplies power to the solenoid valves that control the plant air flow to the airlock door cylinder operators, and to the airlock container handler drive motor and pneumatic actuator controls. The control system also provides power to the solenoid valves that control the operation of the airlock downdraft system exhaust valve and the inert ventilation system supply valve.

2) The 120 volt ac power supply system must supply power to the entry airlock lighting, to the airlock control system, and to the airlock container handler during all normal modes of Pu SPS System operation. The airlock doors are manually controlled at a local pushbutton station. The airlock door controls are interlocked to ensure that an airlock door cannot be opened unless both other airlock doors are fully closed during all modes of Pu SPS system operation. The airlock downdraft system exhaust valve and the inert ventilation system supply valve are also manually controlled at the local pushbutton station. The three airlock doors are normally closed. The airlock downdraft system exhaust valve is normally open and the inert ventilation system supply valve is normally closed. When the airlock is to be opened to either the S16 Chainveyor or the Material Preparation Glovebox to transfer a material container in either direction, the inert 
ventilation system supply valve would be opened to backfill the airlock with the nitrogen inerted atmosphere. The inert ventilation system supply valve and the downdraft system exhaust valve would then both be closed before opening the airlock door into the S16 Chainveyor or the Material Preparation Glovebox. After the material container is transfered, the airlock door would be closed and the downdraft system exhaust valve opened.

3) The interface connection for the 120 volt ac power supply to the entry airlock lighting will be a 2-pole, 3-wire grounding plug that will plug into an overhead receptacle provided by RFETS. Power for the airlock door control system and the airlock container handler is provided by the 120 volt ac distribution system described in Section 20.11.1.2. All wiring between the 120 volt ac distribution panel and the equipment and control devices furnished by BNFL will be furnished and installed by BNFL. The interface connections for the 120 volt ac power supply from the airlock door control system to the solenoid valves controlling the inert ventilation system supply valve and the downdraft system exhaust valve that will be furnished and installed by RFETS will be on a terminal strip in the pneumatic valve panel (later).

4) The interface location for the 120 volt ac power supply connection to the entry airlock lighting will be an overhead receptacle strip at Point 7 on Drawing F-0-10-1-020. The interface locations for the 120 volt ac power supply connections from the airlock door control system to the inert ventilation system supply valve and the downdraft system exhaust valve are in pneumatic valve panel (later) at Point 8 on Drawing F-0-10-1-020.

\subsubsection{Airlock Container Handler}

The purpose of the airlock container handler is to transfer containers from the Receipt Hood and the S16 Chainveyor into the first section of the Material Preparation Glovebox.

External System Interfaces:

\subsubsection{Nitrogen System}

1) The nitrogen system supplies nitrogen to the airlock container handler pneumatic actuators.

2) The nitrogen system must supply nitrogen to the airlock container handler pneumatic actuators during all normal modes of Pu SPS System operation.

3) The required nitrogen flow when operating the airlock container handler pneumatic actuators is (later) $\mathrm{cfm}$ at a minimum pressure of (later) psig. A solenoid valve will be provided to control the nitrogen flow to each actuator and the nitrogen piping will be piped to a single interface connection point. The interface connection will be one (later)-inch $3000 \mathrm{lb}$ NPT threaded couplings. 
4) The interface location for the nitrogen system connection to the can handler and airlock container handler is on the top of the entry airlock at Point 9 on Drawing F-0-10-1-020.

20.1.3.2 120 Volt AC Power Supply System

The 120 volt ac power supply system provides power to the airlock container handler drive motor and to the solenoid valves that control the nitrogen flow to the pneumatic actuators. There are no external 120 volt ac power supply interface connections specifically for this equipment. Power for the airlock container handler motor and solenoid valves is provided by the 120 volt ac distribution system as described in Section 20.1.2.5 (3) above.

\subsection{MATERIAL PREPARATION AREA}

20.2.1 Material Preparation Glovebox

The purpose of the Material Preparation Glovebox is to confine radioactive materials within the glovebox, shield the operators from the radiation sources within the glovebox, contain the inert (nitrogen) atmosphere within the glovebox, and provide structural support for the equipment associated with the glovebox. In order to minimize the spread of contamination from the areas of highest potential contamination to the areas of lowest potential contamination, the glovebox is divided into two sections separated by a pneumatically operated contamination door.

External System Interfaces:

\subsubsection{Inert Ventilation System}

1) The inert ventilation system maintains the required nitrogen inerted environment in the glovebox and maintains the required negative pressure in the glovebox with respect to the room. The system also automatically provides sufficient emergency exhaust flow to maintain a minimum face velocity of $150 \mathrm{ft} / \mathrm{min}$ across the larger of one open gloveport or the largest credible breach in the glovebox.

2) The inert ventilation system must maintain the required negative pressure in the glovebox with respect to the room during all modes of Pu SPS system operation. The system must maintain the nitrogen inerted environment in the glovebox whenever operations involving pyrophoric plutonium are performed.

3) The first section of the Material Preparation Glovebox contains the container assay equipment, container compactor, decontamination station, and the can handler. The required supply flow to this glovebox section is provided at the entry airlock end and the required exhaust flow is provided at the contamination door end to ensure that the ventilation flow is from areas of least potential contamination to areas of greatest potential contamination. The required supply flow to this section of the Material Preparation 
4) The interface location for the inert ventilation system supply connection to the first section of the Material Preparation Glovebox is on top of the glovebox at Point 10 on Drawing F-0-10-1-020. The interface location for the normal exhaust connection from this section is on the top of the glovebox at Point 11. The emergency exhaust connection from this section is on the top of the glovebox at Point 12 and the Photohelic sensing line and gage bracket connections are on the top of the glovebox at Point 13.

The interface location for the inert ventilation system supply connection to the second section of the Material Preparation Glovebox is on top of the glovebox at Point 14 on Drawing F-0-10-1-020. The interface location for the normal exhaust connection from this section is on the top of the glovebox at Point 15. The emergency exhaust connection from this section is on the top of the glovebox at Point 16 and the Photohelic sensing line and gage bracket connections are on the top of the glovebox at Point 17.

\subsubsection{Oxygen Analyzer}

1) The oxygen analyzer monitors the inert atmosphere in the first section of the Material Preparation Glovebox and also in the glovebox suite consisting of the second section of the Material Preparation Glovebox, Transport Glovebox, Furnace Glovebox, and the LOI Glovebox to ensure that the oxygen concentration does not exceed 5 percent by volume. The oxygen analyzer draws a sample from the two Material Preparation Glovebox exhaust ducts and sounds an alarm locally and in the Building 707 Control Room when the oxygen concentration exceeds 5 percent in either area.

2) The oxygen analyzer must be operable whenever operations involving pyrophoric plutonium are performed.

3) The oxygen analyzer piping to the two Material Preparation Glovebox exhaust ducts will be designed, furnished, and installed by RFETS.

4) There is no interface connection for the oxygen analyzer in the Material Preparation Glovebox.

\subsubsection{Glovebox Overheat Detection System}

1) The glovebox overheat detection system monitors the temperature in the two sections of the glovebox to provide an alarm locally (a chime inside the module) and at the Central Alarm Station and the Fire Dispatch Center in the event of a high temperature or fire condition in either section of the glovebox.

2) The glovebox overheat detection system must be operable during all modes of Pu SPS system operation. 
3) The interface connection for the glovebox overheat detection system will be two 2-inch NPT threaded connections in welded reinforced bases in accordance with RFETS Drawing 31200-443-M. The overheat detector assemblies, detector sleeves, and external wiring will be furnished and installed by RFETS.

4) The interface locations for the glovebox overheat detection system connections are on the top of the Material Preparation Glovebox at Points 18 and 19 on Drawing F-0-10-1-020.

20.2.1.4 120 Volt AC Power Supply System

1) The 120 volt ac power supply system provides power to the Material Preparation Glovebox lighting; to the internal and external equipment including the can handler, container assay device, container opener, powder dispensing station, decontamination station, container compactor controls, contamination door controls, bar code reader, and scales; and to spare electrical receptacles.

2) The 120 volt ac power supply system must supply power to the Material Preparation Glovebox lighting, internal and external equipment, and to the spare receptacles during all normal modes of Pu SPS System operation.

3) The interface connections for the 120 volt ac power supply to the glovebox lighting will be 2-pole, 3-wire grounding plugs that will plug into overhead receptacle strips provided by RFETS. Power for the internal and external equipment and spare electrical recepticals is provided by the 120 volt ac distribution system described in Section 20.11.1.2. All wiring between the 120 volt ac distribution panel and the internal and external equipment and spare electrical receptacles will be furnished and installed by BNFL.

4) The interface locations for the 120 volt ac power supply connections to the glovebox lighting will be two overhead receptacle strips at Points 20 and 21 on Drawing F-0-10-1020 .

\subsubsection{Can Handler}

The purpose of the can handlers is to move inner containers and convenience cans within the two sections of the Material Preparation Glovebox.

External System Interfaces:

\subsubsection{Nitrogen System}

1) The nitrogen system supplies nitrogen to the can handler pneumatic actuators. The nitrogen supply line in the second section of the Material Preparation Glovebox also supplies nitrogen to the powder dispensing station. 
2) The nitrogen system must supply nitrogen to the can handler pneumatic actuators and the powder dispensing station actuators during all normal modes of Pu SPS System operation.

3) The required nitrogen flow when operating the pneumatic actuators on the can handler in the first section of the Material Preparation Glovebox is (later) cfm at a minimum pressure of (later) psig. The required nitrogen flow when operating the pneumatic actuators on either the can handler or the powder dispensing station in the second section of the glovebox is (later) $\mathrm{cfm}$ at a minimum pressure of (later) psig. A solenoid valve will be provided to control the nitrogen flow to each actuator and the nitrogen piping will be piped to a single interface connection point in each section of the glovebox. The interface connection in each section of the glovebox will be one (later)-inch $3000 \mathrm{lb}$ NPT threaded coupling.

4) The interface locations for the nitrogen system connections to the can handlers and powder dispensing station are on the top of the Material Preparation Glovebox at Points 22 and 23 on Drawing F-0-10-1-020.

\subsubsection{120 Volt AC Power Supply System}

The 120 volt ac power supply system provides power to the can handler drive motors and to the solenoid valves that control the nitrogen flow to the pneumatic actuators. There are no external 120 volt ac power supply interface connections specifically for this equipment. Power for the can handler motors and solenoid valves is provided by the 120 volt ac distribution system as described in Section 20.2.1.4 (3) above.

\subsubsection{Container Opener}

The purpose of the container opener is to remove the lid from the inner container.

External System Interfaces:

There are no external system interface connections specifically for the container opener. Power for the container opener is provided by the 120 volt ac distribution system as described in Section 20.2.1.4 (3) above.

\subsubsection{Powder Dispensing Station}

The purpose of the powder dispensing station is to transfer plutonium oxide from the inner containers to the furnace trays and to homogenize the oxide in the tray using an in-tray blending technique.

External System Interfaces: 
There are no external system interface connections specifically for this equipment. Nitrogen for the powder dispensing station pneumatic actuators is provided by the nitrogen system as described in Section 20.2.2.1 above. Power for the powder dispensing station motors and solenoid valves is provided by the 120 volt ac distribution system as described in Section 20.2.1.4 (3) above.

\subsubsection{Metal Brushing Station}

The purpose of the metal brushing station is to remove loose $\mathrm{Pu}$ oxides from the $\mathrm{Pu}$ metal.

External System Interfaces:

The metal brushing station is manually operated and has no external interfaces.

\subsubsection{Decontamination Station}

The purpose of the decontamination station is to remove loose contamination from the incoming material cans that will not be reused so that they can be processed out as low level waste (LLW).

External System Interfaces:

\subsubsection{Nitrogen System}

1) The nitrogen system supplies nitrogen to the decontamination station to dislodge loose contamination from the inside of the material cans. This nitrogen supply line also supplies nitrogen to the contamination door cylinder operators.

2) The nitrogen system must supply nitrogen to the decontamination station and the contamination door cylinder operators during all normal modes of Pu SPS System operation.

3) The required nitrogen flow when operating the decontamination station or the contamination door is (later) $\mathrm{cfm}$ at a minimum pressure of (later) psig. A solenoid valve will be provided to control the nitrogen flow to the either the decontamination station or the contamination door and the nitrogen piping will be piped to a single interface connection point. The interface connection will be one (later)-inch $3000 \mathrm{lb}$ NPT threaded couplings.

4) The interface location for the nitrogen system connection to the decontamination station and contamination door is on the top of the Material Preparation Glovebox at Point 24 on Drawing F-0-10-1-020.

20.2.6.2 120 Volt AC Power Supply System 
The 120 volt ac power supply system provides power to the electrostatic precipitation unit and to the solenoid valves that control the nitrogen flow to the decontamination station. There are no external 120 volt ac power supply interface connections specifically for this equipment. Power for the decontamination station is provided by the 120 volt ac distribution system as described in Section 20.2.1.4 (3) above.

\subsubsection{Container Compactor}

The purpose of the container compactor is to crush the material containers that will not be reused after decontamination to reduce the volume of LLW.

External System Interfaces:

\subsubsection{Nitrogen System}

1) The nitrogen system supplies nitrogen to the container compactor pneumatic actuator.

2) The nitrogen system must supply nitrogen to the container compactor when compaction operations are performed.

3) The required nitrogen flow when operating the container compactor is (later) $\mathrm{cfm}$ at a minimum pressure of (later) psig. A solenoid valve will be provided to control the nitrogen flow to the pneumatic actuator. The interface connection will be one (later)-inch $3000 \mathrm{lb}$ NPT threaded coupling.

4) The interface location for the nitrogen system connection is on the top of the Material Preparation Glovebox at Point 25 on Drawing F-0-10-1-020.

\subsubsection{120 Volt AC Power Supply System}

There are no external 120 volt ac power supply system interface connections specifically for the container compactor controls. Power for the container compactor controls is provided by the 120 volt ac distribution system as described in Section 20.2.1.4 (3) above.

\subsubsection{Container Assay Device}

The purpose of the container assay device is to assay the incoming material containers for material control and accountability purposes.

External System Interfaces:

\subsubsection{Liquid Nitrogen}


Liquid nitrogen provides cooling for the container assay device. There is no external liquid nitrogen interface connection for this equipment. Liquid nitrogen is stored in a dewar that is furnished with the equipment. The transport container for refilling the dewar with liquid nitrogen will be furnished by RFETS.

\subsubsection{120 Volt AC Power Supply System}

There are no external 120 volt ac power supply interface connections specifically for the container assay device. Power for the container assay device is provided by the 120 volt ac distribution system as described in Section 20.2.1.4 (3) above.

20.2.9

\section{Contamination Door}

The purpose of the contamination door is to minimize the spread of contamination from the areas of highest potential contamination to the areas of lowest potential contamination within the Material Preparation Glovebox.

External System Interfaces:

There are no external system interface connections specifically for the contamination door controls. Nitrogen for the contamination door cylinder operators is provided by the nitrogen system as described in Section 20.2.6.1 above. Power for the contamination door controls is provided by the 120 volt ac distribution system as described in Section 20.2.1.4 (3) above.

\subsubsection{Bar Code Reader}

The purpose of the bar code reader is to read the bar code on the incomming convenience cans that will be filled with Pu metal.

External System Interfaces:

There are no external system interface connections specifically for the bar code reader. Power for the bar code reader is provided by the 120 volt ac distribution system as described in Section 20.2.1.4 (3) above.

\subsubsection{Convenience Can Scale}

The purpose of the convenience can scale is to weigh the convenience cans containing Pu metal.

External System Interfaces:

There are no external system interface connections specifically for the convenience can scale. 
Power for the convenience can scale is provided by the 120 volt ac distribution system as described in Section 20.2.1.4 (3) above.

\subsubsection{Tray Scale}

The purpose of the tray scale is to weigh the trays containing Pu oxides.

External System Interfaces:

There are no external system interface connections specifically for the tray scale. Power for the tray scale is provided by the 120 volt ac distribution system as described in Section 20.2.1.4 (3) above.

\subsection{TRANSPORT AREA}

\subsection{1}

\section{Transport Glovebox}

The purpose of the Transport Glovebox is to confine radioactive materials within the glovebox, shield the operators from the radiation sources within the glovebox, contain the inert (nitrogen) atmosphere within the glovebox, and provide structural support for the equipment associated with the glovebox.

External System Interfaces:

\subsubsection{Inert Ventilation System}

There are no external inert ventilation system interface connections to the inert ventilation system on the Transport Glovebox. The required supply flow to this glovebox is provided from the Furnace Glovebox and LOI Glovebox as described in Sections 20.4.1.1 and 20.5.1.1. The required exhaust flow from this glovebox is exhausted through the Material Preparation Glovebox and the Tipping Glovebox as described in Sections 20.2.1.1 and 20.6.1.1.

\subsubsection{Oxygen Analyzer}

There are no external system interface connections to the oxygen analyzer on the Transport Glovebox. The oxygen monitoring requirements are provided for as described in Sections 20.2.1.2 and 20.6.1.2.

\subsubsection{Glovebox Overheat Detection System}

1) The glovebox overheat detection system monitors the temperature in the glovebox to provide an alarm locally (a chime inside the module) and at the Central Alarm Station and the Fire Dispatch Center in the event of a high temperature or fire condition in the 
glovebox.

2) The glovebox overheat detection system must be operable during all modes of Pu SPS system operation.

3) The interface connection for the glovebox overheat detection system will be one 2-inch NPT threaded connection in a welded reinforced base in accordance with RFETS Drawing 31200-443-M. The overheat detector assembly, detector sleeve, and external wiring will be furnished and installed by RFETS.

4) The interface location for the glovebox overheat detection system connection is on the top of the Transport Conveyor Glovebox at Point 26 on Drawing F-0-10-1-020.

\subsubsection{120 Volt AC Power Supply System}

1) The 120 volt ac power supply system provides power to the Transport Glovebox lighting, to the internal equipment including the can/tray handler, and to spare electrical receptacles.

2) The 120 volt ac power supply system must supply power to the Material Preparation Glovebox lighting, internal equipment, and to the spare receptacles during all normal modes of Pu SPS System operation.

3) The interface connections for the 120 volt ac power supply to the glovebox lighting will be 2-pole, 3-wire grounding plugs that will plug into an overhead receptacle strip provided by RFETS. Power for the internal equipment and spare electrical receptacles is provided by the 120 volt ac distribution system described in Section 20.11.1.2. All wiring between the 120 volt ac distribution panel and the internal equipment and spare electrical receptacles will be furnished and installed by BNFL.

4) The interface location for the 120 volt ac power supply connection to the glovebox lighting will be an overhead receptacle strip at Point 27 on Drawing F-0-10-1-020.

\subsubsection{Can/Tray Handler}

The purpose of the can/tray handler is to move furnace trays from the Material Preparation Area into and out of the Furnace Area and LOI Area and then into the Tipping/Dispense/Fill Area, to move empty furnace trays from the Tipping/Dispense/Fill Area back to the Material Preparation Area, and to move convenience cans from the Material Prepation Area into the Tipping/Dispense/Fill Area.

External System Interfaces: 
20.3.2.1 Nitrogen System

1) The nitrogen system supplies nitrogen to the can/tray handler pneumatic actuators.

2) The nitrogen system must supply nitrogen to the can/tray handler pneumatic actuators during all normal modes of Pu SPS System operation.

3) The required nitrogen flow when operating the can/tray handler pneumatic actuators is (later) $\mathrm{cfm}$ at a minimum pressure of (later) psig. A solenoid valve will be provided to control the nitrogen flow to each actuator and the nitrogen piping will be piped to a single interface connection point. The interface connection will be one (later)-inch $3000 \mathrm{lb}$ NPT threaded couplings.

4) The interface location for the nitrogen system connection to the can handler is on the top of the Material Preparation Glovebox at Point 28 on Drawing F-0-10-1-020.

\subsubsection{120 Volt AC Power Supply System}

The 120 volt ac power supply system provides power to the can handler drive motors and to the solenoid valves that control the nitrogen flow to the pneumatic actuators. There are no external 120 volt ac power supply interface connections specifically for this equipment. Power for the can handler motors and solenoid valves is provided by the 120 volt ac distribution system as described in Section 20.3.1.4 (3) above.

\subsection{FURNACE AREA}

\subsubsection{Furnace Glovebox}

The purpose of the Furnace Glovebox is to confine radioactive materials within the glovebox, shield the operators from the radiation sources within the glovebox, contain the inert (nitrogen) atmosphere within the glovebox, and provide structural support for the equipment associated with the glovebox.

External System Interfaces:

\subsubsection{Inert Ventilation System}

1) The inert ventilation system maintains the required nitrogen inerted environment in the glovebox and maintains the required negative pressure in the glovebox with respect to the room. The system also automatically provides sufficient emergency exhaust flow to maintain a minimum face velocity of $150 \mathrm{ft} / \mathrm{min}$ across the larger of one open gloveport or the largest credible breach in the glovebox. 
2) The inert ventilation system must maintain the required negative pressure in the glovebox with respect to the room during all modes of Pu SPS system operation. The system must maintain the nitrogen inerted environment in the glovebox whenever operations involving pyrophoric plutonium are performed.

3) The Furnace Glovebox is open to the Transport Glovebox and the required inert ventilation system supply flow to the Furnace Glovebox provides part of the supply flow to the Transport Glovebox. The required supply flow to the Furnace Glovebox from the plenum PL-102 supply system is (later) $\mathrm{cfm}$. The supply interface connection will be a (later)-inch $150 \mathrm{lb} \mathrm{RF}$ flange. The balancing valve in the supply ductwork will be furnished and installed by RFETS. The required exhaust flow from this glovebox is exhausted through the Material Preparation Glovebox and the Tipping Glovebox as described in Sections 20.2.1.1 and 20.6.1.1.

4) The interface location for the inert ventilation system supply connection to the Furnace Glovebox is on top of the glovebox at Point 29 on Drawing F-0-10-1-020.

\subsubsection{Oxygen Analyzer}

There are no external system interface connections to the oxygen analyzer on the Furnace Glovebox. The oxygen monitoring requirements are provided for as described in Sections 20.2.1.2 and 20.6.1.2.

\subsubsection{Glovebox Overheat Detection System}

1) The glovebox overheat detection system monitors the temperature in the glovebox to provide an alarm locally (a chime inside the module) and at the Central Alarm Station and the Fire Dispatch Center in the event of a high temperature or fire condition in the glovebox.

2) The glovebox overheat detection system must be operable during all modes of Pu SPS system operation.

3) The interface connection for the glovebox overheat detection system will be one 2-inch NPT threaded connection in a welded reinforced base in accordance with RFETS Drawing 31200-443-M. The overheat detector assembly, detector sleeve, and external wiring will be furnished and installed by RFETS.

4) The interface location for the glovebox overheat detection system connection is on the top of the Furnace Glovebox at Point 30 on Drawing F-0-10-1-020.

20.4.2 Stabilization Furnaces 
The purpose of the stabilization furnaces is to thermally stabilize plutonium oxide by maintaining the oxide at $1000^{\circ} \mathrm{C}$ in an oxidizing atmosphere for a minimum of one hour.

External System Interfaces:

\subsubsection{Plant Air System}

1) The plant air system supplies air to the two stabilization furnace door cylinder operators.

2) The plant air system must supply air to the stabilization furnace door cylinder operators during all normal modes of Pu SPS System operation.

3) The required plant air flow when operating the stabilization furnace doors is (later) $\mathrm{cfm}$ at a minimum pressure of (later) psig. A solenoid valve will be provided to control the plant air flow to each of the two door cylinder operators and the air piping for the two operators will be piped to a single interface connection point. The interface connection will be one (later)-inch NPT connection.

4) The interface location for the plant air system connection to the stabilization furnace door cylinders is on the top of the Furnace Glovebox at Point 31 shown on Drawing F-0-10-1020.

\subsubsection{Dry Air System}

1) The dry air system supplies air with less than $1000 \mathrm{ppm}$ moisture to the furnaces to provide the required oxidizing atmosphere during the oxidation period.

2) The dry air system must supply dry air to the stabilization furnaces during the oxidation period. The dry air system supply line to each furnace is normally isolated at all other times. The dry air flow to the furnaces is automatically controlled by the furnace controls which open and close a solenoid valve in the air supply line to each furnace. The dry air flow is regulated to between 0.9 and $1.1 \mathrm{cfm}$ by a flow control valve in the air supply line downstream of the solenoid valve. After passing through the furnace, the air is then vented to the Furnace Glovebox.

3) The required dry air flow when operating the furnaces is $1.1 \mathrm{cfm}$ per furnace at a maximum pressure of (later) psig at the flow control valve inlet with a maximum moisture content of $1000 \mathrm{ppm}$. A solenoid valve, pressure control valve, and a flow control valve will be provided to control the dry air flow to each of the two stabilization furnaces and the dry air piping for the two furnaces will be piped to a single interface connection point. The interface connection will be one (later)-inch NPT connection.

4) The interface location for the dry air system connection is on the top of the Furnace 
Glovebox at Point 32 on Drawing F-0-10-1-020.

\subsubsection{Nitrogen System}

1) The nitrogen system supplies nitrogen to the furnaces during the cooldown period.

2) The nitrogen system must supply nitrogen to the stabilization furnaces during the cooldown period. The nitrogen system supply line to each furnace is normally isolated at all other times. The nitrogen flow to the furnaces is automatically controlled by the furnace controls which open and close a solenoid valve in the nitrogen supply line to each furnace. The nitrogen flow is regulated to between 0.9 and $1.1 \mathrm{cfm}$ by the same flow control valve that regulates the dry air flow. After passing through the furnace, the nitrogen is then vented to the Furnace Glovebox.

3) The required nitrogen flow during the cooldown period is $1.1 \mathrm{cfm}$ per furnace at a maximum pressure of (later) psig at the flow control valve inlet. A solenoid valve and a flow control valve will be provided to control the nitrogen flow to each of the two stabilization furnaces and the nitrogen piping for the two furnaces will be piped to a single interface connection point. The interface connection will be one (later)-inch NPT connection.

4) The interface location for the nitrogen system connection is on the top of the Furnace Glovebox at Point 33 on Drawing F-0-10-1-020.

\subsubsection{120 Volt AC Power Supply System}

The 120 volt ac power supply system provides power to the furnace control system that supplies power to the solenoid valves that control the plant air flow to the stabilization furnace door cylinder operators and to the solenoid valves that control the dry air and nitrogen flow to the stabilization furnaces. There are no external 120 volt ac power supply interface connections specifically for the furnace control system. Power for the control system is provided by the 120 volt ac distribution system described in Section (later). All wiring between the 120 volt ac distribution panel and the furnace control system will be furnished and installed by BNFL.

\subsubsection{5 $\quad 480$ Volt ac Power Supply System}

The 480 volt ac power supply system provides power to the heating elements in the two stabilization furnaces. There are no external 480 volt ac power supply interface connections specifically for the two furnaces. Power for the two furnaces is provided by the 480 volt ac distribution system described in Section 20.11.1.1. All wiring between the 480 volt ac distribution panel and the furnaces will be furnished and installed by BNFL.

\subsection{LOI TEST AREA}




\subsubsection{LOI Glovebox}

The purpose of the LOI Glovebox is to confine radioactive materials within the glovebox, shield the operators from the radiation sources within the glovebox, contain the inert (nitrogen) atmosphere within the glovebox, and provide structural support for the equipment associated with the glovebox.

External System Interfaces:

\subsubsection{Inert Ventilation System}

1) The inert ventilation system maintains the required nitrogen inerted environment in the glovebox and maintains the required negative pressure in the glovebox with respect to the room. The system also automatically provides sufficient emergency exhaust flow to maintain a minimum face velocity of $150 \mathrm{ft} / \mathrm{min}$ across the larger of one open gloveport or the largest credible breach in the glovebox.

2) The inert ventilation system must maintain the required negative pressure in the glovebox with respect to the room during all modes of Pu SPS system operation. The system must maintain the nitrogen inerted environment in the glovebox whenever operations involving pyrophoric plutonium are performed.

3) The LOI Glovebox is open to the Transport Glovebox and the required inert ventilation system supply flow to the LOI Glovebox provides part of the supply flow to the Transport Glovebox. The required supply flow to the LOI Glovebox from the plenum PL-102 supply system is (later) cfm. The supply interface connection will be a (later)-inch 150 lb RF flange. The balancing valve in the supply ductwork will be furnished and installed by RFETS. The required exhaust flow from this glovebox is exhausted through the Material Preparation Glovebox as described in Section 20.2.1.1.

4) The interface location for the inert ventilation system supply connection to the LOI Glovebox is on top of the glovebox at Point 34 on Drawing F-0-10-1-020.

\subsubsection{Oxygen Analyzer}

There are no external system interface connections to the oxygen analyzer on the LOI Glovebox. The oxygen monitoring requirements are provided for as described in Section 20.2.1.2 above.

\subsubsection{Glovebox Overheat Detection System}

1) The glovebox overheat detection system monitors the temperature in the glovebox to provide an alarm locally (a chime inside the module) and at the Central Alarm Station and the Fire Dispatch Center in the event of a high temperature or fire condition in the 
glovebox.

2) The glovebox overheat detection system must be operable during all modes of Pu SPS system operation.

3) The interface connection for the glovebox overheat detection system will be one 2-inch NPT threaded connection in a welded reinforced base in accordance with RFETS Drawing 31200-443-M. The overheat detector assembly, detector sleeve, and external wiring will be furnished and installed by RFETS.

4) The interface location for the glovebox overheat detection system connection is on the top of the LOI Glovebox at Point 35 on Drawing F-0-10-1-020.

\subsubsection{120 Volt AC Power Supply System}

1) The 120 volt ac power supply system provides power to the LOI Glovebox lighting; to the internal equipment including the sample scale, furnace controls, and sample dessicator controls; and to spare electrical receptacles.

2) The 120 volt ac power supply system must supply power to the LOI Glovebox lighting, internal equipment, and to the spare electrical receptacles during all normal modes of $\mathrm{Pu}$ SPS System operation.

3) The interface connection for the 120 volt ac power supply to the glovebox lighting will be a 2-pole, 3-wire grounding plug that will plug into an overhead receptacle provided by RFETS. Power for the internal equipment and spare electrical receptacles is provided by the 120 volt ac distribution system described in Section 20.11.1.2. All wiring between the 120 volt ac distribution panel and the internal equipment and spare electrical receptacles will be furnished and installed by BNFL.

4) The interface location for the 120 volt ac power supply connection to the glovebox lighting will be an overhead receptacle strip at Point 36 on Drawing F-0-10-1-020.

\subsubsection{LOI Furnace}

The purpose of the LOI furnace is to test samples of stabilized $\mathrm{Pu}$ oxide to verify that there is less than 0.5 percent mass loss on ignition (LOI) by maintaining the sample at $1000^{\circ} \mathrm{C}$ in an oxidizing atmosphere for a minimum of one hour.

External System Interfaces:

20.5.2.1 Plant Air System 
1) The plant air system supplies air to the LOI furnace door cylinder operator.

2) The plant air system must supply air to the LOI furnace door cylinder operator during all normal modes of Pu SPS System operation.

3) The required plant air flow when operating the LOI furnace door is (later) cfm at a minimum pressure of (later) psig. A solenoid valve will be provided to control the plant air flow to the cylinder operator. The interface connection will be one (later)-inch NPT connection.

4) The interface location for the plant air system connection to the LOI furnace door cylinder is on the top of the LOI Glovebox at Point 37 shown on Drawing F-0-10-1-020.

\subsubsection{Dry Air System}

1) The dry air system supplies air with less than $1000 \mathrm{ppm}$ moisture to the LOI furnace to provide the required oxidizing atmosphere during the LOI test period.

2) The dry air system must supply dry air to the LOI furnace during the test period. The dry air system supply line to the LOI furnace is normally isolated at all other times. The dry air flow to the furnace is automatically controlled by the furnace controls which open and close a solenoid valve in the air supply line to the furnace. The dry air flow is regulated to between 0.9 and $1.1 \mathrm{cfm}$ by a flow control valve in the air supply line downstream of the solenoid valve. After passing through the furnace, the air is then vented to the LOI Glovebox.

3) The required dry air flow when operating the furnace is $1.1 \mathrm{cfm}$ at a maximum pressure of (later) psig at the flow control valve inlet with a maximum moisture content of 1000 $\mathrm{ppm}$. A solenoid valve, pressure control valve, and a flow control valve will be provided to control the dry air flow to the LOI furnace. The interface connection will be one (later)-inch NPT connection.

4) The interface location for the dry air system connection is on the top of the LOI Glovebox at Point 38 on Drawing F-0-10-1-020.

\subsubsection{Nitrogen System}

1) The nitrogen system supplies nitrogen to the LOI furnace during the cooldown period.

2) The nitrogen system must supply nitrogen to the LOI furnace during the cooldown period. The nitrogen system supply line to the furnace is normally isolated at all other times. The nitrogen flow to the furnace is automatically controlled by the furnace controls which open and close a solenoid valve in the nitrogen supply line to the furnace. The nitrogen flow 
is regulated to between 0.9 and $1.1 \mathrm{cfm}$ by the same flow control valve that regulates the dry air flow. After passing through the furnace, the nitrogen is then vented to the LOI Glovebox.

3) The required nitrogen flow during the cooldown period is $1.1 \mathrm{cfm}$ at a maximum pressure of (later) psig at the flow control valve inlet. A solenoid valve and a flow control valve will be provided to control the nitrogen flow to the LOI furnace. The interface connection will be one (later)-inch NPT connection.

4) The interface location for the nitrogen system connection is on the top of the LOI Glovebox at Point 39 on Drawing F-0-10-1-020.

\subsubsection{120 Volt AC Power Supply System}

The 120 volt ac power supply system provides power to the furnace control system that supplies power to the solenoid valves that control the plant air flow to the LOI furnace door cylinder operator and to the solenoid valves that control the dry air and nitrogen flow to the LOI furnace. There are no external 120 volt ac power supply interface connections specifically for the furnace control system. Power for the control system is provided by the 120 volt ac distribution system as described in Section 20.5.1.4 (3) above.

\subsubsection{5 $\quad 480$ Volt AC Power Supply}

The 480 volt ac power supply provides power to the heating elements in the LOI furnace. There are no external 480 volt ac power supply interface connections specifically for the LOI furnace. Power for the furnace is provided by the 480 volt ac distribution system described in Section (later). All wiring between the 480 volt ac distribution panel and the furnace will be furnished and installed by BNFL.

\subsubsection{Sample Scale}

The purpose of the sample scale is to weigh the Pu oxide samples before and after LOI testing.

External System Interfaces:

There are no external system interface connections specifically for the sample scale. Power for the sample scale is provided by the 120 volt ac distribution system as described in Section 20.5.1.4 (3) above.

\subsubsection{Sample Desiccator}

The purpose of the sample desiccator is to provide an ultra dry atmosphere for the Pu oxide sample during the LOI test cooldown period. 


\subsubsection{Nitrogen System}

1) The nitrogen system supplies nitrogen with less than $100 \mathrm{ppm}$ moisture to the sample desiccator to provide the required ultra dry atmosphere during the LOI test cooldown period.

2) The nitrogen system must supply nitrogen to the sample desiccator during the cooldown period. The nitrogen system supply line to the sample desiccator is normally isolated at all other times. The nitrogen flow to the sample desiccator is controlled by the desiccator controls which open and close a solenoid valve in the nitrogen supply line. The nitrogen flow is regulated by a flow control valve in the nitrogen supply line downstream of the solenoid valve. After passing through the desiccator, the nitrogen is then vented to the LOI Glovebox.

3) The required nitrogen flow when operating the sample desiccator is (later) $\mathrm{cfm}$ at a maximum pressure of (later) psig at the flow control valve inlet with a maximum moisture content of $100 \mathrm{ppm}$. A solenoid valve, pressure control valve, and a flow control valve will be provided to control the nitrogen flow to the desiccator. The interface connection will be one (later)-inch NPT connection.

4) The interface location for the nitrogen system connection is on top of the LOI Glovebox at Point 40 on Drawing F-0-10-1-020.

\subsubsection{120 Volt AC Power Supply System}

The 120 volt ac power supply system provides power to the desiccator control system that supplies power to the solenoid valve that controls the nitrogen flow to the desiccator. There are no external 120 volt ac power supply interface connections specifically for the desiccator control system. Power for the control system is provided by the 120 volt ac distribution system as described in Section 20.5.1.4 (3) above.

\subsection{TIPPING/DISPENSE/FILL AREA}

\subsubsection{Tipping and Dispense/Fill Gloveboxes}

The purpose of the Tipping and Dispense/Fill Gloveboxes is to confine radioactive materials within the gloveboxes, shield the operators from the radiation sources within the gloveboxes, contain the inert (nitrogen) atmosphere within the gloveboxes, and provide structural support for the equipment associated with the gloveboxes.

External System Interfaces:

20.6.1.1 Inert Ventilation System 
1) The inert ventilation system maintains the required nitrogen inerted environment in the Tipping and Dispense/Fill Gloveboxes and maintains the required negative pressure in the gloveboxes with respect to the room. The system also automatically provides sufficient emergency exhaust flow to maintain a minimum face velocity of $150 \mathrm{ft} / \mathrm{min}$ across the larger of one open gloveport or the largest credible breach in the gloveboxes.

2) The inert ventilation system must maintain the required negative pressure in the gloveboxes with respect to the room during all modes of Pu SPS system operation. The system must maintain the nitrogen inerted environment in the gloveboxes whenever operations involving pyrophoric plutonium are performed.

3) The Tipping/Dispense/Fill Area is made up of the Tipping Glovebox and Dispense/Fill Glovebox. The required inert ventilation system supply flow to the two gloveboxes is provided at the Dispense/Fill Glovebox end and the required exhaust flow is porovided at the Tipping Glovebox end. The required supply flow to the Dispense/Fill Glovebox from the plenum PL-102 Supply System is (later) cfm. The supply interface connection will be a (later)-inch $150 \mathrm{lb}$ RF flange. The balancing valve in the supply ductwork will be furnished and installed by RFETS. The Tipping Glovebox is open to the Transport Glovebox and the exhaust from the Tipping Glovebox exhausts from both areas. The required normal exhaust flow from the Tipping Glovebox to the plenum PL-102 Exhaust System is (later) cfm. The normal exhaust interface connection will be a (later)-inch 150 lb RF flange. The required emergency exhaust flow to the plenum PL-102 Exhaust System is (later) $\mathrm{cfm}$. The dump valve interface connection will be a (later)-inch $150 \mathrm{lb}$ RF flange. The dump valve Photohelic sensing line interface connection will be a $1 / 4$ inch $3000 \mathrm{lb}$ NPT threaded coupling. The dump valve Photohelic gage mounting bracket interface connection will be two $1 / 4-20 \times 1 / 2$ inch long weld studs on the top of the glovebox per RFP Standard SMU-301. The balancing valve and local flow indicator in the normal exhaust ductwork will be furnished and installed by RFETS. The emergency exhaust dump valve and all dump valve controls including the Photohelic gage and mounting bracket, sensing line tubing and accessories, dump valve air supply piping and solenoid valve, 120 volt ac power supply to the Photohelic gage, and wiring between the Photohelic gage and the solenoid valve will be furnished and installed by RFETS.

4) The interface location for the inert ventilation system supply connection is on top of the Dispense/Fill Glovebox at Point 41 on Drawing F-0-10-1-021. The interface location for the normal exhaust connection is on the top of the Tipping Glovebox at Point 42. The emergency exhaust connection is on the top of the Tipping Glovebox at Point 43 and the Photohelic sensing line and gage bracket connections are on the top of the Tipping Glovebox at Point 44.

20.6.1.2 Oxygen Analyzer

1) The oxygen analyzer monitors the inert atmosphere in the Tipping and Dispense/Fill 
Gloveboxes and also in the Furnace and Transport Gloveboxes to ensure that the oxygen concentration does not exceed 5 percent by volume. The oxygen analyzer draws a sample from the Tipping Glovebox exhaust ductwork and sounds an alarm locally and in the Building 707 Control Room when the oxygen concentration exceeds 5 percent.

2) The oxygen analyzer must be operable whenever operations involving pyrophoric plutonium are performed.

3) The oxygen analyzer piping to the Tipping Glovebox exhaust ductwork will be designed, furnished, and installed by RFETS.

4) There is no interface connection for the oxygen analyzer in the Tipping/Dispense/Fill Glovebox.

\subsubsection{Glovebox Overheat Detection System}

1) The glovebox overheat detection system monitors the temperature in the glovebox to provide an alarm locally (a chime inside the module) and at the Central Alarm Station and the Fire Dispatch Center in the event of a high temperature or fire condition in the glovebox.

2) The glovebox overheat detection system must be operable during all modes of Pu SPS system operation.

3) The interface connection for the glovebox overheat detection system will be two 2-inch NPT threaded connections in welded reinforced bases in accordance with RFETS Drawing 31200-443-M. The overheat detector assemblies, detector sleeves, and external wiring will be furnished and installed by RFETS.

4) The interface locations for the glovebox overheat detection system connections are on the top of the Tipping Glovebox at Point 45 and on top of the Dispense/Fill Glovebox at point 46 on Drawing F-0-10-1-021.

\subsubsection{Nitrogen System}

1) The nitrogen system supplies nitrogen to the pneumatic actuators on the internal equipment including the elevator/transpose unit, tipper, convenience can transfer unit, and the convenience can carousel and handling equipment.

2) The nitrogen system must supply nitrogen to the internal equipment pneumatic actuators during all normal modes of Pu SPS System operation.

3) The required nitrogen flow when operating the pneumatic actuators is (later) $\mathrm{cfm}$ at a minimum pressure of (later) psig. A solenoid valve will be provided to control the 
nitrogen flow to each actuator and the nitrogen piping will be piped to a single interface connection point. The interface connection will be one (later)-inch $3000 \mathrm{lb}$ NPT threaded coupling.

4) The interface location for the nitrogen system connection is on the top of the Tipping Glovebox at Point 47 on Drawing F-0-10-1-021.

20.6.1.5 120 Volt AC Power Supply System

1) The 120 volt ac power supply system provides power to the Tipping Glovebox and Dispense/Fill Glovebox lighting; to the internal equipment including the pneumatic control solenoid valves, convenience can scale, and bar code reader; and to spare electrical receptacles.

2) The 120 volt ac power supply system must supply power to the Tipping Glovebox and Dispense/Fill Glovebox lighting, internal equipment, and to the spare receptacles during all normal modes of Pu SPS System operation.

3) The interface connections for the 120 volt ac power supply to the glovebox lighting will be 2-pole, 3-wire grounding plugs that will plug into an overhead receptacle strip provided by RFETS. Power for the internal equipment and spare receptacles is provided by the 120 volt ac distribution system described in Section 20.11.1.2. All wiring between the 120 volt ac distribution panel and the internal equipment and spare electrical receptacles will be furnished and installed by BNFL.

4) The interface location for the 120 volt ac power supply connection to the glovebox lighting will be an overhead receptacle strip at Point 48 on Drawing F-0-10-1-021.

\subsubsection{Elevator/Transpose Unit}

The purpose of the elevator/transpose unit is to transfer the furnace trays from the can/tray handler to the tipper.

External System Interfaces:

There are no external system interface connections specifically for the elevator/transpose unit. Power for the elevator/transpose unit motor is provided by the 480 volt ac distribution system described in Section 20.11.1.1. All wiring between the 480 volt ac distribution panel and the elevator/transpose unit will be furnished and installed by BNFL. Nitrogen for the pneumatic actuator is provided by the nitrogen system as described in Section 20.6.1.4 (3) above. Power for the pneumatic actuator solenoid valve is provided by the 120 volt ac distribution system as described in Section 20.6.1.5 (3) above. 


\subsubsection{Tipper}

The purpose of the tipper is to empty the $\mathrm{Pu}$ oxide in the furnace trays into convenience cans.

External System Interfaces:

There are no external system interface connections specifically for the tipper. Power for the tipper motor and electric tray clamp is provided by the 480 volt ac distribution system described in Section 20.11.1.1. All wiring between the 480 volt ac distribution panel and the tipper will be furnished and installed by BNFL. Nitrogen for the pneumatic valve actuator is provided by the nitrogen system as described in Section 20.6.1.4 (3) above. Power for the pneumatic valve actuator solenoid valve is provided by the 120 volt ac distribution system as described in Section 20.6.1.5 (3) above.

\subsubsection{Convenience Can Transfer Unit}

The purpose of the convenience can transfer unit is to move convenience cans of $\mathrm{Pu}$ metal in the Tipping and Dispense/Fill Gloveboxes.

\section{External System Interfaces:}

There are no external system interface connections specifically for the convenience can transfer unit. Power for the convenience can transfer unit electromagnet is provided by the 480 volt ac distribution system described in Section 20.11.1.1. All wiring between the 480 volt ac distribution panel and the convenience can transfer unit will be furnished and installed by BNFL. Nitrogen for the pneumatic actuators is provided by the nitrogen system as described in Section 20.6.1.4 (3) above. Power for the pneumatic actuator solenoid valves is provided by the 120 volt ac distribution system as described in Section 20.6.1.5 (3) above.

\subsubsection{Convenience Can Carousel and Handling Equipment}

The purpose of the convenience can carousel and handling equipment is to move convenience cans from the convenience can transfer unit and the can fill station into the gaslock.

\section{External System Interfaces:}

There are no external system interface connections specifically for the convenience can carousel and handling equipment. Power for the convenience can carousel motor is provided by the 480 volt ac distribution system described in Section 20.11.1.1. All wiring between the 480 volt ac distribution panel and the convenience can handler will be furnished and installed by BNFL. Nitrogen for the pneumatic actuators is provided by the nitrogen system as described in Section 20.6.1.4 (3) above. Power for the pneumatic actuator solenoid valves is provided by the 120 volt 
ac distribution system as described in Section 20.6.1.5 (3) above.

20.6.6

\section{Can Fill Station Scale}

The purpose of the can fill station scale is to weigh the convenience cans containing Pu oxide.

External System Interfaces:

There are no external system interface connections specifically for the convenience can scale. Power for the convenience can scale is provided by the 120 volt ac distribution system as described in Section 20.6.1.5 (3) above.

\subsubsection{Bar Code Reader}

The purpose of the bar code reader is to read the bar code on the incoming convenience cans that will be filled with $\mathrm{Pu}$ oxide.

External System Interfaces:

There are no external system interface connections specifically for the bar code reader. Power for the bar code reader is provided by the 120 volt ac distribution system as described in Section 20.6.1.5 (3) above.

\subsection{CAN WEIGH AND CAP INSERTION AREA}

\subsubsection{Can Weigh and Cap Insertion Glovebox}

The purpose of the Can Weigh and Cap Insertion Glovebox is to confine radioactive materials within the glovebox, shield the operators from the radiation sources within the glovebox, contain the inert (helium) atmosphere within the glovebox, and provide structural support for the equipment associated with the glovebox.

External System Interfaces:

20.7.1.1 Downdraft System

1) The downdraft system maintains the required negative pressure in the glovebox with respect to the room. The system also automatically provides sufficient emergency exhaust flow to maintain a minimum face velocity of $150 \mathrm{ft} / \mathrm{min}$ across the larger of one open gloveport or the largest credible breach in the glovebox.

2) The downdraft system must maintain the required negative pressure in the glovebox with 
respect to the room during all modes of Pu SPS system operation.

3) The required normal exhaust flow to the plenum PL-104 Exhaust System from the Can Weigh and Cap Insertion Glovebox is (later) cfm. The normal exhaust interface connection will be a (later)-inch $150 \mathrm{lb}$ RF flange. The required emergency exhaust flow to the plenum PL-104 Exhaust System is (later) cfm. The dump valve interface connection will be a (later)-inch $150 \mathrm{lb}$ RF flange. The dump valve Photohelic sensing line interface connection will be a $1 / 4$ inch $3000 \mathrm{lb}$ NPT threaded coupling. The dump valve Photohelic gage mounting bracket interface connection will be two 1/4-20 X 1/2 inch long weld studs on the top of the glovebox per RFP Standard SMU-301. The balancing valve and local flow indicator in the normal exhaust ductwork will be furnished and installed by RFETS. The emergency exhaust dump valve and all dump valve controls including the Photohelic gage and mounting bracket, sensing line tubing and accessories, dump valve air supply piping and solenoid valve, 120 volt ac power supply to the Photohelic gage, and wiring between the Photohelic gage and the solenoid valve will be furnished and installed by RFETS.

4) The interface location for the normal exhaust connection is on the top of the glovebox at Point 49 shown on Drawing F-0-10-1-021. The emergency exhaust connection is on the top of the glovebox at Point 50 and the Photohelic sensing line and gage bracket connections are on the top of the glovebox at Point 51.

20.7.1.2 Helium System

1) The helium system maintains the required inerted environment in the glovebox.

2) The helium system must maintain the helium inerted environment in the glovebox whenever operations involving pyrophoric plutonium are performed.

3) The required supply flow to the Can Weigh and Cap Insertion Glovebox from the helium system is (later) cfm at a maximum pressure of (later) psig at the flow control valve inlet. A pressure control valve and a flow control valve will be provided to control the helium flow to the glovebox. The supply interface connection will be a (later)-inch NPT connection.

4) The interface location for the helium system supply connection is on the top of the Can Weigh and Cap Insertion Glovebox at Point 52 shown on Drawing F-0-10-1-021.

\subsubsection{Oxygen Analyzer}

1) The oxygen analyzer monitors the inert atmosphere in the glovebox to ensure that the oxygen concentration does not exceed 5 percent by volume. The oxygen analyzer draws a sample from the glovebox exhaust ductwork and sounds an alarm locally and in the 
Building 707 Control Room when the oxygen concentration exceeds 5 percent.

2) The oxygen analyzer must be operable whenever operations involving pyrophoric plutonium are performed.

3) The oxygen analyzer piping to the glovebox exhaust ductwork will be designed, fumished, and installed by RFETS.

4) There is no interface connection for the oxygen analyzer in the Can Weigh and Cap Insertion Glovebox.

\subsubsection{Glovebox Overheat Detection System}

1) The glovebox overheat detection system monitors the temperature in the glovebox to provide an alarm locally (a chime inside the module) and at the Central Alarm Station and the Fire Dispatch Center in the event of a high temperature or fire condition in the glovebox.

2) The glovebox overheat detection system must be operable during all modes of Pu SPS system operation.

3) The interface connection for the glovebox overheat detection system will be one 2-inch NPT threaded connection in a welded reinforced base in accordance with RFETS Drawing 31200-443-M. The overheat detector assembly, detector sleeve, and external wiring will be furnished and installed by RFETS.

4) The interface location for the glovebox overheat detection system connection is on the top of the Can Weigh and Cap Insertion Glovebox at Point 53 on Drawing F-0-10-1-021.

\subsubsection{Nitrogen System}

1) The nitrogen system supplies nitrogen to the pneumatic actuators on the internal and external equipment including the convenience can extraction unit, convenience can turntable, convenience can pusher, and intermediate cap magazine.

2) The nitrogen system must supply nitrogen to the pneumatic actuators on the internal and external equipment during all normal modes of Pu SPS System operation.

3) The required nitrogen flow when operating the pneumatic actuators is (later) $\mathrm{cfm}$ at a minimum pressure of (later) psig. A solenoid valve will be provided to control the nitrogen flow to each actuator and the nitrogen piping will be piped to a single interface connection point. The interface connection will be one (later)-inch $3000 \mathrm{lb}$ NPT threaded coupling. In order to prevent dilution of the helium atmosphere in the glovebox, the 
exhaust ports on the actuators inside the glovebox will be piped to a single interface connection point that will be piped to the external downdraft system exhaust ductwork. The interface connection will be one (later)-inch $3000 \mathrm{lb}$ NPT threaded coupling. The external piping between the interface connection and the downdraft system exhaust ductwork will be furnished and installed by RFETS.

4) The interface location for the nitrogen system supply connection is on the top of the Can Weigh and Cap Insertion Glovebox at Point 54 on Drawing F-0-10-1-021. The nitrogen system exhaust connection is on top of the glovebox at Point 55.

20.7.1.6 120 Volt AC Power Supply System

1) The 120 volt ac power supply system provides power to the Can Weigh and Cap Ins ertion Glovebox lighting; to the internal and external equipment including the pneumatic control solenoid valves, convenience can scale, and bar code reader; and to spare electrical receptacles.

2) The 120 volt ac power supply system must supply power to the Can Weigh and Cap Insertion Glovebox lighting, internal and external equipment, and to the spare electrical receptacles during all normal modes of Pu SPS System operation.

3) The interface connection for the 120 volt ac power supply to the glovebox lighting will be a 2-pole, 3-wire grounding plug that will plug into an overhead receptacle provided by RFETS. Power for the internal and external equipment and spare electrical receptacles is provided by the 120 volt ac distribution system described in Section 20.11.1.2. All wiring between the 120 volt ac distribution panel and the internal and external equipment and spare electrical receptacles will be furnished and installed by BNFL.

4) The interface location for the 120 volt ac power supply to the glovebox lighting will be an overhead receptacle strip at Point 56 on Drawing F-0-10-1-021.

\subsubsection{Gaslock}

The purpose of the gaslock is to transfer convenience cans from the nitrogen atmosphere in the Dispense/Fill Glovebox to the helium atmosphere in the Can Weigh and Cap Insertion Glovebox.

External System Interfaces:

\subsubsection{Downdraft System}

1) The downdraft system exhausts air from the gaslock to provide the capability to purge the gaslock during purge and backfill operations when the gaslock atmosphere is changed from a nitrogen inerted atmosphere to a helium inerted atmosphere or from a helium inerted 
atmosphere to a nitrogen inerted atmosphere.

2) The downdraft system must exhaust air from the gaslock during purge and backfill operations before either gaslock valve is opened. The downdraft system exhaust line from the gaslock is normally isolated at all other times.

3) The required exhaust flow from the gaslock to the plenum PL-104 Exhaust System during purge and backfill operations is (later) $\mathrm{cfm}$. The interface connection will be a (later)-inch $150 \mathrm{lb}$ RF flange. The balancing valve, local flow indicator, and the air operated isolation valve in the exhaust ductwork will be furnished and installed by RFETS.

4) The interface location for the downdraft system exhaust connection is on the top of the Can Weigh and Cap Insertion Glovebox at Point 57 shown on Drawing F-0-10-1-021.

\subsubsection{Inert Ventilation System}

1) The inert ventilation system provides the capability to backfill the gaslock with the nitrogen inerted atmosphere before the gaslock is opened to the Dispense/Fill Glovebox.

2) The inert ventilation system is used to backfill the gaslock before the gaslock will be opened to the Dispense/Fill Glovebox. The inert ventilation system supply line to the gaslock is normally isolated at all other times.

3) The required supply flow to the gaslock from the plenum PL-102 Supply System during backfill operations is (later) $\mathrm{cfm}$. The supply interface connection will be a (later)-inch $150 \mathrm{lb}$ RF flange. The balancing valve and the air operated isolation valve in the supply ductwork will be furnished and installed by RFETS.

4) The interface locations for the inert ventilation system supply connection is on the top of the Can Weigh and Cap Insertion Glovebox at Point 58 on Drawing F-0-10-1-021.

20.7.2.3 Helium System

1) The helium system provides the capability to backfill the gaslock with the helium inerted atmosphere before the gaslock is opened to the Can Weigh and Cap Insertion Glovebox.

2) The helium system is used to backfill the gaslock before the gaslock will be opened to the Can Weigh and Cap Insertion Glovebox. The helium system backfill supply line to the gaslock is normally isolated at all other times.

3) The required supply flow to the gaslock from the helium system during backfill operations is (later) cfm at a maximum pressure of (later) psig at the flow control valve inlet. A solenoid valve, pressure control valve, and a flow control valve will be provided to control 
the helium flow to the gaslock. The supply interface connection will be a (later)-inch NPT connection.

4) The interface location for the helium system supply connection is on the top of the Can Weigh and Cap Insertion Glovebox at Point 59 on Drawing F-0-10-1-021.

\subsubsection{Plant Air System}

1) The plant air system supplies air to the two gaslock valve operators, to the downdraft system exhaust valve operator, and to the inert ventilation system supply valve operator.

2) The plant air system must supply air to the gaslock valve operators, to the downdraft system exhaust valve operator, and to the inert ventilation system supply valve operator during all normal modes of Pu SPS System operation.

3) The required plant air flow when operating the gaslock valves is (later) $\mathrm{cfm}$ at a minimum pressure of (later) psig. A solenoid valve will be provided to control the plant air flow to each of the two gaslock valve operators and the air piping for the two operators will be piped to a single interface connection point. The interface connection will be one (later)inch NPT connection. The plant air flow and connection requirements for the downdraft system exhaust valve and the inert ventilation system supply valve will be determined by RFETS.

4) The interface location for the plant air system connection to the gaslock valve operators is on the top of the Can Weigh and Cap Insertion Glovebox at Point 60 shown on Drawing F-0-10-1-021.

\subsubsection{5 $\quad 120$ Volt AC Power Supply System}

1) The 120 volt ac power supply system provides power to the control system that supplies power to the solenoid valves that control the plant air flow to the gaslock valve operators, and the helium backfill flow to the gaslock. The control system also provides power to the solenoid valves that control the operation of the gaslock downdraft system exhaust valve and the inert ventilation system supply valve.

2) The 120 volt ac power supply system must supply power to the gaslock control system during all normal modes of Pu SPS System operation. The gaslock valves are manually controlled at a local pushbutton station. The gaslock valve controls are interlocked to ensure that a gaslock valve cannot be opened unless the other gaslock valve is fully closed during all modes of Pu SPS system operation. The gaslock downdraft system exhaust valve, the inert ventilation system supply valve, and the helium backfill supply valve are also manually controlled at the local pushbutton station. The two gaslock valves are normally closed. The gaslock downdraft system exhaust valve, the inert ventilation system 
supply valve, and the helium backfill supply valve are normally closed. When the gaslock is to be opened to transfer a convenience can from the Tipping/Dispense/Fill Glovebox to the Intermediate Cap Insertion Glovebox, the downdraft system exhaust valve would be opened and the inert ventilation system supply valve would be opened to backfill the gaslock with the nitrogen inerted atmosphere. These valves would then be closed before opening the gaslock valve on the Tipping/Dispense/Fill Glovebox side of the gaslock. After the convenience can is transfered into the gaslock, the gaslock valve would be closed. The downdraft system exhaust valve and the helium backfill supply valve would then be opened to backfill the airlock with the helium inerted atmosphere. These valves would then be closed before opening the gaslock valve on the Intermediate Cap Insertion Glovebox side of the slock. After the convenience can is transfered into the Intermediate Cap Insertion Glovebox, the gaslock valve would be closed.

3) Power for the gaslock valve control system is provided by the 120 volt ac distribution system described in Section 20.11.1.2. All wiring between the 120 volt ac distribution panel and the control devices furnished by BNFL will be furnished and installed by BNFL. The interface connections for the 120 volt ac power supply from the control system to the solenoid valves controlling the inert ventilation system supply valve and the downdraft system exhaust valve that will be furnished and installed by RFETS will be on a terminal strip in the pneumatic valve panel (later).

4) The interface locations for the 120 volt ac power supply connections from the gaslock valve control system to the inert ventilation system supply valve and the downdraft system exhaust valve are in pneumatic valve panel (later) at Point 61 on Drawing F-0-10-1-021.

Convenience Can Extraction Unit

The purpose of the convenience can extraction unit is to transfer the convenience cans from the gaslock to the convenience can turntable.

External System Interfaces:

There are no external system interface connections specifically for the convenience can extraction unit. Nitrogen for the pneumatic actuator is provided by the nitrogen system as described in Section 20.7.1.5 (3) above. Power for the pneumatic actuator solenoid valve is provided by the 120 volt ac distribution system as described in Section 20.7.1.6 (3) above.

\subsubsection{Convenience Can Turntable}

The purpose of the convenience can turntable is to handle the convenience cans in the Can Weigh and Cap Insertion Glovebox.

External System Interfaces: 
There are no external system interface connections specifically for the convenience can turntable. Nitrogen for the pneumatic actuators is provided by the nitrogen system as described in Section 20.7.1.5 (3) above. Power for the pneumatic actuator solenoid valves is provided by the 120 volt ac distribution system as described in Section 20.7.1.6 (3) above.

\subsubsection{Convenience Can Pusher}

The purpose of the convenience can pusher is to push a convenience can and intermediate can cap into an intermediate can located in the rotating sphincter seal.

External System Interfaces:

There are no external system interface connections specifically for the convenience can pusher. Nitrogen for the pneumatic actuator is provided by the nitrogen system as described in Section 20.7.1.5 (3) above. Power for the pneumatic actuator solenoid valve is provided by the 120 volt ac distribution system as described in Section 20.7.1.6 (3) above.

20.7.6

Intermediate Cap Magazine

The purpose of the intermediate cap magazine is to stage intermediate can caps in the Can Weigh and Cap Insertion Glovebox.

External System Interfaces:

There are no external system interface connections specifically for the intermediate cap magazine. Nitrogen for the pneumatic actuator is provided by the nitrogen system as described in Section 20.7.1.5 (3) above. Power for the pneumatic actuator solenoid valve is provided by the 120 volt ac distribution system as described in Section 20.7.1.6 (3) above.

\subsubsection{Intermediate Can Post Out Rotating Sphincter}

The purpose of the intermediate can post out rotating sphincter is to rotate the intermediate cans during welding and cutting operations, and to transfer sealed intermediate cans from the helium atmosphere in the Can Weigh and Cap Insertion Glovebox to the air atmosphere in the Fume Cabinet.

External System Interfaces:

There are no external system interface connections specifically for the intermediate can post out rotating sphincter. Power for the rotating sphincter motor is provided by the 480 volt ac distribution system described in Section 20.11.1.1. All wiring between the 480 volt ac distribution panel and the rotating sphincter will be furnished and installed by BNFL. 


\subsubsection{Convenience Can Weigh Unit}

The purpose of the convenience can weigh unit is to weigh the convenience cans containing $\mathrm{Pu}$ metal and oxide.

External System Interfaces:

There are no external system interfaces specifically for the convenience can weigh unit. Power for the convenience can weigh unit is provided by the glovebox 120 volt ac distribution system described in Section 20.7.1.6 (3) above.

20.7.9 Bar Code Reader

The purpose of the bar code reader is to read the bar code on the incoming convenience cans containing Pu metal and oxide.

External System Interfaces:

There are no external system interfaces specifically for the bar code reader. Power for the bar code reader is provided by the glovebox 120 volt ac distribution system described in Section 20.7.1.6 (3) above.

\subsection{INTERMEDIATE CAN HANDLING AREA}

\subsubsection{Fume Cabinet}

The purpose of the Fume Cabinet is to provide ventilation for the laser welding and cutting operations and to prevent the spread of any loose contamination into the room.

External System Interfaces:

\subsubsection{Downdraft System}

1) The downdraft system maintains the required ventilation flow in the Fume Cabinet. The system also provides sufficient exhaust flow to maintain a minimum face velocity of 150 $\mathrm{ft} / \mathrm{min}$ across the largest opening in the Fume Cabinet.

2) The downdraft system must maintain the required exhaust flow from the Fume Cabinet during all modes of Pu SPS system operation.

3) The required exhaust flow to the plenum PL-104 Exhaust System is (later) cfm. The exhaust interface connection will be a (later)-inch $150 \mathrm{lb} \mathrm{RF}$ flange. 
4) The interface location for the downdraft system exhaust connection is on the top of the glovebox at Point 62 shown on Drawing F-0-10-1-021.

20.8.1.2 Glovebox Overheat Detection System

1) The glovebox overheat detection system monitors the temperature in the Fume Cabinet to provide an alarm locally (a chime inside the module) and at the Central Alarm Station and the Fire Dispatch Center in the event of a high temperature or fire condition in the Fume Cabinet.

2) The glovebox overheat detection system must be operable during all modes of Pu SPS system operation.

3) The interface connection for the glovebox overheat detection system will be one 2-inch NPT threaded connection in a welded reinforced base in accordance with RFETS Drawing 31200-443-M. The overheat detector assembly, detector sleeve, and external wiring will be furnished and installed by RFETS.

4) The interface location for the glovebox overheat detection system is on the top of the Fume Cabinet at Point 63 on Drawing F-0-10-1-021.

\subsubsection{Plant Air System}

1) The plant air system supplies air to the pneumatic actuators on the internal equipment including the welding/cutting head, intermediate can handling unit, and intermediate can storage magazine.

2) The plant air system must supply air to the pneumatic actuators on the internal equipment during all normal modes of Pu SPS System operation.

3) The required plant air flow when operating the pneumatic actuators is (later) cfm at a minimum pressure of (later) psig. A solenoid valve will be provided to control the air flow to each actuator and the plant air piping will be piped to a single interface connection point. The interface connection will be one (later)-inch $3000 \mathrm{lb}$ NPT threaded coupling.

4) The interface location for the plant air system connection is on the top of the Fume Cabinet at Point 64 on Drawing F-0-10-1-021.

20.8.1.4 120 Volt AC Power Supply System

1) The 120 volt ac power supply system provides power to the Fume Cabinet lighting; to the internal equipment including the pneumatic control solenoid valves, and bar code reader; and to spare electrical receptacles. 
2) The 120 volt ac power supply system must supply power to the Fume Cabinet lighting, internal equipment, and to the spare electrical receptacles during all normal modes of $\mathrm{Pu}$ SPS System operation.

3) The interface connection for the 120 volt ac power supply to the glovebox lighting will be a 2-pole, 3-wire grounding plug that will plug into an overhead receptacle provided by RFETS. Power for the internal equipment and spare electrical receptacles is provided by the 120 volt ac distribution system described in Section 20.11.1.2. All wiring between the 120 volt ac distribution panel and the internal equipment and spare electrical receptacles will be furnished and installed by BNFL.

4) The interface location for the 120 volt ac power supply to the Fume Cabinet lighting will be an overhead receptacle strip at Point 65 on Drawing F-0-10-1-021.

Intermediate Can Storage Magazine

The purpose of the intermediate can storage magazine is to stage intermediate cans in the Fume Cabinet.

External System Interfaces:

There are no external system interface connections specifically for the intermediate can storage magazine. Plant air for the pneumatic actuator is provided by the plant air system as described in Section 20.8.1.3 (3) above. Power for the pneumatic actuator solenoid valve is provided by the 120 volt ac distribution system as described in Section 20.8.1.4 (3) above.

\subsubsection{Laser Welding/Cutting Unit}

The purpose of the laser welding/cutting unit is to weld the cap to the intermediate can and to cut the can from the unwanted sealed stub portion of the cap.

External System Interfaces:

\subsubsection{Plant Air System}

The plant air system supplies air to the pneumatic positioner on the welding/cutting head. There is no external plant air interface connection specifically for the welding/cutting head positioner. Air for the positioner is provided by the plant air system as described in Section 20.8.1.3 (3) above.

\subsubsection{Welding Gases}

1) Welding gas consisting of a mixture of nitrogen and helium are used to purge the weld 
zone during welding operations.

2) Welding gases must be supplied to the welding/cutting head when welding operations are performed.

3) The welding gases for the welding head will be stored in high pressure cylinders. The required welding gas flow during welding operations is (later) $\mathrm{cfm}$ at a minimum pressure of (later) psig. A solenoid valve will be provided to control the gas flow to the welding head. The interface connection will be a (later)-inch $3000 \mathrm{lb}$ NPT threaded coupling. The welding gas cylinders, cylinder regulators, and cylinder rack will be furnished and installed by RFETS.

4) The interface location for the welding gas connection is on the top of the Fume Cabinet at Point 66 on Drawing F-0-10-1-021.

20.8.3.3 120 Volt AC Power Supply System

There are no external 120 volt ac power supply system interface connections specifically for the welding/cutting unit controls. Power for the welding/cutting unit controls is provided by the 120 volt ac distribution system as described in Section 20.8.1.4 (3) above.

\subsubsection{Laser Generator}

The purpose of the laser generator is to generate the laser light used for welding and cutting of the intermediate cans.

External System Interfaces:

\subsubsection{480 Volt AC Power Supply}

1) The 480 volt ac power supply provides power to the laser generator.

2) The 480 volt ac power supply must supply power to the laser generator when intermediate can welding/cutting operations are performed.

3) The interface connections for the 480 volt ac power supply for the laser generator will be on a main isolation switch in panel (later). All wiring between the panel and the laser generator will be furnished and installed by BNFL.

4) The interface location for the 480 volt ac power supply for the laser generator is in panel (later) on the second floor of Building 707 at Point 67 on Drawing F-0-10-1-021.

\subsubsection{Process Cooling Water}


1) The process cooling water system provides cooling water to the laser generator.

2) The process cooling water system must supply cooling water to the laser generator during all normal modes of Pu SPS System operation.

3) The required process cooling water flow for the laser generator is (later) gpm at a minimum pressure of (later) psig and a maximum temperature of (later) ${ }^{\circ} \mathrm{F}$. The interface connections for the process cooling water supply and return piping will be (later)-inch NPT connections.

4) The interface location for the process cooling water supply and return piping will be at Point 68 on Drawing F-0-10-1-021.

\subsubsection{Laser Gases}

1) Laser gases consisting of nitrogen, carbon dioxide, and helium are used for the generation of the laser light.

2) Laser gases must be supplied to the laser generator when welding/cutting operations are performed.

3) The laser gases for the laser generator will be stored in high pressure cylinders. The required nitrogen flow during welding/cutting operations is (later) $\mathrm{cfm}$ at a minimum pressure of (later) psig. The required carbon dioxide flow during welding/cutting operations is (later) cfm at a minimum pressure of (later) psig. The required helium flow during welding/cutting operations is (later) $\mathrm{cfm}$ at a minimum pressure of (later) psig. A solenoid valve will be provided to control flow of each gas to the laser generator. The interface connections will be three (later)-inch $3000 \mathrm{lb}$ NPT threaded coupling. The laser gas cylinders, cylinder regulators, and cylinder rack will be furnished and installed by RFETS.

4) The interface location for the laser gas connections is on the top of the Laser Generator at Point 69 on Drawing F-0-10-1-021.

\subsubsection{Intermediate Can Handling Equipment}

The purpose of the intermediate can handling equipment is to handle intermediate cans of $\mathrm{Pu}$ metal and oxide in the Fume Cabinet.

External System Interfaces:

There are no external system interface connections specifically for the intermediate can handling equipment. Plant air for the pneumatic actuators is provided by the plant air system as described 
in Section 20.8.1.3 (3) above. Power for the pneumatic actuator solenoid valves is provided by the 120 volt ac distribution system as described in Section 20.8.1.4 (3) above.

\subsubsection{Bar Code Reader}

The purpose of the bar code reader is to read the bar code on the incomming intermediate cans.

External System Interfaces:

There are no external system interfaces specifically for the bar code reader. Power for the bar code reader is provided by the glovebox 120 volt ac distribution system described in Section 20.8.1.4 (3) above.

\subsection{OUTER CAN WELD AND MONITORING AREA}

\subsubsection{Can Turntable/Trolley and Outer Can Handler}

The purpose of the can turntable/trolley and outer can handler is to handle outer cans in the outer can weld and monitoring area.

External System Interfaces:

\subsubsection{Plant Air System}

1) The plant air system supplies air to the pneumatic motor and actuators on the can turntable/trolley and outer can handler.

2) The plant air system must supply air to the pneumatic motor and actuators during all normal modes of Pu SPS System operation.

3) The required plant air flow when operating the can turntable/trolley and outer can handler pneumatic motor and actuators is (later) $\mathrm{cfm}$ at a minimum pressure of (later) psig. A solenoid valve will be provided to control the air flow to the motor and each actuator and the plant air piping will be piped to a single interface connection point. The interface connection will be one (later)-inch $3000 \mathrm{lb}$ NPT threaded coupling.

4) The interface location for the plant air system connection is on the can turntable/trolley at Point 70 on Drawing F-0-10-1-021.

\subsubsection{2 $\quad 120$ Volt AC Power Supply System}

The 120 volt ac power supply system provides power to the control system that supplies power to the solenoid valves that control the plant air flow to the pneumatic motor and actuators on the 
can turntable/trolley and outer can handler. There are no external 120 volt ac power supply interface connections specifically for the control system. Power for the control system is provided by the 120 volt ac distribution system described in Section 20.11.1.2. All wiring between the 120 volt ac distribution panel and the solenoid valves will be furnished and installed by BNFL.

\subsubsection{Intermediate Can Leak Detection Unit}

The purpose of the intermediate can leak detection unit is to check the welded intermediate cans for leakage.

External System Interfaces:

20.9.2.1 Downdraft System

1) The downdraft system exhausts the discharge gas from the intermediate can leak detection unit vacuum pump.

2) The downdraft system must maintain the required exhaust flow from the vacuum pump during all normal modes of Pu SPS system operation.

3) The required exhaust flow to the plenum PL-104 Exhaust System is (later) cfm. The exhaust interface connection will be a (later)-inch $150 \mathrm{lb}$ RF flange.

4) The interface location for the downdraft system exhaust connection is at the intermediate can leak detection unit at Point 71 shown on Drawing F-0-10-1-021.

\subsubsection{120 Volt AC Power Supply System}

The 120 volt ac power supply system provides power to the intermediate can leak detection unit mass spectrometer. There are no external 120 volt ac power supply interface connections specifically for the mass spectrometer. Power for the mass spectrometer is provided by the 120 volt ac distribution system described in Section 20.11.1.2. All wiring between the 120 volt ac distribution panel and the mass spectrometer will be furnished and installed by BNFL.

\subsubsection{3 $\quad 480$ Volt ac Power Supply System}

The 480 volt ac power supply system provides power to the vacuum pump motor. There are no external 480 volt ac power supply interface connections specifically for the motor. Power for the motor is provided by the 480 volt ac distribution system described in Section 20.11.1.1. All wiring between the 480 volt ac distribution panel and the vacuum pump motor will be furnished and installed by BNFL.

20.9.3 Quter Can Helium Fill/Lid Fitment Unit 
The purpose of the outer can helium fill/lid fittment unit is to backfill the outer can with helium and install the outer can lid prior to welding.

External System Interfaces:

\subsubsection{Downdraft System}

1) The downdraft system exhausts the discharge gas from the outer can helium fill/lid fittment unit vacuum pump.

2) The downdraft system must maintain the required exhaust flow from the vacuum pump during all normal modes of Pu SPS system operation.

3) The required exhaust flow to the plenum PL-104 Exhaust System is (later) cfm. The exhaust interface connection will be a (later)-inch $150 \mathrm{lb}$ RF flange.

4) The interface location for the downdraft system exhaust connection is at the outer can helium fill/lid fittment unit at Point 72 shown on Drawing F-0-10-1-021.

\subsubsection{Helium System}

1) The helium system provides the capability to backfill the outer can with helium before the lid is welded.

2) The helium system is used to backfill the outer can before the lid is welded. The helium system supply line to the outer can helium fill/lid fittment unit is normally isolated at all other times.

3) The required supply flow to the outer can from the helium system during fill operations is (later) $\mathrm{cfm}$ at a maximum pressure of (later) psig at the flow control valve inlet. A solenoid valve, pressure control valve, and a flow control valve will be provided to control the helium flow to the outer can. The supply interface connection will be a (later)-inch NPT connection.

4) The interface location for the helium system supply connection is at the outer can helium fill/lid fittment unit at Point 73 on Drawing F-0-10-1-021.

\subsubsection{120 Volt AC Power Supply System}

The 120 volt ac power supply system provides power to the control system that supplies power to the solenoid valve that controls the helium flow to the outer can. There are no external 120 volt ac power supply interface connections specifically for the control system. Power for the control system is provided by the 120 volt ac distribution system described in Section 20.11.1.2. 
All wiring between the 120 volt ac distribution panel and the solenoid valve will be furnished and installed by BNFL.

\subsubsection{4 $\quad 480$ Volt ac Power Supply System}

The 480 volt ac power supply system provides power to the vacuum pump motor. There are no external 480 volt ac power supply interface connections specifically for the motor. Power for the motor is provided by the 480 volt ac distribution system described in Section 20.11.1.1. All wiring between the 480 volt ac distribution panel and the vacuum pump motor will be furnished and installed by BNFL.

\subsubsection{Resistance Welder}

The purpose of the resistance welder is to weld the lid on the outer can.

External System Interfaces:

\subsubsection{480 Volt AC Power Supply}

1) The 480 volt ac power supply provides power to the resistance welder and to the outer can rotation motor.

2) The 480 volt ac power supply must supply power to the resistance welder and outer can rotation motor when the outer can lid welding operation is performed.

3) The interface connections for the 480 volt ac power supply for the resistance welder will be on a main isolation switch in panel (later). All wiring between the panel and the resistance welder will be furnished and installed by BNFL. There are no external 480 volt ac power supply interface connections specifically for the can rotation motor. Power for the motor is provided by the 480 volt ac distribution system described in Section 20.11.1.1. All wiring between the 480 volt ac distribution panel and the outer can rotation motor will be furnished and installed by BNFL.

4) The interface location for the 480 volt ac power supply for the resistance welder is in panel (later) at Point 74 on Drawing F-0-10-1-021.

\subsubsection{Contamination Check Unit}

The purpose of the contamination check unit is to verify that the outer can is free of external contamination.

External System Interfaces: 
There are no external system interfaces specifically for the contamination check unit. Power for the contamination check unit outer can rotation motor is provided by the 480 volt ac distribution system described in Section 20.11.1.1. All wiring between the 480 volt ac distribution panel and the outer can rotation motor will be furnished and installed by BNFL.

\subsubsection{Quter Can Leak Detection Unit}

The purpose of the leak detection unit is to check the welded outer cans for leakage.

External System Interfaces:

20.9.6.1 Downdraft System

1) The downdraft system exhausts the discharge gas from the leak detection unit vacuum pump.

2) The downdraft system must maintain the required exhaust flow from the vacuum pump during all normal modes of Pu SPS system operation.

3) The required exhaust flow to the plenum PL-104 Exhaust System is (later) cfm. The exhaust interface connection will be a (later)-inch $150 \mathrm{lb}$ RF flange.

4) The interface location for the downdraft system exhaust connection is at the leak detection unit at Point 75 shown on Drawing F-0-10-1-021.

\subsubsection{120 Volt AC Power Supply System}

The 120 volt ac power supply system provides power to the leak detection unit mass spectrometer. There are no external 120 volt ac power supply interface connections specifically for the mass spectrometer. Power for the mass spectrometer is provided by the 120 volt ac distribution system described in Section 20.11.1.2. All wiring between the 120 volt ac distribution panel and the mass spectrometer will be furmished and installed by BNFL.

\subsubsection{3 $\quad 480$ Volt ac Power Supply System}

The 480 volt ac power supply system provides power to the vacuum pump motor. There are no external 480 volt ac power supply interface connections specifically for the motor. Power for the motor is provided by the 480 volt ac distribution system described in Section 20.11.1.1. All wiring between the 480 volt ac distribution panel and the vacuum pump motor will be furnished and installed by BNFL.

\subsection{PuSPS CONTROL SYSTEM}




\subsubsection{Plutonium Stabilization Control System (PSCS)}

The purpose of the Plutonium Stabilization Control System is to control the stabilization process within the Pu SPS System including the activities in the Receipt Area, Material Preparation Area, Transport Area, Furnace Area, and LOI Test Area.

External System Interfaces:

There are no external system interface connections specifically for the Plutonium Stabilization Control System. Power for the PSCS is provided by the 120 volt ac distribution system described in Section 20.11.1.2. All wiring between the 120 volt ac distribution panel and the PSCS will be furnished and installed by BNFL.

\subsubsection{Plutonium Packaging Control System (PPCS)}

The purpose of the Plutonium Packaging Control System is to control the packaging process within the Pu SPS System including the activities in the Tipping/Dispense/Fill Area, Can Weigh and Cap Insertion Area, Intermediate Can Handling Area, and Outer Can Weld and Monitoring Area.

External System Interfaces:

There are no external system interface connections specifically for the Plutonium Packaging Control System. Power for the PPCS is provided by the 120 volt ac distribution system described in Section 20.11.1.2. All wiring between the 120 volt ac distribution panel and the PSCS will be furnished and installed by BNFL.

\subsubsection{Data Management System (DMS)}

The purpose of the Data Management System is to collect and report process data.

External System Interfaces:

\subsubsection{120 Volt AC Power Supply System}

There are no external 120 volt ac power supply interface connections specifically for the Data Management System. Power for the DMS is provided by the 120 volt ac distribution system described in Section 20.11.1.2. All wiring between the 120 volt ac distribution panel and the DMS will be furnished and installed by BNFL.

\subsubsection{Safeguards Control Computer/SAN}


The external interface requirements for the connection between the DMS and the Security Control Computer/SAN will be determined by RFETS. All wiring between the DMS and the Security Control Computer/SAN will be furnished and installed by RFETS.

\subsection{POWER DISTRIBUTION}

\subsubsection{Volt AC Power Distribution System}

The purpose of the 480 volt ac power distribution system is to provide power to the stabilization system and packaging system components that require 480 volt ac power.

\subsubsection{1 $\quad 480$ Volt AC Power Supply System}

1) The 480 volt ac power supply system provides power to the stabilization system 480 volt ac distribution panel, to the packaging system 480 volt ac distribution cubicle, to the laser generator 480 volt ac panel, and to the resistance welder 480 volt ac panel.

2) The 480 volt ac power supply system must provide power to the four panels during all normal modes of Pu SPS System operation.

3) The interface connection for the 480 volt ac power supply for the stabilization system will be on a main isolationm switch in the 480 volt ac distribution panel (later). The interface connection for the power supply for the packaging system will be on a main isolation switch in the 480 volt ac distribution cubicle (later). The interface connections for the 480 volt ac power supply for the laser generator and resistance welder are described in Sections 20.8.4.1 (3) and 20.9.4.1 (3) above.

4) The interface location for the 480 volt ac power supply for the stabilization system is in panel (later) at Point 76 on Drawing F-0-10-1-020. The interface location for the 480 volt ac power supply for the packaging system is in cubicle (later) at Point 77 on Drawing F-010-1-021. The interface locations for the 480 volt ac power supplies for the laser generator and resistance welder are given in Sections 20.8.4.1 (4) and 20.9.4.1 (4) above.

\subsubsection{120 Volt AC Power Supply System}

1) The 120 volt ac power supply system provides power to the stabilization system 120 volt ac distribution panel and to the laser generator 120 volt ac panel.

2) The 120 volt ac power supply system must provide power to the two panels during all normal modes of Pu SPS System operation.

3) The interface connection for the 120 volt ac power supply for the stabilization system will be on a main circuit breaker in the 120 volt ac distribution panel (later). The interface 
connections for the 120 volt ac power supply for the laser generator are described in Section 20.8.4.2 (3) above.

4) The interface location for the 120 volt ac power supply for the stabilization system is in panel (later) at Point 78 on Drawing F-0-10-1-020. The interface location for the 120 volt ac power supply for the laser generator is given in Sections 20.8.4.2 (4) above.

\section{BUILDING 707 SYSTEM INTERFACE REQUIREMENTS}

This section summarizes the interface requirements for each applicable Building 707 system.

\subsection{MECHANICAL SYSTEM INTERFACES}

\begin{tabular}{||c|c|c|c||}
\hline System & $\begin{array}{c}\text { Operating } \\
\text { Pressure }\end{array}$ & $\begin{array}{c}\text { Operating } \\
\text { Temperature }\end{array}$ & Flow \\
\hline $\begin{array}{c}\text { Ventilation } \\
\text { System }\end{array}$ & & & \\
\hline $\begin{array}{c}\text { Downdraft } \\
\text { System }\end{array}$ & & & \\
\hline $\begin{array}{c}\text { Nitrogen } \\
\text { System }\end{array}$ & & & \\
\hline $\begin{array}{c}\text { Process } \\
\text { Cooling Water } \\
\text { System }\end{array}$ & & & \\
\hline He System & & & \\
\hline $\begin{array}{c}\text { Dry Air } \\
\text { System }\end{array}$ & & & \\
\hline $\begin{array}{c}\text { Plant Air } \\
\text { System }\end{array}$ & & & \\
\hline $\begin{array}{c}\text { Conveyor } \\
\text { System }\end{array}$ & & & \\
\hline
\end{tabular}




\subsection{ELECTRICAL SYSTEM INTERFACES}

\begin{tabular}{||c|c|c|c||}
\hline System & Volts & Amps & KVA \\
\hline $\begin{array}{c}\text { 120 Volt Power } \\
\text { Supply System } \\
\text { (Lighting) }\end{array}$ & 120 & 10 & 1.2 \\
\hline $\begin{array}{c}120 \text { Volt Power } \\
\text { Supply System } \\
\text { (equipment) }\end{array}$ & 120 & 233 & 196 \\
\hline $\begin{array}{c}480 \text { Volt } 3 \text { ph } \\
\text { Power Supply } \\
\text { System }\end{array}$ & 480 & 302 & 252 \\
\hline $\begin{array}{c}480 \text { Volt 2 ph } \\
\text { Power Supply } \\
\text { System }\end{array}$ & 480 & N/A & N/A \\
\hline $\begin{array}{c}\text { Glovebox } \\
\text { Overheat } \\
\text { Detection and } \\
\text { Alarm System }\end{array}$ & N/A & N/A & N/A \\
\hline $\begin{array}{c}\text { O2 Detection } \\
\text { and Alarm } \\
\text { System }\end{array}$ & & & \\
\hline
\end{tabular}

Note: The Amps and KVA values in the above table are preliminary and are not to be used for design purposes. 


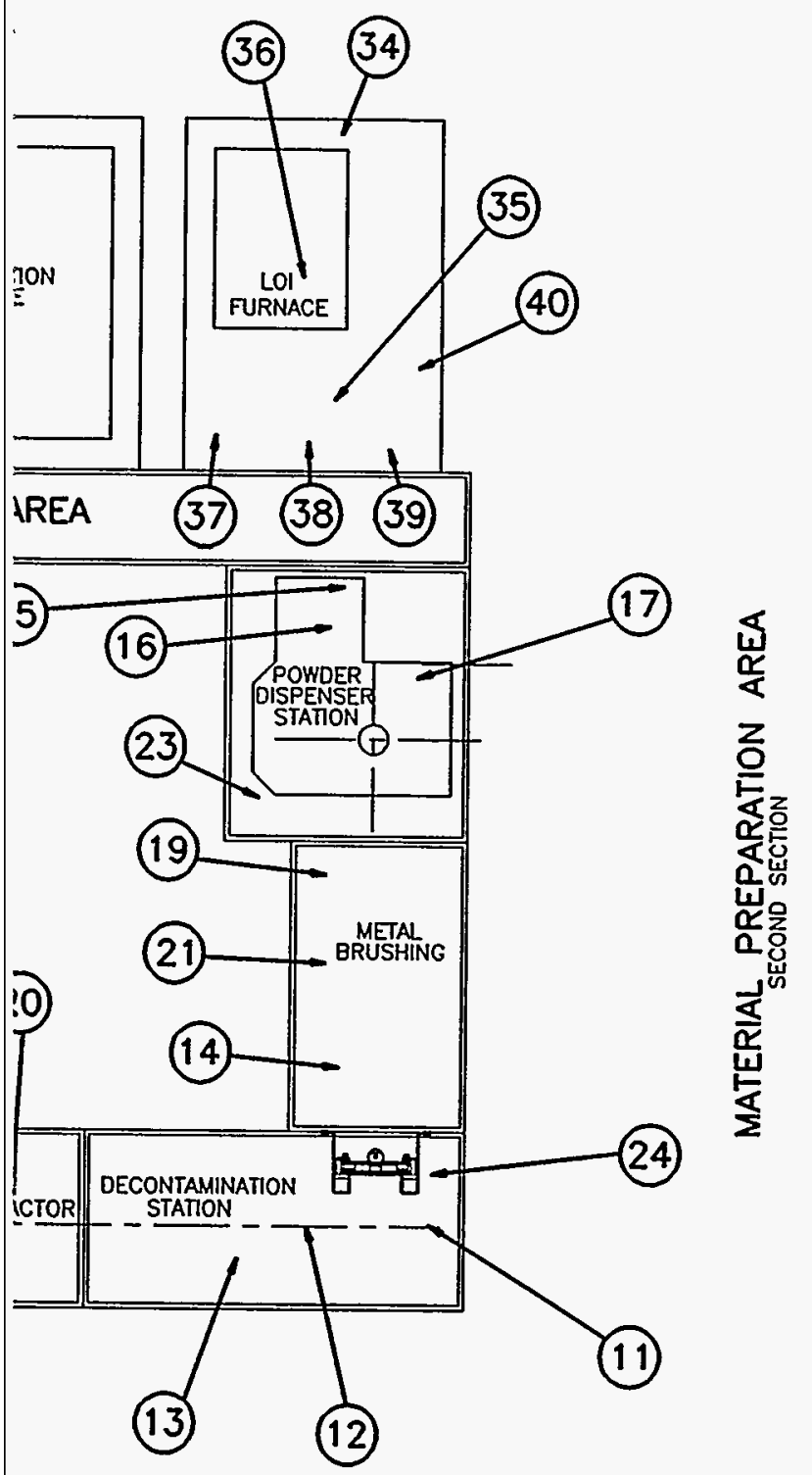

1. Downdroft Exhaust

2. 120 Volt oc Lighting

3. $\$ 16$ Choinveyor

4. Downdroft Exhaust

5. Inert Ventilation Supply

6. Plant Air

7. 120 Volt oc Lighting

8. 120 Volt ac Power to Volve Solenoids

9. Nitrogen

10. Inert Ventilation Supply

11. Inert Ventilation Normal Exhoust

12. Inert Ventilation Emergency Exhoust

13. Photohelic

14. Inert Ventilation Supply

15. Inert Ventilation Normal Exhaust

16. Inert Ventilotion Emergency Exhoust

17. Photohelic

18. Glovebox Overheot

19. Glovebox Overheat

20. 120 Volt oc Lighting

21. 120 Volt oc Lighting

22. Nitrogen

23. Nitrogen

24. Nitrogen

25. Nitrogen

26. Glovebox Overheat

27. 120 Volt oc Lighting

28. Nitrogen

29. Inert Ventilation Supply

30. Glovebox Overheat

31. Plant Air

32. Dry Air

33. Nitrogen

34. Inert Ventilation Supply

35. Glovebox Overheot

36. 120 Volt oc Lighting

37. Plant Air

38. Dry Air

39. Nitrogen

40. Nitrogen

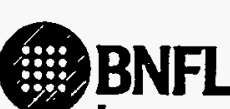
Inc.

Denver Engineering and Construction 5655 S. Yosemite St. Suife 100 Englewood Co. 80111
Prepared for:

U. S. DEPARTMENT OF ENERGY Oakland Operations Office

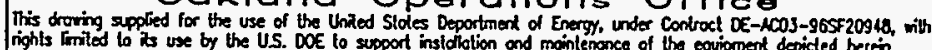

$$
P 山 S P S
$$

Plutonium Stabilization and Packaging System

\section{EXTERNAL SYSTEM INTERFACES SHEET 1 \\ PACKAGING SYSTEM}


\begin{tabular}{l|l} 
PACKAGING SYSTEM & STABILIZATION SYSTEM \\
\hline SEE DWG F-0-10-1-021 &
\end{tabular}

$\sqrt{T}$

(33)

FURNACE AREA
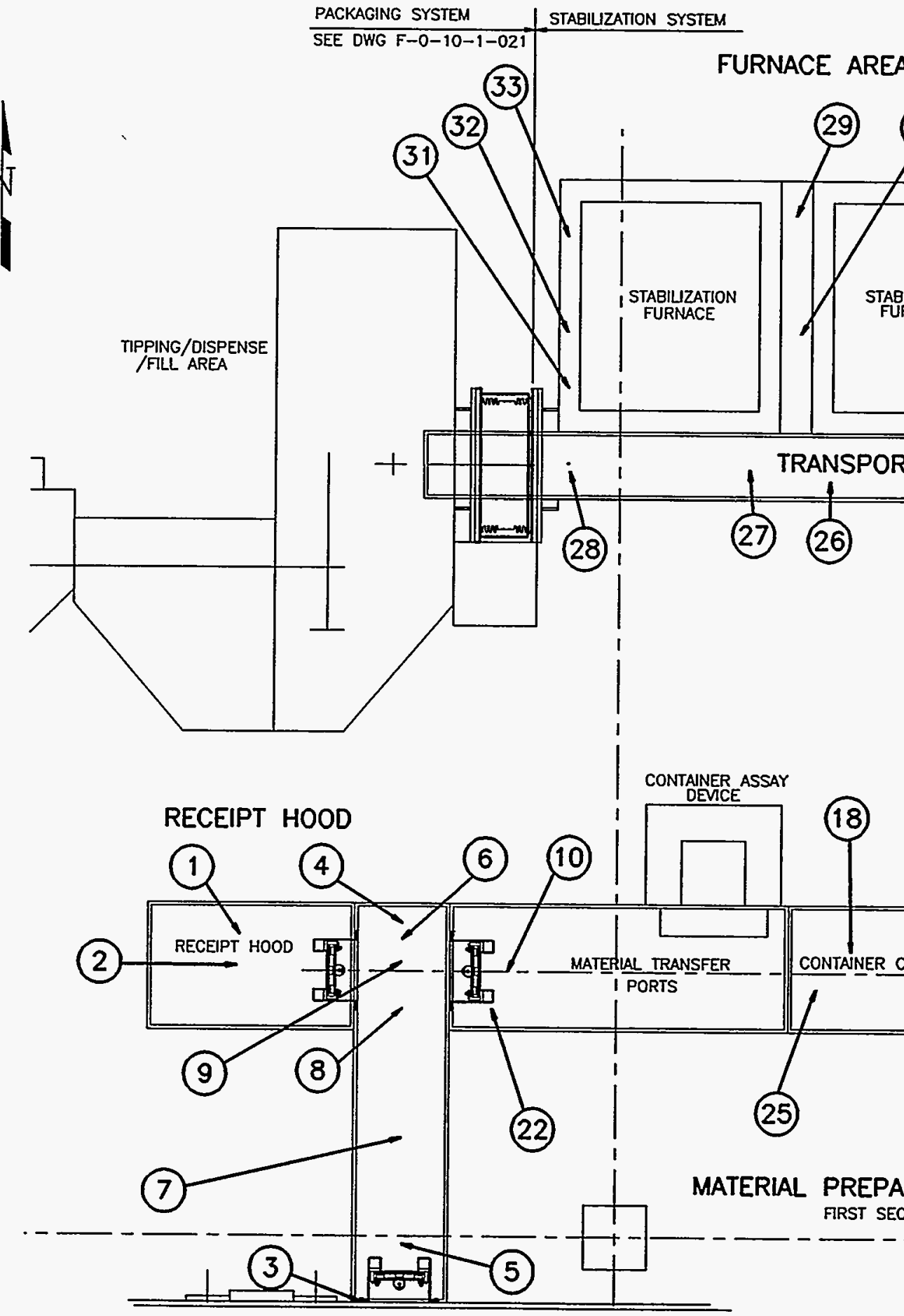

S16 CONVEYOR

(EXISTING)

\section{$\frac{\text { PLAN }}{\text { MODULE " } s "}$}

\begin{tabular}{l|l}
\hline Rev. & Rev. \\
\hline
\end{tabular}

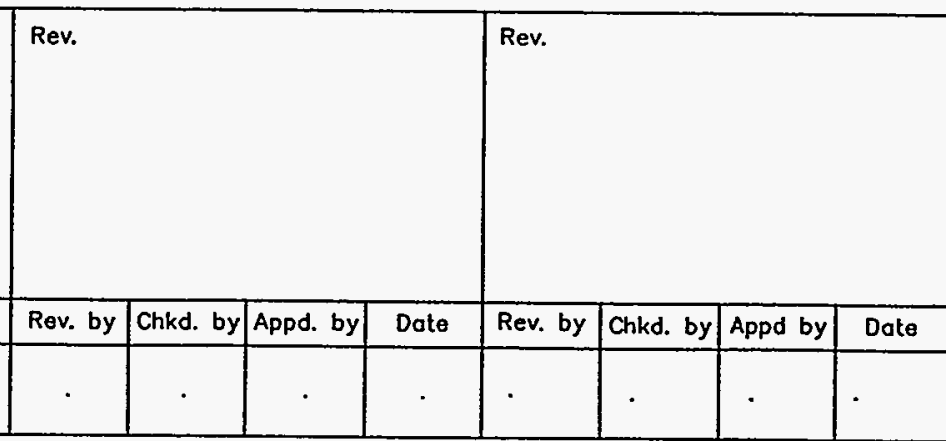

BNFL Inc Proprietary

This drawing is copyright 1 BNFL Ine as doted below. issued in confidence for informotion only, it sholl nol in whole

(1) Copied. reproduced or tronsmitted

(2) Oisclosed to ony other porty. (4) Used on retrieval System. without tho millen permission the Vice President peraission of

\begin{tabular}{|l|l|l|l|l|l|l|l|l|l|l|l|l|l|l|}
\hline Rev. by & Chkd. by & Appd. by & Date & Rev. by & Chkd. by & Appd. by & Date & Rev. by & Chkd. by Appd by & Date
\end{tabular} Services, Bresident 


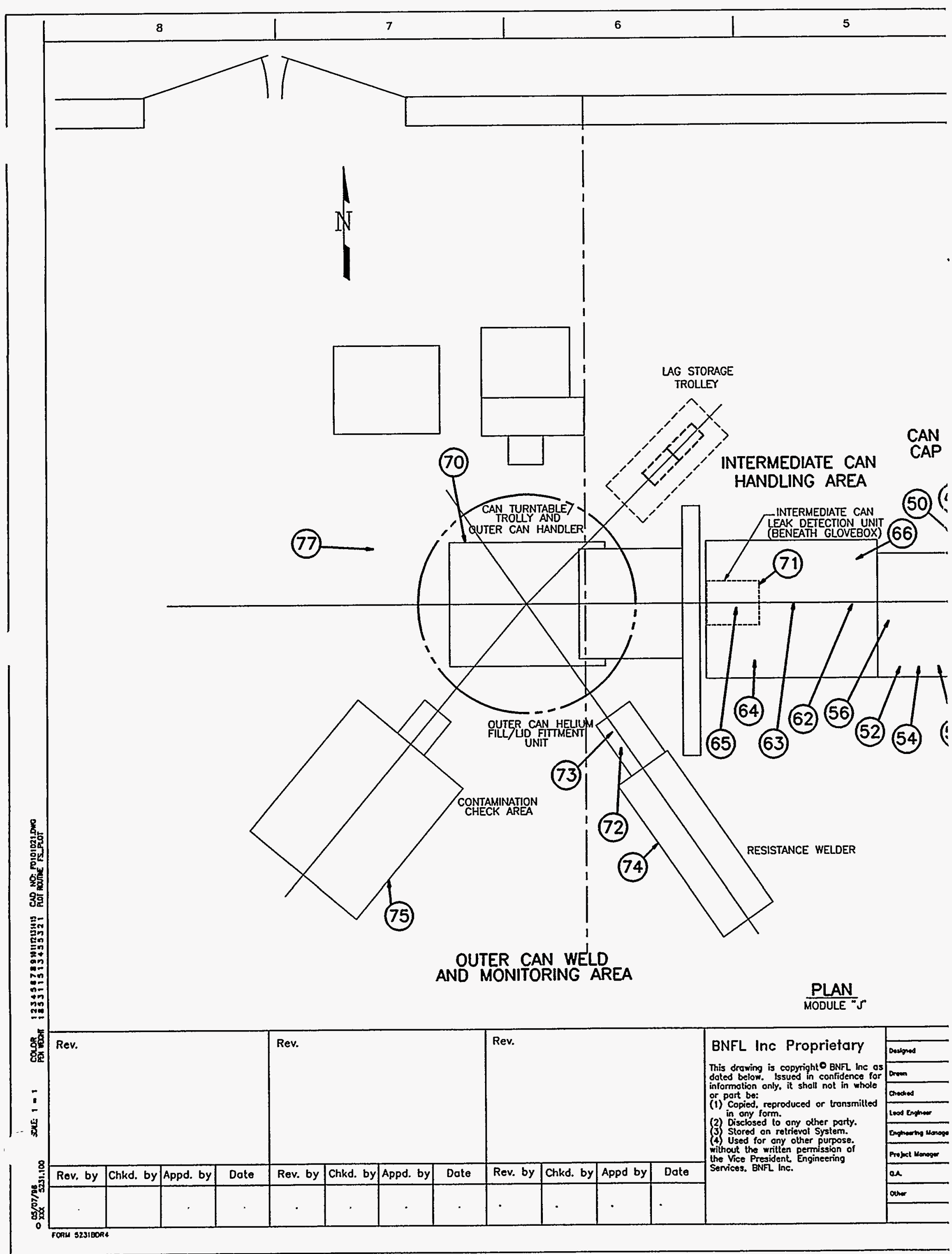




\section{Appendix B}

\section{Methods of Demonstrating Compliance}

The attached table identifies each of the requirements identified in sections 3 and 5 of this document, and also identifies the specific method, level, and event for demonstrating compliance to these requirements. 


\begin{tabular}{|c|c|c|c|c|c|}
\hline \multicolumn{6}{|c|}{$\begin{array}{l}\text { Methods of Demonstrating Compliance } \\
\text { to Specification Requirements }\end{array}$} \\
\hline SS No. & $\begin{array}{l}\text { Summary of } \\
\text { Requirement }\end{array}$ & $\begin{array}{l}\text { Compliance } \\
\text { Method }\end{array}$ & $\begin{array}{c}\text { Level of } \\
\text { Demonstration }\end{array}$ & $\begin{array}{l}\text { Event for } \\
\text { Compliance }\end{array}$ & $\begin{array}{l}\text { Documentation } \\
\text { Reference } \\
\text { (letere) }\end{array}$ \\
\hline SPS-1 & Throughput & Test & Integrated System & Integrated System Startup & \\
\hline SPS-2 & Minimize waste & Internal Design Review & Process & Pre-Site Dellivery & \\
\hline SPS-3 & MC\&A support & Design Check & Integrated System & Pre-Site Delivery & \\
\hline SPS-4 & Ops thru contam walls & Analysis & Integrated System & Integrated System Startup & \\
\hline SPS-5 & Pyro/Chem reactivity & Internal Design Review & Process & Pro-Site Delivery & \\
\hline SPS-6 & Adsorbed water hazand & Internal Design Revlew & Process & Pre-Site Delivery & \\
\hline SPS-7 & Spread of powders & Internal Design Reviow & Process & Pre-Site Delivery & \\
\hline SPS-8 & Design for PC-3/Group II & Design Check & Process & Pre-Procurement & \\
\hline SPS-9 & SSC loads, Including selsmic & Design Check & Component & Integrated System Startup & \\
\hline SPS-10 & sc/ss Installation & Quality Control & Component & Pre-Site Delivery & \\
\hline SPS-11 & Basis for design throughput & (by others) & Integrated System & Pre-Procurement & \\
\hline SPS-12 & Retention of mat'l in PU SPS & (by others) & Integrated System & Pre-Procurement & \\
\hline RA-1 & Receive existing containers & Tost & Integrated System & Integrated System Startup & \\
\hline RA-2 & Interface with site conveyer & Test & Integrated System & Integrated System Startup & \\
\hline RA-3 & Aillock size & Design Check & Component & Pre-Procurement & \\
\hline$R A-4$ & Process Traveller No. & Test & Subsystem & Pre-Slte Delivery & \\
\hline RA-5 & Recelpt via manual trolley & Test & Integrated System & Integrated System Startup & \\
\hline RA-6 & Support needs for frisker & Design Check & Component & Pre-Site Delivery & \\
\hline MPA-1 & Unload/decon existing cont. & Test & Integrated System & Integrated System Startup & \\
\hline
\end{tabular}


ID: SS/Pu SPS, _.ovision 0 (05/09/96)

\begin{tabular}{|c|c|c|c|c|c|}
\hline \multicolumn{6}{|c|}{$\begin{array}{l}\text { Methods of Demonstrating Compliance } \\
\text { to Specification Requirements }\end{array}$} \\
\hline SS No. & $\begin{array}{l}\text { Summary of } \\
\text { Requirement }\end{array}$ & $\begin{array}{l}\text { Compliance } \\
\text { Method }\end{array}$ & $\begin{array}{c}\text { Level of } \\
\text { Demonstration }\end{array}$ & $\begin{array}{l}\text { Event for } \\
\text { Compliance }\end{array}$ & $\begin{array}{c}\text { Documentation } \\
\text { Reference } \\
\text { (latere) }\end{array}$ \\
\hline MPA-2 & $\begin{array}{l}\text { Remove oxide/inert } \\
\text { atmosphere }\end{array}$ & Internal Design Review & Process & Pre-Site Delivery & \\
\hline MPA-3 & Combine brushed oxides & Design Check & Subsystem & Pre-Procurement & \\
\hline MPA-4 & Homogenize oxides & Design Check & Subsystem & Pre-Procurement & \\
\hline MPA-5 & Remove plastics, etc. & Design Chieck & Subsystem & Pro-Procurement & \\
\hline MPA-6 & Open new packages & Design Check & Subsystem & Pre-Procurement & \\
\hline MPA-7 & Compact existing containers & Test & Component & Pre-Site Delivery & \\
\hline MPA-8 & Maximum compaction height & Test & Component & Pre-Site Delivery & \\
\hline MPA-9 & Interlock protection & Test & Subsystem & Integrated System Startup & \\
\hline MPA-10 & Operation within 5 minutes & Test & Component & Pre-Site Dellivery & \\
\hline MPA-11 & Automated oxide dispensing & Test & Subsystem & Integrated System Startup & \\
\hline MPA-12 & Auto tray overfill checking & Test & Subsystem & Integrated System Startup & \\
\hline TA-1 & Transport cans without spills & Test & Subsystem & Integrated System Startup & \\
\hline TA-2 & Transport trays without spills & Test & Subsystem & Integrated System Startup & \\
\hline TA-3 & Accurate can/tray movement & Test & Integrated System & Integrated System Startup & \\
\hline FURN-1 & Oxide temp/time & Test & Component & Pro-Site Dellvery & \\
\hline FURN-2 & Throughput temperature/time & Analysis & Process & Pre-Procurement & \\
\hline FURN-3 & Furnace atmosphere & Design Check & Subsystem & Pre-Procurement & \\
\hline FURN-4 & Inside glovebox & Design Check & Subsystem & Pre-Procurement & \\
\hline FURN-5 & Outslde temperature & Test & Component & Integrated System Startup & \\
\hline
\end{tabular}


ID: SS/Pu SPS、 Jvision 0 (05/09/96)

\begin{tabular}{|c|c|c|c|c|c|}
\hline \multicolumn{6}{|c|}{$\begin{array}{c}\text { Methods of Demonstrating Compliance } \\
\text { to Specification Requirements }\end{array}$} \\
\hline SS No. & $\begin{array}{l}\text { Summary of } \\
\text { Requirement }\end{array}$ & $\begin{array}{l}\text { Compliance } \\
\text { Method }\end{array}$ & $\begin{array}{l}\text { Level of } \\
\text { Demonstration }\end{array}$ & $\begin{array}{l}\text { Event for } \\
\text { Compliance }\end{array}$ & $\begin{array}{c}\text { Documentation } \\
\text { Reference } \\
\text { (latere) }\end{array}$ \\
\hline FURN-6 & Furnace controller & Design Check & Component & Pre-Procurement & \\
\hline FURN-7 & Holds two trays & Destgn Check & Component & Pro-Procurement & \\
\hline LOI-1 & Test mothod & Test & Component & Pre-Site Dellvery & \\
\hline LOOI-2 & Test accuracy & (by others) & Component & (by others) & (by others) \\
\hline LOI-3 & Cool in desiccator & Design Check & Component & Pre-Site Delivery & \\
\hline LOI-4 & Weigh just after cooling & Design Check & Component & Pro-Site Dellvery & \\
\hline TFA-1 & Auto move trays to nozzle & Test & Subsystem & Integrated System Startup & \\
\hline TFA-2 & Remove/replace screw caps & Test & Subsystem & Integrated System Startup & \\
\hline TFA-3 & Controlled oxide tipping & Test & Subsystem & Integrated System Startup & \\
\hline TFA-4 & Woight confirmation & Test & Subsystem & Integrated System Startup & \\
\hline TFA-5 & Auto move cans in area & Test & Subsystem & Integrated System Startup & \\
\hline TFA-6 & Auto move cans to gaslock & Test & Subsystem & Integrated System Startup & \\
\hline CWCl-1 & Auto move cans fm gaslock & Test & Subsystem & Integrated System Startup & \\
\hline CWCl-2 & Auto move cans in area & Test & Subsystem & Integrated System Startup & \\
\hline CWCl-3 & Auto can weighing and ID & Test & Subsystem & Integrated System Startup & \\
\hline CWCl-4 & Auto fill of intermediate can & Test & Subsystem & Integrated System Startup & \\
\hline ICHA-1 & Automated welding/cutting & Test & Subsystem & Integrated System Startup & \\
\hline ICHA-2 & Auto can movement in area & Test & Subsystem & Integrated System Startup & \\
\hline ICHA-3 & Auto push out of stubs & Test & Subsystem & Integrated System Startup & \\
\hline
\end{tabular}





\begin{tabular}{|c|c|c|c|c|c|}
\hline \multicolumn{6}{|c|}{$\begin{array}{l}\text { Methods of Demonstrating Compliance } \\
\text { to Specification Requirements }\end{array}$} \\
\hline SS No. & $\begin{array}{l}\text { Summary of } \\
\text { Requirement }\end{array}$ & $\begin{array}{l}\text { Compliance } \\
\text { Method }\end{array}$ & $\begin{array}{c}\text { Level of } \\
\text { Demonstration }\end{array}$ & $\begin{array}{l}\text { Event for } \\
\text { Compliance }\end{array}$ & $\begin{array}{l}\text { Documentation } \\
\text { Reference } \\
\text { (aetere) }\end{array}$ \\
\hline OWM-1 & Helium leak detection & Design Check & Subsystem & Pre-Procurement & \\
\hline OWM-2 & Auto intermediate leak check & Test & Subsystem & Integrated System Startup & \\
\hline OWM-3 & Auto outer can wolding & Test & Subsystem & Integrated System Startup & \\
\hline OWM-4 & Auto outer can contam check & Test & Subsystem & Integrated System Startup & \\
\hline OWM-5 & Auto outer can leak check & Test & Subsystem & Integrated System Startup & \\
\hline OWM-6 & Auto receipt intermediate can & Test & Subsystem & Integrated System Startup & \\
\hline OWM-7 & Auto move cans in area & Test & Subsystem & Integrated System Startup & \\
\hline OWM-8 & Auto move package to trolley & Test & Subsystem & Integrated System Startup & \\
\hline LST-1 & Two packages in trolley & Design Check & Component & Pre-Site Delivery & \\
\hline LST-2 & Trolloy movement interlocks & Test & Subsystem & Integrated System Startup & \\
\hline LST-3 & Spare trolleys & Design Check & Component & Pre-Site Delivery & \\
\hline LST-4 & ALARA trolley shielding & Analysis & Component & Pre-Site Defivery & \\
\hline LST-5 & Attached \& fixed shielding & Design Check & Subsystem & Pro-Site Delivery & \\
\hline FT-1 & Maximum container capacity & Design Check & Component & Pre-Procurement & \\
\hline FT-2 & Maximum oxide depth & Test & Subsystem & Integrated System Startup & \\
\hline FT-3 & Tray sizing & Design Check & Component & Pre-Procurement & \\
\hline FT-4 & Tray durability & Test & Component & Pre-Site Delivery & \\
\hline SP-1 & Two confinement barriers & Design Check & Component & Pre-Procurement & \\
\hline SP-2 & No organics & Design Check & Component & Pre-Procurement & \\
\hline
\end{tabular}





\begin{tabular}{|c|c|c|c|c|c|}
\hline \multicolumn{6}{|c|}{$\begin{array}{c}\text { Methods of Demonstrating Compliance } \\
\text { to Specification Requirements }\end{array}$} \\
\hline SS No. & $\begin{array}{l}\text { Summary of } \\
\text { Requirement }\end{array}$ & $\begin{array}{l}\text { Compliance } \\
\text { Method }\end{array}$ & $\begin{array}{l}\text { Level of } \\
\text { Demonstration }\end{array}$ & $\begin{array}{l}\text { Event for } \\
\text { Compliance }\end{array}$ & $\begin{array}{c}\text { Documentation } \\
\text { Reference } \\
\text { (laters) }\end{array}$ \\
\hline SP-3 & No surface contamination & Design Check & Subsystem & Pre-Procurement & \\
\hline SP-4 & Thermal loads & Design Check & Component & Pre-Procurement & \\
\hline SP-5 & Container markings & Design Check & Component & Pre-Procurement & \\
\hline SP-6 & Storage amounts & Design Check & Component & Pro-Procurement & \\
\hline SP-7 & Filled with hellum (inner) & Design Check & Component & Pre-Procurement & 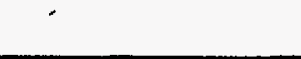 \\
\hline SP-8 & Sealed/leaktight (inner) & Test & Subsystem & Integrated System Startup & \\
\hline SP.8 & 304L stainless steol (inner) & Design Check & Component & Pre-Procurement & \\
\hline$S P-10$ & Leaktight post drops (inner) & Test & Component & Pre-Site Delivery & \\
\hline SP-11 & Pressure test (inner) & Test & Component & Pre-Site Delivery & \\
\hline SP-12 & Sizenthermal expansion & Design Check & Component & Pre-Procurement & \\
\hline SP-13 & Free standing (inner) & Design Check & Component & Pre-Procurement & \\
\hline SP-14 & Filled with helium (outer) & Test & Subsystem & Integrated System Startup & \\
\hline SP-15 & 304L stainless steel (outer) & Design Check & Component & Pre-Procurement & \\
\hline SP-16 & ASME VIII (outer) & Destgn Check & Component & Pre-Procurement & \\
\hline SP-17 & Max design pressure (outer) & Design Check & Component & Pre-Procurement & \\
\hline SP-18 & External pressure (outér) & Design Check & Component & Pre-Procurement & \\
\hline SP-19 & Free standing (outer) & Design Check & Component & Pre-Procurement & \\
\hline SP-20 & Maximum size (outer) & Design Check & Component & Pre-Procurement & \\
\hline SP-21 & Robotics compatible (outer) & Design Check & Component & Pre-Procurement & \\
\hline SP-22 & Automated closure & Deslgn Check & Component & Pre-Procurement & \\
\hline
\end{tabular}




\begin{tabular}{|c|c|c|c|c|c|}
\hline \multicolumn{6}{|c|}{$\begin{array}{l}\text { Methods of Demonstrating Compliance } \\
\text { to Specification Requirements }\end{array}$} \\
\hline SS No. & $\begin{array}{l}\text { Summary of } \\
\text { Requirement }\end{array}$ & $\begin{array}{l}\text { Compliance } \\
\text { Method }\end{array}$ & $\begin{array}{c}\text { Level of } \\
\text { Demonstration }\end{array}$ & $\begin{array}{l}\text { Event for } \\
\text { Compliance }\end{array}$ & $\begin{array}{l}\text { Documentation } \\
\text { Reference } \\
\text { (1ateres }\end{array}$ \\
\hline SP-23 & Leaktight post drops (outer) & Test & Component & Pre-Site Delivery & \\
\hline HGA-1 & SS/SC seismic requirements & Design Check & Subsystem & Pre-site Delivery & \\
\hline HGA-2 & Backflow prevention & Design Check & Subsystem & Pre-Procurement & \\
\hline HGA-3 & Intake filters & Design Check & Subsystem & Pre-Procurement & \\
\hline HGA-4 & Exhaust filters & Design Check & Subsystem & Pre-Procurement & \\
\hline HGA-5 & Hood air velocity & Test & Component & Pre-Site Delivery & \\
\hline HGA-6 & Oxygen analysis equipment & Design Check & Component & Pre-Procurement & \\
\hline HGA-7 & Excess oxygen actions & Analysis & Process & Pre-Site Delivery & \\
\hline HGA-8 & Flow to less contamination & Design Check & Integrated System & Pro-Site Dellvery & \\
\hline HGA-9 & HEPA fiftration & Design Check & Subsystem & Pre-Procurement & \\
\hline HGA-10 & Dump valve design & Design Check & Subsystem & Pre-Procurement & \\
\hline E-1 & Design criteria (SRS n/a ??) & Quality Control & Subsystem & Pre-Site Delivery & \\
\hline E-2 & Free standing cabinets & Design Check & Subsystem & Pre-Procurement & \\
\hline E-3 & Electrical connectors (dust) & Design Check & Subsystem & Pre-Procurement & \\
\hline$E-4$ & Electrical connectors (plugs) & Design Check & Subsystem & Pre-Procurement & \\
\hline E-5 & UPS, per safety analysis & Design Check & Subsystem & Pre-Procurement & \\
\hline E-6 & Lighting - amounts & Design Check & Subsystem & Pre-Procurement & \\
\hline E-7 & Lighting - type & Design Check & Subsystem & Pre-Procurement & \\
\hline$E-8$ & Lighting - location & Design Check & Subsystem & Pre-Procurement & \\
\hline
\end{tabular}




\begin{tabular}{|c|c|c|c|c|c|}
\hline \multicolumn{6}{|c|}{$\begin{array}{l}\text { Methods of Demonstrating Compliance } \\
\text { to Specification Requirements }\end{array}$} \\
\hline SS No. & $\begin{array}{l}\text { Summary of } \\
\text { Requirement }\end{array}$ & $\begin{array}{l}\text { Compliance } \\
\text { Method }\end{array}$ & $\begin{array}{l}\text { Level of } \\
\text { Demonstration }\end{array}$ & $\begin{array}{l}\text { Event for } \\
\text { Compliance }\end{array}$ & $\begin{array}{c}\text { Documentation } \\
\text { Reference } \\
\text { (latex) }\end{array}$ \\
\hline SSP-1 & Support design per Perf Cat & Design Check & Component & Pre-Procurement & \\
\hline SSP-2 & Support constr per Perf Cat & Quality Control & Component & Integrated System Startup & \\
\hline SSP-3 & Impact with existing items & $\begin{array}{l}\text { Post Installation } \\
\text { Checklist }\end{array}$ & Integrated System & Integrated System Startup & \\
\hline SSP-4 & Concrete anchorage & Design Check & Process & Pre-Site Delivery & \\
\hline SSP-5 & Support frequency & Design Check & Process & Pre-Site Delivery & \\
\hline SSP-6 & 304 stalnless steel & Design Check & Process & Pre-Site Delivery & \\
\hline SSP-7 & Selsmic decoupling & Analysis & Component & Pre-Site Delivery & \\
\hline FPS-1 & Detection/alarm system & Design Check & Subsystem & Pre-Procurement & \\
\hline FPS-2 & Mag oxide extinguishers & Design Check & Subsystem & Pre-Site Delfivery & \\
\hline FPS-3 & Quick-disconnects & Design Check & Subsystem & Pre-Procurement & \\
\hline PSC-1 & Monitor/control Interlocks & Test & Process & Integrated System Startup & \\
\hline PSC-2 & Monitor/control environment & Test & Process & Integrated System Startup & \\
\hline PSC-3 & Manual entry of process data & Test & Process & Integrated System Startup & \\
\hline PSC-4 & Control automatic ops & Test & Process & Integrated System Startup & \\
\hline PSC-5 & Info to DMS & Design Check & Subsystem & Pro-Site Delkery & \\
\hline PPC-1 & Can balances & Design Check & Component & Pre-Procurement & \\
\hline PPC-2 & Monitor/control interlocks & Test & Process & Integrated System Startup & \\
\hline PPC-3 & Monitor/control environment & Test & Process & Integrated System Startup & \\
\hline
\end{tabular}


ID: SS/Pu SPS; _.evision 0 (05/09/96)

\begin{tabular}{|c|c|c|c|c|c|}
\hline \multicolumn{6}{|c|}{$\begin{array}{l}\text { Methods of Demonstrating Compliance } \\
\text { to Specification Requirements }\end{array}$} \\
\hline SS No. & $\begin{array}{l}\text { Summary of } \\
\text { Requirement }\end{array}$ & $\begin{array}{l}\text { Compliance } \\
\text { Method }\end{array}$ & $\begin{array}{c}\text { Level of } \\
\text { Demonstration }\end{array}$ & $\begin{array}{l}\text { Event for } \\
\text { Compliance }\end{array}$ & $\begin{array}{l}\text { Documentation } \\
\text { Reference } \\
\text { (latere) }\end{array}$ \\
\hline PPC-4 & Manual entry of process data & Test & Process & Integrated System Startup & \\
\hline PPC-5 & Control automatic ops & Test & Process & Integrated System Startup & \\
\hline PPC-6 & Info to DMS & Design Check & Subsystem & Pre-Site Delivery & \\
\hline PPC-7 & Leak \& contam test info & Test & Process & Integrated System Startup & \\
\hline DMS-1 & MC\&A info to SAN & Test & Subsystem & Integrated System Startup & \\
\hline DMS-2 & Purge data & Test & Subsystem & Integrated System Startup & \\
\hline DMS-3 & Storage package certification & Test & Subsystem & Integrated System Startup & \\
\hline DMS-4 & System ops info & Test & Subsystem & Integrated System Startup & \\
\hline PRI-1 & Assay equipment & Design Check & Subsystem & Pre-Procurement & \\
\hline PRI-2 & Sodium lodine detectors & Design Check & Subsystem & Pro-Procurement & \\
\hline PRI-3 & Limited assay data transfer & Design Check & Subsystem & Pre-Procurement & \\
\hline PHYS-1 & Route for installation & Design Check & Integrated System & Pre-Site Delivery & \\
\hline PHYS-2 & Maximum component size & Design Check & Subsystem & Pre-Site Delivery & \\
\hline PHYS-3 & Fit into existing space & Design Check & Subsystem & Pre-Site Delivery & \\
\hline COAT-1 & Cleaning requirements. & Quality Control & Component & Pre-Slte Delivery & \\
\hline COAT-2 & No paint on stainless steel & Quality Control & Component & Pre-Site Dellvery & \\
\hline RAM-1 & Design life of 50 years & Internal Design. Review & Process & Pre-Site Delivery & \\
\hline RAM-2 & Robust operation & Test & Integrated System & Integrated System Startup & \\
\hline RAM-3 & Maintain within 2 hours & Internal Design Reviow & Process & Pre-Site Dellvery & \\
\hline
\end{tabular}




\begin{tabular}{|c|c|c|c|c|c|}
\hline \multicolumn{6}{|c|}{$\begin{array}{l}\text { Methods of Demonstrating Compliance } \\
\text { to Specification Requirements }\end{array}$} \\
\hline SS No. & $\begin{array}{l}\text { Summary of } \\
\text { Requirement }\end{array}$ & $\begin{array}{l}\text { Compliance } \\
\text { Method }\end{array}$ & $\begin{array}{c}\text { Level of } \\
\text { Demonstration }\end{array}$ & $\begin{array}{l}\text { Event for } \\
\text { Compliance }\end{array}$ & $\begin{array}{l}\text { Documentation } \\
\text { Reference } \\
\text { (atere) }\end{array}$ \\
\hline RADP-8 & Methods of ALARA design & Analysis & Integrated System & Integrated System Startup & \\
\hline RADP-9 & Contamination containment & Design Check & Subsystem & Pre-Procurement & \\
\hline RADP-10 & Components minimize radcon & Design Check & Component & Pre-Procurement & \\
\hline RADP-11 & Shieldingftime \& motion & Analysis & Integrated System & Integrated System Startup & \\
\hline BOX-1 & Design reference documents & Design Check & Subsystem & Pre-Procurement & \\
\hline BOX-2 & 304 stainless steel & Design Check & Component & Pre-Procurement & \\
\hline BOX-3 & Light windows & Design Check & Component & Pre-Procurement & \\
\hline BOX-4 & Gloveports & Design Check & Component & Pre-Procurement & \\
\hline BOX-5 & Storage shelves & Design Check & Component & Pre-Procurement & \\
\hline $\mathrm{BOX}-6$ & Butt wolds/floor fit & Design Check & Component & Pre-Procurement & \\
\hline BOX-7 & Airlocks & Design Check & Component & Pre-Procurement & \\
\hline BOX-8 & Consistent appearances & Design Check & Subsystem & Pre-Procurement & \\
\hline BOX-9 & Pass-through connectors & Design Check & Component & Pre-Procurement & \\
\hline$B 0 x-10$ & Gas supphy HEPA filters & Design Check & Component & Pre-Procurement & \\
\hline$B 0 X-11$ & Leak tightness & Test & Subsystem & Pre-Site Delivery & \\
\hline BOX-12 & Glovebox cooling & Design Check & Component & Pre-Procurement & \\
\hline BOX-13 & Criticality drains & Design Check & Component & Pre-Procurement & \\
\hline BOX-14 & Shutoffs for utilities & Design Check & Component & Pre-Procurement & \\
\hline BOX-15 & Alrlock inop if operator near & Test & Subsystem & Integrated System Startup & \\
\hline
\end{tabular}


, 
ID: SS/Pu SPS; nevision 0 (05/09/96)

\begin{tabular}{|c|c|c|c|c|c|}
\hline \multicolumn{6}{|c|}{$\begin{array}{l}\text { Methods of Demonstrating Compliance } \\
\text { to Specification Requirements }\end{array}$} \\
\hline SS No. & $\begin{array}{l}\text { Summary of } \\
\text { Requirement }\end{array}$ & $\begin{array}{l}\text { Compliance } \\
\text { Method }\end{array}$ & $\begin{array}{c}\text { Level of } \\
\text { Demonstration }\end{array}$ & $\begin{array}{l}\text { Event for } \\
\text { Compliance }\end{array}$ & $\begin{array}{l}\text { Documentation } \\
\text { Reference } \\
\text { (latere) }\end{array}$ \\
\hline DECON-1 & No glovebox crevices & Design Check & Subsystem & Pre-Procurement & \\
\hline DECON-2 & Glovebox finish & Design Check & Component & Pre-Procurement & \\
\hline DECON-3 & Surface sealing & Design Check & Component & Pre-Procurement & \\
\hline DECON-4 & Lffing lugs & Design Check & Component & Pre-Procurement & \\
\hline DECON-5 & Easy decon disassembly & Design Check & Component & Pre-Procurement & \\
\hline CRIT-1 & Desirable geometry & Design Check & Subsystem & Pro-Site Dellvery & \\
\hline CRIT-2 & Assume moderation via arms & Analysis & Subsystem & Pre-Procurement & \\
\hline CRIT-3 & No hydrogenous kquids & Design Check & Component & Pre-Procurement & \\
\hline CRIT-4 & Initial container assay & Test & Subsystem & Pre-Site Delivery & \\
\hline CRIT-5 & Fixed location for metal cans & Design Check & Subsystem & Pre-Procurement & \\
\hline CRIT-6 & Fixed locations in processes & Design Check & Subsystem & Pre-Procurement & \\
\hline CRIT-7 & Furnace tray spacing & Design Check & Component & Pre-Procurement & \\
\hline CRIT-8 & Covered trays and cans & Design Check & Component & Integrated System Startup & \\
\hline CRIT-8 & Metal cans separate in DBE & Design Check & Subsystem & Pre-Procurement & \\
\hline CRIT-10 & No DBE water in furnace & Analysis & Subsystem & Pre-Slte Delivery & \\
\hline CRIT-11 & One metal convenience can & Design Check & Subsystem & Pre-Procurement & \\
\hline CRIT-12 & Only one container (make-up) & Design Check & Subsystem & Pre-Procurement & \\
\hline CRIT-13 & Area Pu metal limit & Design Check & Subsystem & Pre-Procurement & \\
\hline CRIT-14 & Area Pu oxide limit & Design Check & Subsystem & Pre-Procurement & \\
\hline
\end{tabular}


i 


\begin{tabular}{|c|c|c|c|c|c|}
\hline \multicolumn{6}{|c|}{$\begin{array}{l}\text { Methods of Demonstrating Compliance } \\
\text { to Specification Requirements }\end{array}$} \\
\hline SS No. & $\begin{array}{l}\text { Summary of } \\
\text { Requirement }\end{array}$ & $\begin{array}{l}\text { Compliance } \\
\text { Method }\end{array}$ & $\begin{array}{c}\text { Level of } \\
\text { Demonstration }\end{array}$ & $\begin{array}{l}\text { Event for } \\
\text { Compliance }\end{array}$ & $\begin{array}{l}\text { Documentation } \\
\text { Reference } \\
\text { (letere) }\end{array}$ \\
\hline HENG-1 & Work surface height & Design Check & Component & Pre-Procurement & \\
\hline HENG-2 & Internal support locations & Design Check & Component & Pre-Procurement & \\
\hline HENG-3 & Human body dimenslons & Design Check & Component & Pre-Site Dellvery & \\
\hline HENG-4 & Process control strategy & Design Check & Subsystem & Pre-site Delivery & \\
\hline HENG-5 & Operating procedures & Design Check & Process & Integrated System Startup & \\
\hline HENG-6 & Display devices & Design Check & Subsystem & Pre-Site Delivery & \\
\hline HENG-7 & Warning alarms/indications & Design Check & Subsystem & Pre-site Dellvery & \\
\hline HENG-8 & Laboling & Design Check & Component & Pre-Procurement & \\
\hline HENG-9 & Handicap access & Internal Design Review & Process & Integrated System Startup & \\
\hline HENG-10 & Environmental conditions & Design Check & Subsystem & Pre-Site Delivery & \\
\hline SECR-1 & Password for config software & Design Check & Subsystem & Pre-Site Delivery & \\
\hline PERS-1 & Basic skills & Training & Process & Integrated System Startup & \\
\hline PERS-2 & Minimum technical skllis & Tralning & Process & Integrated System Startup & \\
\hline PERS-3 & Supervisory skills & Training & Process & Integrated System Startup & \\
\hline PERS 4 & RadCon skills & Training & Process & Integrated System Startup & \\
\hline QUAL-1 & QA program per NQA-1 & DOE Approved QAP & Integrated System & Integrated System Startup & \\
\hline QUAL-2 & Perform work per contract & DOE Approved QAP & Integrated System & Integrated System Startup & \\
\hline QUAL-3 & Quality Lovel 1 for SC design & Design Check & Component & Integrated System Startup & \\
\hline QUAL-4 & Quality Level 1 for SC constr & Quality Control & Component & Integrated System Startup & \\
\hline
\end{tabular}




\begin{tabular}{|c|c|c|c|c|c|}
\hline \multicolumn{6}{|c|}{$\begin{array}{l}\text { Methods of Demonstrating Compliance } \\
\text { to Specification Requirements }\end{array}$} \\
\hline SS No. & $\begin{array}{l}\text { Summary of } \\
\text { Requirement }\end{array}$ & $\begin{array}{l}\text { Compliance } \\
\text { Method }\end{array}$ & $\begin{array}{c}\text { Level of } \\
\text { Demonstration }\end{array}$ & $\begin{array}{l}\text { Event for } \\
\text { Compliance }\end{array}$ & $\begin{array}{l}\text { Documentation } \\
\text { Reference } \\
\text { (latere) }\end{array}$ \\
\hline QUAL-5 & Testing responsibilities & DOE Approved QAP & Integrated System & Integrated System Startup & \\
\hline TRANS-1 & Delivery location & Design Check & Integrated System & Pro-Sito Delivery & \\
\hline TRANS-2 & via truck from Idaho & Design Check & Integrated System & Pre-Site Dellvery & \\
\hline TRANS-3 & via air frieght from U.K. & Design Check & Integrated System & Pre-Site Delivery & \\
\hline SHIP-1 & Preparation requirements & Design Check & Integrated System & Pre-Site Dellvery & \\
\hline SHIP-2 & Crating requirements & Design Check & Integrated System & Pro-Site Dellvery & \\
\hline SHIP-3 & Seal openings & Design Check & Integrated System & Pro-Site Delivery & \\
\hline SHIP-4 & Low chloride if taping S/S & Design Check & Integrated System & Pre-Site Delivery & \\
\hline
\end{tabular}




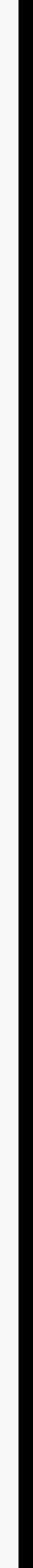




\section{Index for Requirement Identifiers}

Identifier

Page

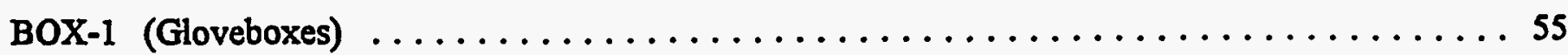

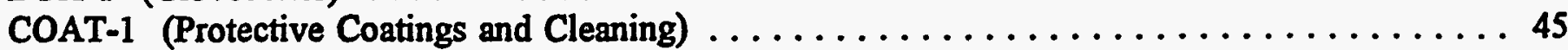

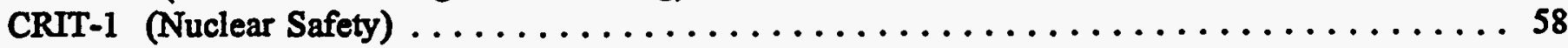

CWCI-1 (Can Weigh and Cap Insertion Area) $\ldots \ldots \ldots \ldots \ldots \ldots \ldots \ldots \ldots \ldots \ldots \ldots \ldots \ldots \ldots \ldots \ldots$

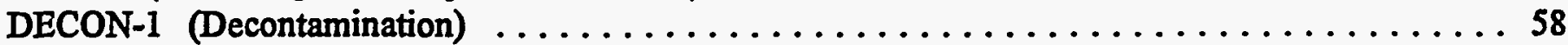

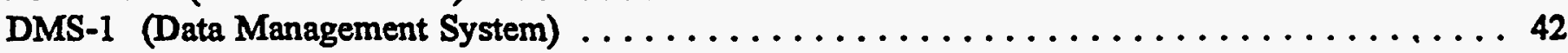

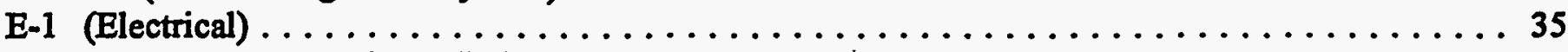

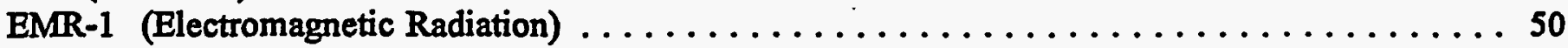

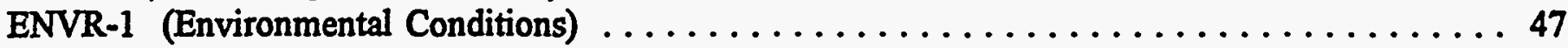

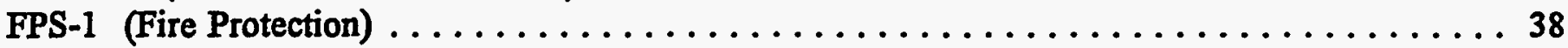

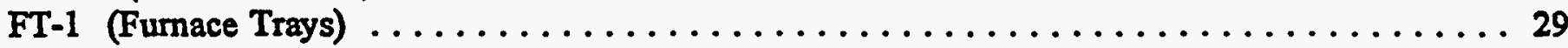

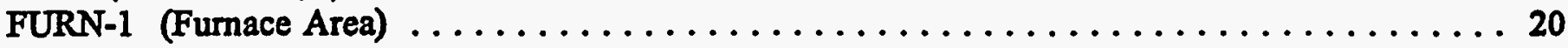

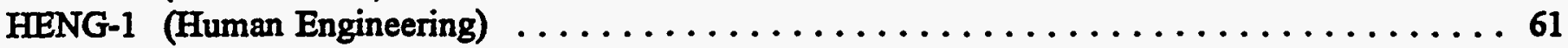

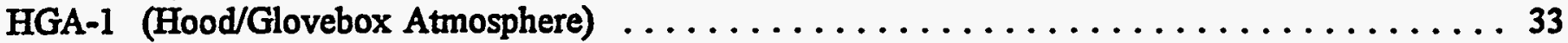

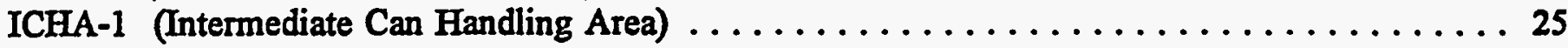

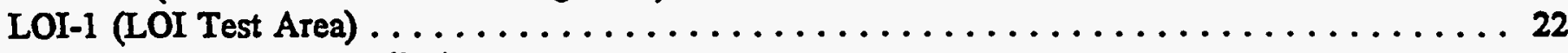

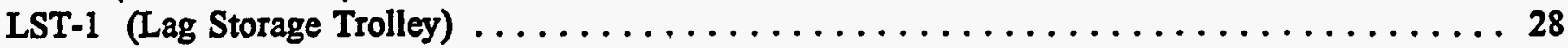

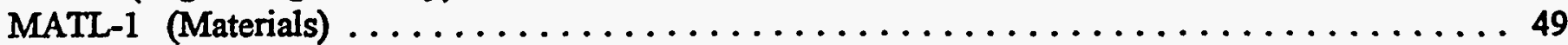

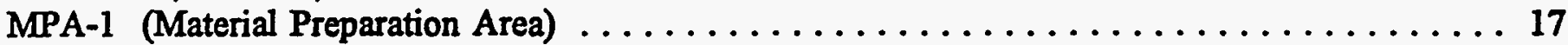

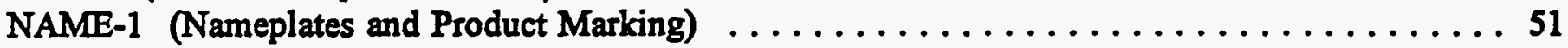

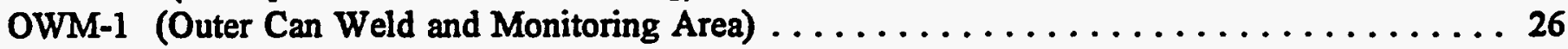

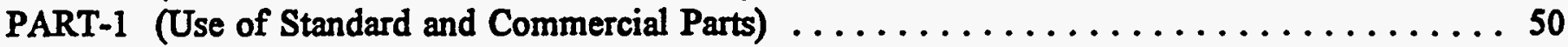

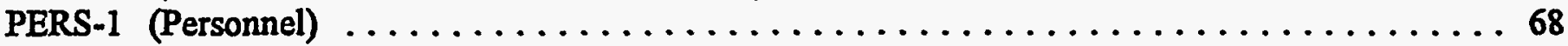

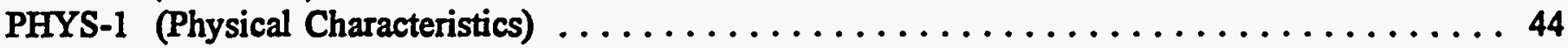

PPC-1 (Plutonium Packaging Control System) $\ldots \ldots \ldots \ldots \ldots \ldots \ldots \ldots \ldots \ldots \ldots \ldots \ldots \ldots \ldots \ldots$

PRI-1 (Process Radiometric Instrumentation) $\ldots \ldots \ldots \ldots \ldots \ldots \ldots \ldots \ldots \ldots \ldots \ldots \ldots \ldots \ldots \ldots \ldots$

PSC-1 (Plutonium Stabilization Control System) $\ldots \ldots \ldots \ldots \ldots \ldots \ldots \ldots \ldots \ldots \ldots \ldots \ldots \ldots$

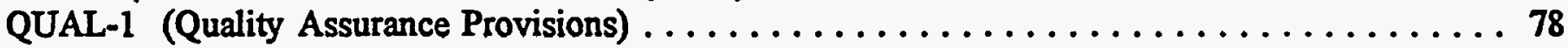

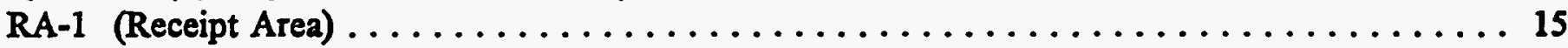

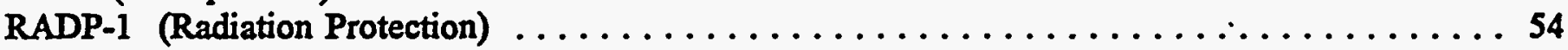

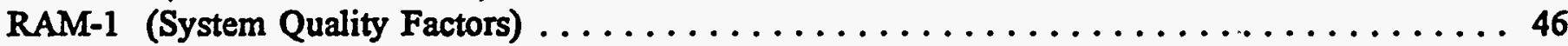

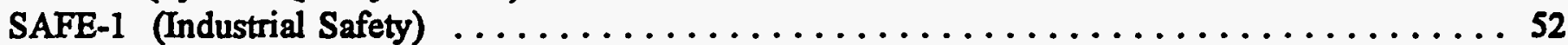

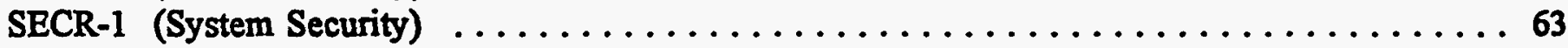

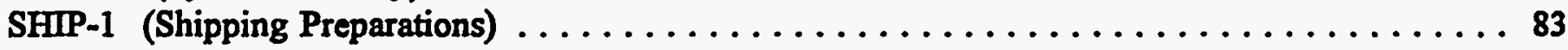

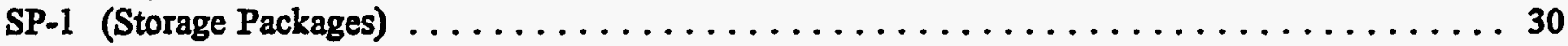

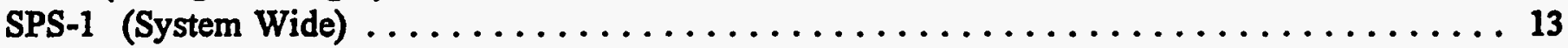

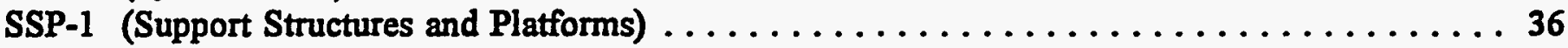





\section{Index for Requirement Identifiers}

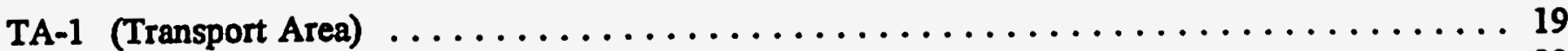

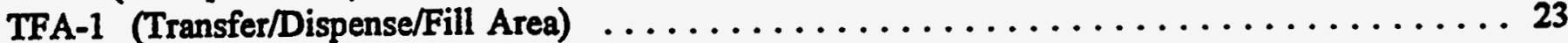

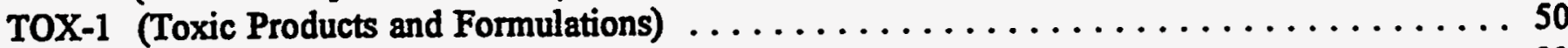

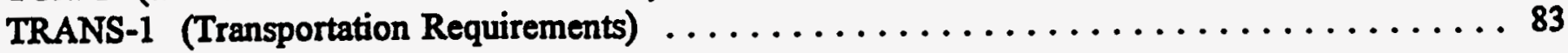




\section{Index for Requirement Identifiers}

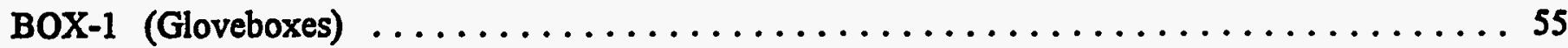

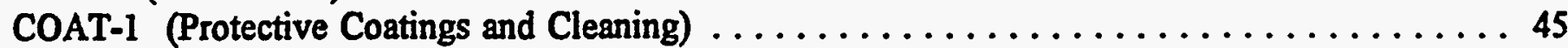

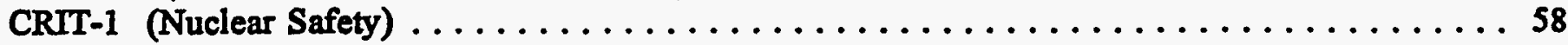

CWCI-1 (Can Weigh and Cap Insertion Area) $\ldots \ldots \ldots \ldots \ldots \ldots \ldots \ldots \ldots \ldots \ldots \ldots \ldots \ldots$

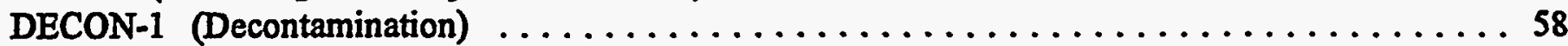

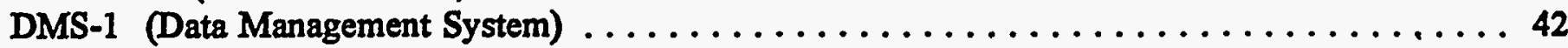

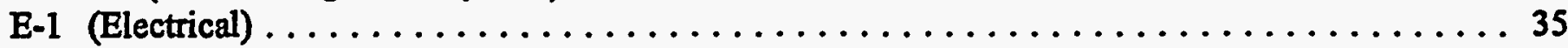

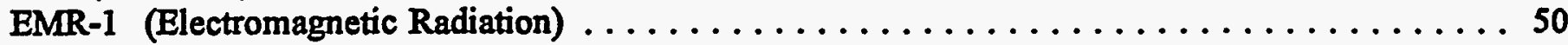

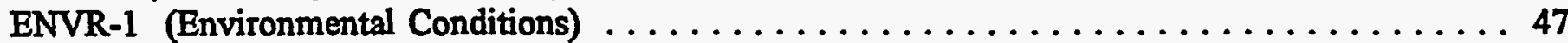

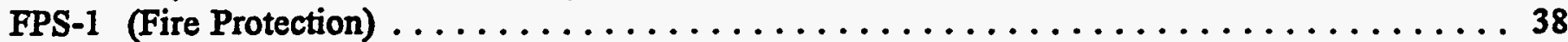

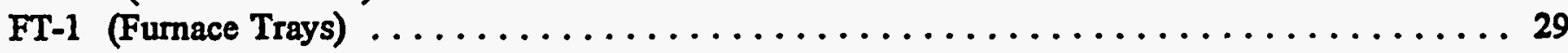

FURN-1 (Furnace Area) . . . . . . . . . . . . . . . . 20

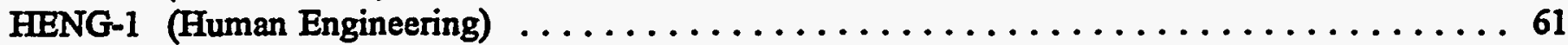

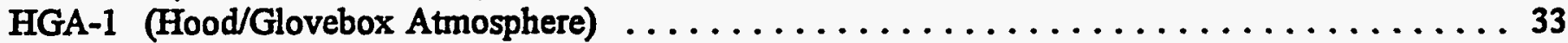

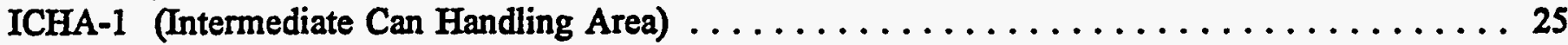

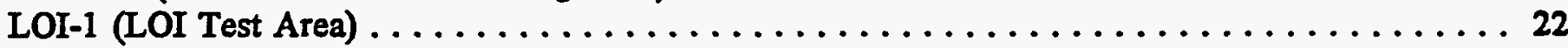

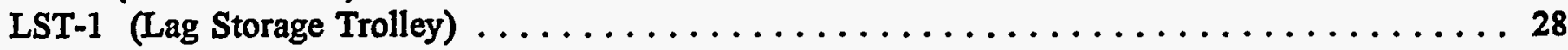

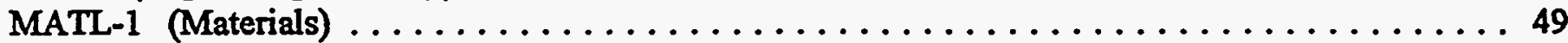

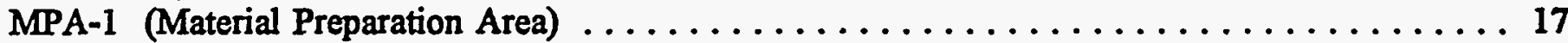

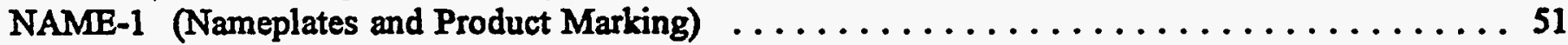

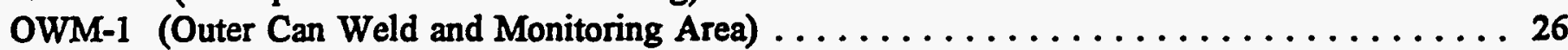

PART-1 (Use of Standard and Commercial Parts) $\ldots \ldots \ldots \ldots \ldots \ldots \ldots \ldots \ldots \ldots \ldots \ldots \ldots \ldots$

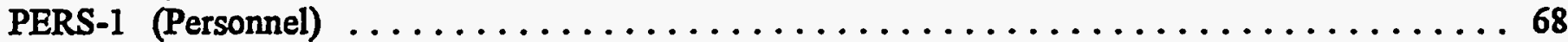

PHYS-1 (Physical Characteristics) ............................ 44

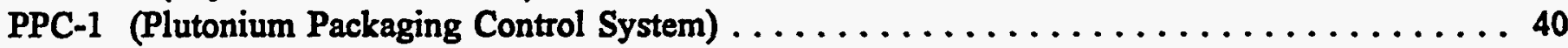

PRI-1 (Process Radiometric Instrumentation) $\ldots \ldots \ldots \ldots \ldots \ldots \ldots \ldots \ldots \ldots \ldots \ldots \ldots \ldots \ldots \ldots \ldots$

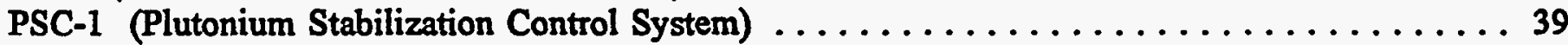

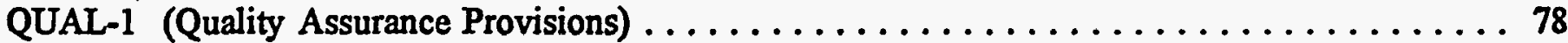

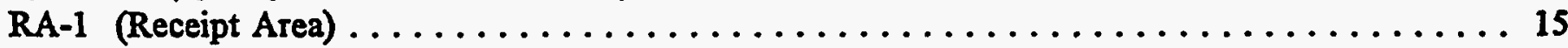

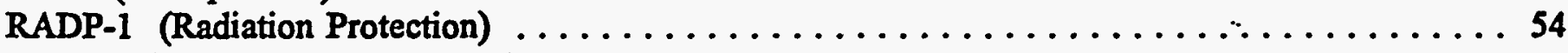

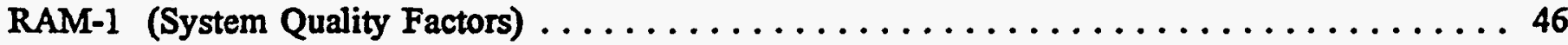

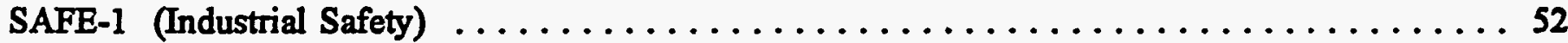

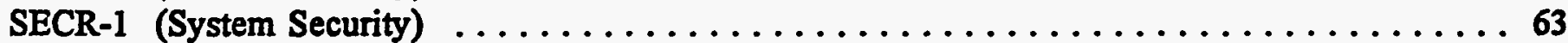

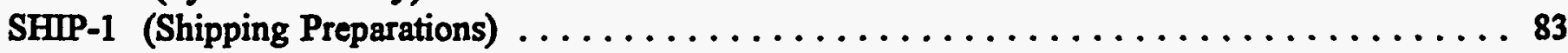

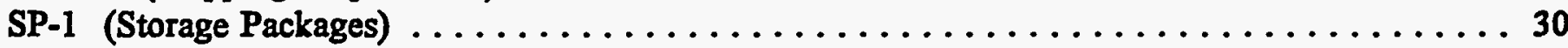

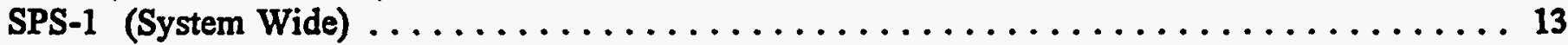

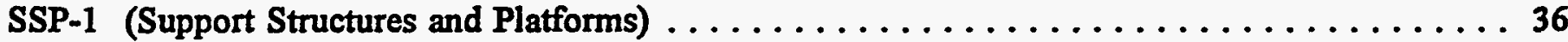




\section{Index for Requirement Identifiers}

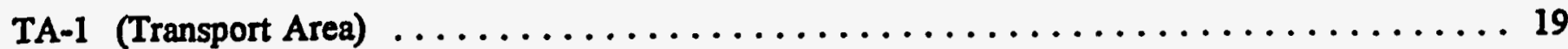

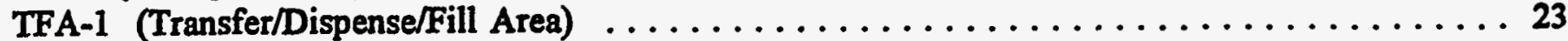

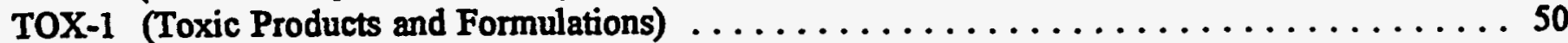

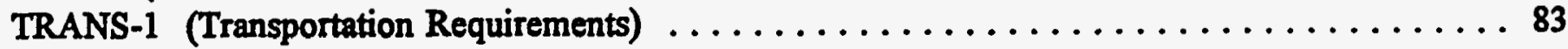


<smiles>C[I-]</smiles> 